\title{
3-D AMBIENT NOISE TOMOGRAPHY \\ OF LLAIMA VOLCANO, CHILE
}

\author{
by
}

Claudia Kristina Rossavik

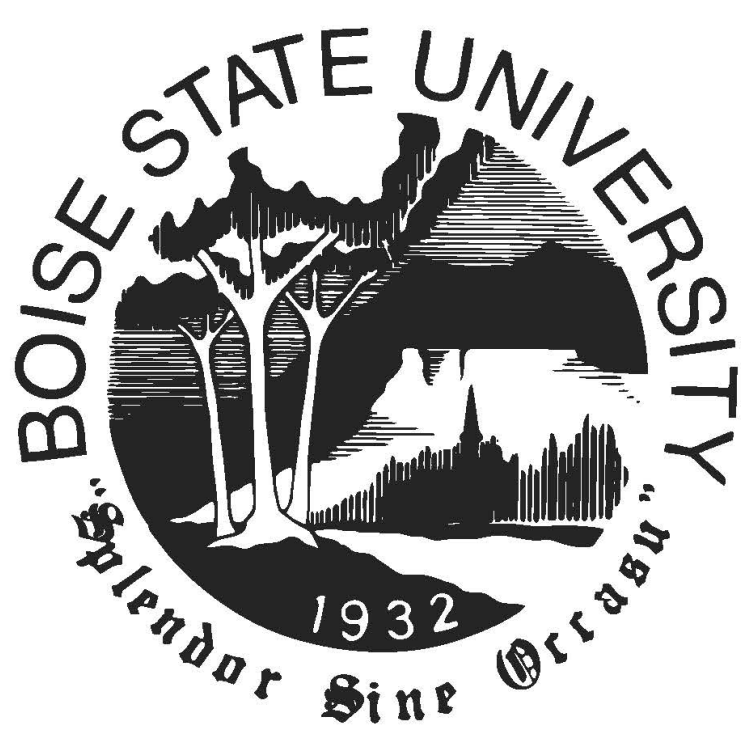

\author{
A thesis \\ submitted in partial fulfillment \\ of the requirements for the degree of \\ Master of Science in Geophysics \\ Boise State University
}


(C) 2021

Claudia Kristina Rossavik

ALL RIGHTS RESERVED 
BOISE STATE UNIVERSITY GRADUATE COLLEGE

\title{
DEFENSE COMMITTEE AND FINAL READING APPROVALS
}

\author{
of the thesis submitted by \\ Claudia Kristina Rossavik
}

Thesis Title: 3-D Ambient Noise Tomography of Llaima Volcano, Chile

Date of Final Oral Examination: 2 June 2021

The following individuals read and discussed the dissertation submitted by student Claudia Kristina Rossavik, and they evaluated the student's presentation and response to questions during the final oral examination. They found that the student passed the final oral examination.

$\begin{array}{ll}\text { Dylan Mikesell, Ph.D. } & \text { Chair, Supervisory Committee } \\ \text { Brittany Brand, Ph.D. } & \text { Member, Supervisory Committee } \\ \text { Lee Liberty, M.S. } & \text { Member, Supervisory Committee }\end{array}$

The final reading approval of the thesis was granted by Dylan Mikesell, Ph.D., Chair of the Supervisory Committee. The thesis was approved by the Graduate College. 


\section{DEDICATION}

This thesis is dedicated to my late father and to my canine best friend, Freia. 


\section{ACKNOWLEDGMENTS}

Thank you, Dr. Dylan Mikesell for being a patient advisor and excellent mentor. Thank you to my thesis committee members, Dr. Brittany Brand and Lee Liberty, whose expertise in either volcanology or seismology contributed very much to my understanding of these topics while helping my project to evolve. Thank you, Dr. Luis Franco for your incredibly helpful suggestions and time. This project uses seismic waveforms which were prepared by Dr. Luis Franco. Dr. Franco provided the locations of volcano tectonic and long period events which are shown throughout this report as well. Thank you, Dr. Sielfeld for providing 1-D shear wave velocity models from your Southern Andes Intra-Arc Seismicity (SAIAS) experiment and for sharing your expertise, time, and valuable input. Thank you, Dr. Browning, Dr. Oncken, Dr. Tassara, and Dr. Díaz for helping me to find geophysical data for the region. Thank you to the BSU/UNC field team who deployed the LL seismic network. Thank you, James Nelson for administrating our servers and for your patience with me while making this work possible, as well as the work of others. Finally, thank you to the other Geoscience students, professors, and staff at Boise State University, the mentors and

friends I have connected with since attending Western Washington University such as Jackie, Lu, Jim, and Arvind, and William for your support and encouragement. 


\section{ABSTRACT}

Llaima is a glaciated, basaltic-andesitic stratocone in the South-Central Andean Volcanic Zone. It is one of the largest and most active volcanoes in Chile. However, uncertainty remains regarding the depths and geometry of where magma is stored and the routes which it takes towards the Earth's surface. To provide a structural framework for the interpretation of petrological and geochemical data, I apply am-

bient noise tomography (ANT) to produce a 3-D shear wave velocity $\left(v_{s}\right)$ model of Llaima's magmatic plumbing. The results of this project show slow shear wave velocity anomalies within the upper $8 \mathrm{~km}$ of the crust which are interpreted as the locations of upper and lower magma reservoirs. Among the structures that are revealed by fast shear wave velocity anomalies is a geometry that is interpreted as a dike within a cluster of volcano tectonic (VT) activity. This VT cluster has been suggested to have followed the 2010 M8.8 Maule megathrust earthquake off the coast of Chile (Mora-Stock et al., 2014; Franco, 2019). I use information that has been derived from previous studies such as the coordinates of scoria cones along Llaima's flanks, gravitational anomalies, and local seismicity (which includes the depths and locations of volcano tectonic and long period seismicity) to place the resulting model within a framework that provides insight on the current state of this magmatic system. 


\section{TABLE OF CONTENTS}

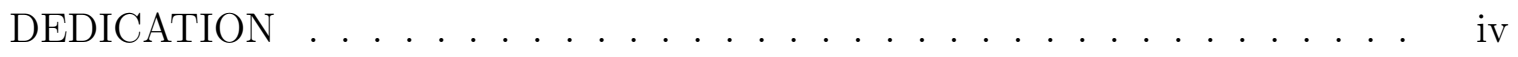

ACKNOWLEDGMENTS ........................ . .

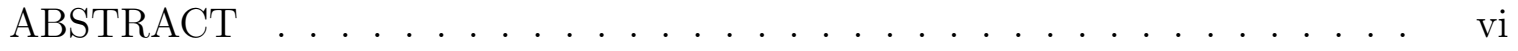

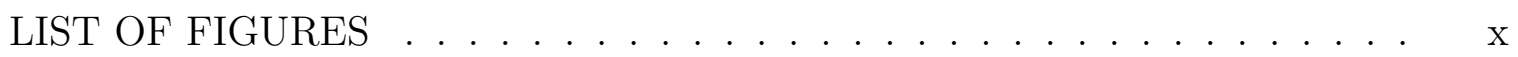

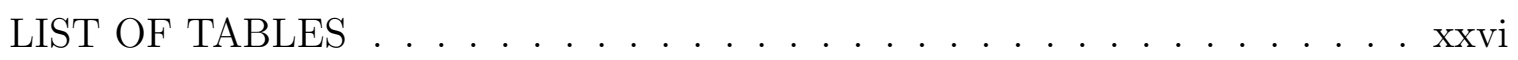

LIST OF ABBREVIATIONS ................... . . xxix

LIST OF SYMBOLS .................... . . . $\ldots x x$

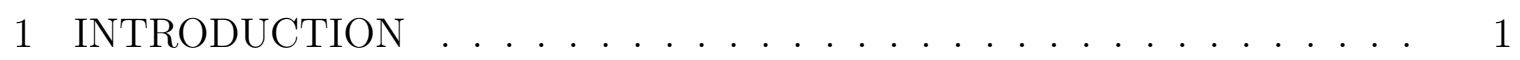

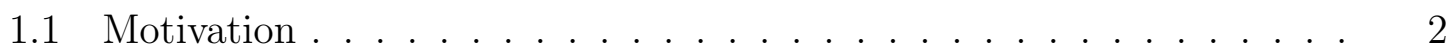

1.1.1 Increased Eruptive Activity . . . . . . . . . . . . . 2

1.1.2 Unknown Structural Architecture . . . . . . . . . . . . . 3

1.1.3 Developments in Ambient Noise Tomography . . . . . . . . . 4

1.2 Geologic Setting . . . . . . . . . . . . . . . 5

1.2.1 Geochemistry .................... 8

1.2.2 Seismicity . . . . . . . . . . . . . . . . 9 
1.2.3 Regional Gravity . . . . . . . . . . . . . . . . . . . . 12

1.3 Scientific Questions . . . . . . . . . . . . . . . . 13

1.4 Hypothesis . . . . . . . . . . . . . . . . . . . . . . 13

1.5 Seismic Networks . . . . . . . . . . . . . . . . . . . . . . 17

1.5.1 Network LL . . . . . . . . . . . . . . . . . . . . 17

1.5.2 Network TC . . . . . . . . . . . . . . . 20

1.5.3 Network $3 \mathrm{H}$. . . . . . . . . . . . . . . . 20

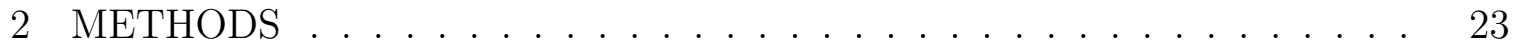

2.1 Summary . . . . . . . . . . . . . . . . . . . 23

2.2 Introduction . . . . . . . . . . . . . . . . . . 24

2.3 Single Station Data Preparation . . . . . . . . . . . . . 25

2.4 Cross-Correlation . . . . . . . . . . . . . . . . . . . 27

2.5 Phase Weighted Stacking . . . . . . . . . . . . . . . . 28

2.6 Frequency Time Analysis . . . . . . . . . . . . . . . . . . . . . 29

2.7 2-D Group Velocity Tomography . . . . . . . . . . . . . . 35

2.7.1 Grid Size . . . . . . . . . . . . . . . 38

2.7.2 Regularization Parameters . . . . . . . . . . . . . . 39

2.7.3 Group Velocity Maps . . . . . . . . . . . . . . . . . 44

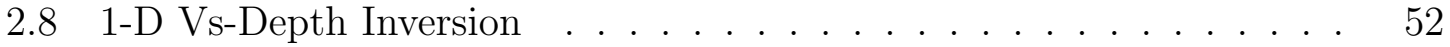

2.92 2-D Vs structure with depth . . . . . . . . . . . . . . 58

$2.103-\mathrm{D}$ Vs structure with depth . . . . . . . . . . . . . 62

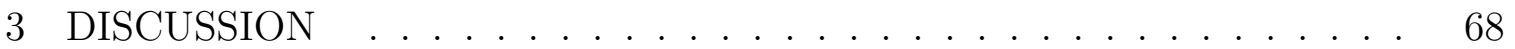

3.1 Magma Storage . . . . . . . . . . . . . . . . . . . 68 
3.1.1 Melt Fraction . . . . . . . . . . . . . . . 70

3.2 Scoria Cone Distribution . . . . . . . . . . . . . . . . . . 71

3.3 Geophysical Constraints . . . . . . . . . . . . . . 75

3.4 Conclusions .......................... 80

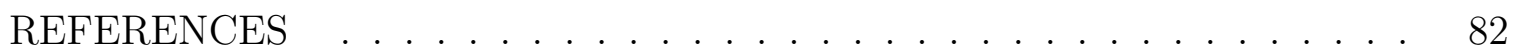

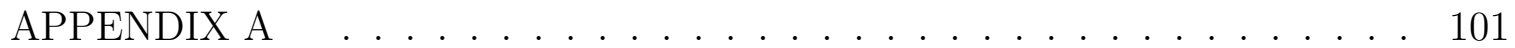

APPENDIX B . . . . . . . . . . . . . . . . . . . 104

APPENDIX C . . . . . . . . . . . . . . . . 107

APPENDIX D . . . . . . . . . . . . . . . . . . . 110

APPENDIX E . . . . . . . . . . . . . . . . . . . . . 112

APPENDIX F $F \ldots \ldots \ldots \ldots \ldots \ldots \ldots$

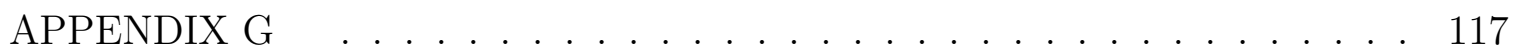

APPENDIX $\mathrm{H} \ldots \ldots \ldots \ldots \ldots$ 


\section{LIST OF FIGURES}

1.1 a) Eruptive activity at Llaima since 1980 showing the Volcanic Explosivity Indices (VEI) for eruptions during these years. b) Years of eruptions since 1650 vs. VEI showing an increase in activity since 1850 . This information was derived from Venzke (2013) . . . . . . . . . .

1.2 A map of Llaima (left) showing the locations of scoria cones on Llaima's flanks. The locations of glomeroporphyritic and pilotaxitic scoria cones were obtained from the supplementary information in SchonwalderAngel et al. (2018) and are shown as blue and red circles, respectively. The white circles represent the locations of scoria cones which were picked on 04/1/2021 using Google Earth imagery that was collected on 3/21/2021 by Image Landsat/Copernicus- CNES/Airbus. The inset maps at right of the main map show 1) a map of Llaima's summit, showing the main summit crater and Pichi Llaima 2) A map showing the location of Llaima within the Araucanìa region of Chile. Regions are outlined in black. The map shows the locations of volcanoes in Chile as red crosses, and the location of the Atacama (Peru-Chile) Trench as a white line in the Pacific Ocean, and 3) a map of South America where Chile is outlined in red. . . . . . . . . . . . . 
1.3 A map of the locations of volcano tectonic (VT) events between 20092014, the locations of VT events between 2015-2020, the locations of long period (LP) events between 2009-2014, and crustal seismicity between 2014-2015 from the $3 \mathrm{H}$ network. The focal mechanisms are interpreted from Sielfeld et al. (2019), which provided values to plot focal mechanisms. The values were entered into a focal mechanism generator found at: https://demonstrations.wolfram.com/EarthquakeFocalMechanism/. They are numbered according to their order in Table 1.1. VT and LP events were provided by Dr. Luis Franco (OVDAS-SERNAGEOMIN.) 11

1.4 Isostatic residual gravity overlain by seismicity from Figure 1.3. The coordinates of VT and LP seismic events were provided by Dr. Luis Franco (Volcano Observatory of the Southern Andes (OVDAS)-The National Geology and Mining Service (SERNAGEOMIN)). The coordinates of events associated with $3 \mathrm{H}$ crustal seismicity were computed by Sielfeld et al. (2019) as part of the SAIAS experiment. The gravity dataset was distributed by Schmidt \& Götze (2006). Gravitational lows are represented by cooler colors while gravitational highs are representedby warmer colors. The shapefile for this gravity model was found through: http://portalgeominbeta.sernageomin.cl. The underlying $30 \mathrm{~m}$ digital elevation model (DEM) of the Araucanía region was retrieved from: https://www.ide.cl/index.php/imagenes-y-mapasbase. .................................... 14 
1.5 A map of the stations used from the LL, TC, and 3H networks. The locations of the two seismic stations that were used from the $3 \mathrm{H}$ network are shown as teal triangles. The locations of seismic stations from the LL network are shown as red triangles. The locations of seismic stations in the TC network are shown as blue triangles. Solid red lines denote the locations of nearby faults. A dotted red line denotes the location of an unnamed fault that was inferred from Schonwalder-Angel et al. (2018) and Melnick et al. (2006). The $30 \mathrm{~m}$ DEM was retrieved from https://www.ide.cl/index.php/imagenes-y-mapas-base. . . . . .

2.1 A standard workflow for ambient noise tomography. . . . . . . . . .

2.2 Noise models computed by the ambient noise data analysis software PQLX (McNamara \& Boaz, 2010) showing (a) Spectral variations of seismic noise recorded January through April 2015 at station BVL, and (b) The probabilistic power spectral density recorded by the vertical component (HHZ) of station LL.BVL between January to April 2015.

2.3 The 0.01-10 Hz bandpassed filtered, stacked cross-correlation functions for the Rayleigh (ZZ) and Love (TT) waves recorded by the available waveforms from seismic stations in the LL, TC, and $3 \mathrm{H}$ networks. . .

2.4 a) The MSNoise FTAN GUI for the cross-correlation of Rayleigh waves travelling between the stations $\mathrm{HFH}$ and $\mathrm{MIC}$, showing values that were selected for automated FTAN (i.e.: Vg min. and max., min. signal-to-noise-ratio (SNR), min. wavelength, min. and max. frequency, Bmin, Bmax, and amp. min.). b) The FTAN GUI for the cross-correlation of Love waves travelling between $\mathrm{HFH}$ and MIC. . . 
2.5 a) Configurations for a second automated run of FTAN shown in a) the FTAN GUI for the cross-correlation of Love waves travelling between stations HRD and AGU, and b) the FTAN GUI for the crosscorrelation of Love waves travelling between stations HRD and AGU.

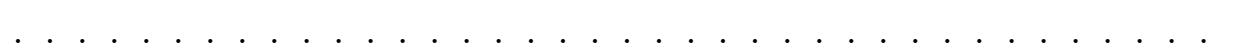

2.6 a) FTAN picked Rayleigh group velocity dispersion curves for periods 1-10 s b) FTAN picked Love wave group velocity dispersion curves. . 36

2.7 a) The relative density of a) Rayleigh wave group velocities within periods of 1-10 s, and of b) Love wave group velocities within 1-10 $\mathrm{s}$. These distributions correspond to the velocities in Figure 2.6. . . . 36

2.8 The number of group velocity dispersion picks within each period from 1-10 s via FTAN corresponding to the dispersion picks shown in Figure 2.6v for a) Rayleigh wave dispersion and b) Love wave dispersion. 37

2.9 Histograms showing the distribution of distances between station pairs travelled by a) Rayleigh waves and b) Love waves. The distributions correspond to the group velocity picks in Figure 2.6. . . . . . . . .

2.10 The tomography grid for both Love and Rayleigh waves. Grid points are shown as hollow yellow circles, resulting in a $12 \times 19$ grid. Each grid spacing is equivalent to $2.8 \mathrm{~km}$. Llaima's summit is indicated by a red triangle. Blue triangles represent the locations of seismic stations. 40 
2.11 a) The root mean square (RMS) data fit and b) the variance reduction while varying the regularization parameter beta. The measurements for each period are represented by hollow circles that are connected with a line. Each line corresponds to the measurements for a different period between 3-9 s. The lines are colored by varying shades of grey, where the lightest shade of grey represents the measurements for a period of $3 \mathrm{~s}$ and the darkest shade represents measurements at $9 \mathrm{~s}$. .

2.12 a) RMS for periods 3-9 s while varying the regularization parameter alpha. b) Variance reduction for periods 3-9 s while varying alpha. The measurements for each period are represented by hollow circles that are connected with a line. Each line corresponds to the measurements for a different period between 3-9 s. The lines are colored by varying shades of grey, where the lightest shade of grey represents the measurements for a period of $3 \mathrm{~s}$ and the darkest shade represents measurements at $9 \mathrm{~s} .42$

2.13 a) RMS for periods 3-9 s vs. the regularization parameter sigma. b) Variance reduction for periods 3-9 s while varying sigma. The measurements for each period are represented by hollow circles that are connected with a line. Each line corresponds to the measurements for a different period between 3-9 s. The lines are colored by varying shades of grey, where the lightest shade of grey represents the measurements for a period of $3 \mathrm{~s}$ and the darkest shade represents measurements at $9 \mathrm{~s} .43$ 
2.14 a) RMS for periods 3-9 s vs. the regularization parameter lambda. b) Variance reduction for periods 3-9 s while varying lambda. The measurements for each period are represented by hollow circles that are connected with a line. Each line corresponds to the measurements for a different period between 3-9 s. The lines are colored by varying shades of grey, where the lightest shade of grey represents the measurements for a period of $3 \mathrm{~s}$ and the darkest shade represents measurements at $9 \mathrm{~s} .43$

2.15 Ray paths computed from group velocities and periods for 2-D group velocity tomography for a period of $3.2 \mathrm{~s}$ for a) Rayleigh wave tomography and b) Love wave tomography. The color bar represents group velocities with cooler shades representing lower group velocities and warmer shades representing higher group velocities. Black triangles represent seismic stations. Red triangles represent Llaima's summit.

2.16 Ray paths computed from group velocities and periods for 2-D group velocity tomography for a period of $9.0 \mathrm{~s}$ for a) Rayleigh wave tomography and b) Love wave tomography. The color bar represents group velocities with cooler shades representing lower group velocities and warmer shades representing higher group velocities. Black triangles represent seismic stations. Red triangles represent Llaima's summit.

2.17 Ray path densities for 2-D group velocity tomography at a period of $3.2 \mathrm{~s}$ for a) Rayleigh wave group velocity tomography and b) Love wave group velocity tomography. Black triangles represent the locations of seismic stations, while the red triangles represent Llaima's summit. The brightest areas represent the most densely covered areas. . . . 
2.18 Ray path densities for 2-D group velocity tomography at a period of 9.0 s for a) Rayleigh wave group velocity tomography and b) Love wave group velocity tomography. Black triangles represent the locations of seismic stations, while the red triangles represent Llaima's summit. The brightest areas represent the most densely covered areas. . . .

2.19 A map of Rayleigh wave group velocity distributions at a period of $3.2 \mathrm{~s}$. The color bar ranges between shear wave velocities of 1.0-4.0 km/s. Warmer shades represent locations where materials have lower group wave velocities. Cooler shades represent locations where materials have higher group wave velocities. Grey contours are labelled according to group velocity between $0.1 \mathrm{~km} / \mathrm{s}$ intervals. Bilinear interpolation has been applied. Llaima's summit is located at (-38.697407, -71.730445).

2.20 A map of Rayleigh wave group velocity distributions at a period of $9.0 \mathrm{~s}$. The color bar ranges between shear wave velocities of $1.0-4.0 \mathrm{~km} / \mathrm{s}$. Warmer shades represent locations where materials have lower group wave velocities. Cooler shades represent locations where materials have higher group wave velocities. Grey contours are labelled according to group velocity between $0.1 \mathrm{~km} / \mathrm{s}$ intervals. Bilinear interpolation has been applied. Llaima's summit is located at (-38.697407, -71.730445). 
2.21 A map of Love wave group velocity distributions at a period of $3.2 \mathrm{~s}$. The color bar ranges between shear wave velocities of $1.0-4.0 \mathrm{~km} / \mathrm{s}$. Warmer shades represent locations where materials have lower group wave velocities. Cooler shades represent locations where materials have higher group wave velocities. Grey contours are labelled according to group velocity between $0.1 \mathrm{~km} / \mathrm{s}$ intervals. Bilinear interpolation has been applied. Llaima's summit is located at (-38.697407, -71.730445).

2.22 A map of Love wave group velocity distributions at a period of $9.0 \mathrm{~s}$. The color bar ranges between shear wave velocities of $1.0-4.0 \mathrm{~km} / \mathrm{s}$. Warmer shades represent locations where materials have lower group wave velocities. Cooler shades represent locations where materials have higher group wave velocities. Grey contours are labelled according to group velocity between $0.1 \mathrm{~km} / \mathrm{s}$ intervals. Bilinear interpolation has been applied. Llaima's summit is located at (-38.697407, -71.730445).

2.23 Regionalized group velocity dispersion curves for a) Rayleigh waves and b) Love waves. The curves correspond to (x,y) locations in each of the period maps obtained through 2-D group velocity tomography. The mean measurements at each period and their standard deviations are shown as teal hollow circles with error bars. The minimum group velocities at each period are represented by a dashed green line. The maximum group velocities are represented by a dashed blue line. . 
2.24 a) The development of likelihood over an iteration for 50 chains. This starts in a burn in phase and ends in the exploration phase. b) The development of joint misfit. c) The development of noise for Love wave dispersion. d) The development of noise for Rayleigh wave dispersion.

2.25 a) The development of $v_{s}$ structure with depth over 50 chains. b) The development of the modeled data fit using Rayleigh group dispersion. The blue curve is the observed dispersion curve for the grid point $(9,12)$. c) The development of the modeled fit using the observed Love group dispersion curve. d) The final $v_{s}$ model from the best chains. . . .

2.26 a) The best data fit for the grid point $(9,10)$ corresponding to a) observed Rayleigh wave group velocity dispersion and b) observed Love wave group velocity dispersion. c) The 1-D shear wave velocity profile at the grid point $(9,10)$ that results from the BayHunter inversion. d) Each of the shear wave velocity profiles from the BayHunter inversion. The mean shear wave velocity is shown as a black curve. . . . . . .

2.27 Horizontal slices of $v_{s}$ distributions at depths of $0.8-24.8 \mathrm{~km}$. The color bar scale represents $v_{s}$ and is set to range between $1.5-4.0 \mathrm{~km} / \mathrm{s}$. The red triangle corresponds to the coordinates of Llaima's summit. . . .

2.28 Horizontal slices of $v_{s}$ distributions at depths of $0.8-24.8 \mathrm{~km}$. The color bar scale represents $v_{s}$ and is set to range between $1.5-4.0 \mathrm{~km} / \mathrm{s}$. The red triangle corresponds to the coordinates of Llaima's summit. . . . 
2.29 a) Depth sensitivity kernels for the fundamental mode of Rayleigh wave group velocities. I used the 1-D average $v_{s}$ model from Sielfeld et al. (2019) with the lowest RMS as input. b) The depth sensitivity kernels for the fundamental mode of Love wave group velocities. . . . . . .

2.30 The A-A' transect corresponding to the $\mathrm{A}-\mathrm{A}$ ' line in Figure 2.27, plotted in a) without interpolation applied, and b) with a bilinear interpolation applied. The color scale ranges between $v_{s}$ of $1.5-4.0 \mathrm{~km} / \mathrm{s}$. The red triangle corresponds to the coordinates of Llaima's summit. . . .

2.31 The B-B' transect corresponding to the B-B' line in Figure 2.27, plotted in a) without interpolation applied, and b) with a bilinear interpolation applied. The color scale ranges between $v_{s}$ of $1.5-4.0 \mathrm{~km} / \mathrm{s}$. The red triangle corresponds to the coordinates of Llaima's summit. . . . . . .

2.32 a) 1-D shear wave velocity profiles that are best able to resolve structure that was found in the original 3-D shear wave velocity model which resulted from BayHunter. The values for these profiles were provided by Dr. Sielfeld through personal communication and result from Sielfeld et al. (2019). b) A -17\% dvs showing the 1-D shear wave velocity profile that was used for normalization. . . . . . . . . . 
2.33 a) A $20 \% d v_{s}$ showing dike-like structures NW and south of Llaima's summit (shown as a red triangle), as well as a transition towards a high shear wave anomaly southwest of Llaima's summit. b) A 35\% shear wave velocity anomaly which outlines a positive $d v_{s}$ SW of Llaima's summit. The figures are plotted over an image of the topographic grid that was shown in Figure 2.10. The hollow yellow circles represent grid points, while the blue triangles represent locations of seismic stations.

3.1 a) $\mathrm{A}-30 \% d v_{s}$ showing low shear wave anomalies beneath Llaima's summit (shown as a red triangle). b) A $-20 \% d v_{s}$ showing low shear wave anomalies beneath Llaima's summit (shown as a red triangle). .

3.2 a) $\mathrm{A}-14 \% d v_{s}$ and b) a $-13 \% d v_{s}$ showing low shear wave anomalies beneath Llaima's summit (indicated by a red triangle). . . . . . . . .

3.3 A $-19 \% d v_{s}$ plotted with the locations of glomeroporphyritic (cyan circles) and pilotaxitic scoria cones (yellow circles). These locations were obtained from the supplementary information in SchonwalderAngel et al. (2018). The locations of scoria cones that are denoted as 'Observed scoria cones (Google Earth)' are shown as dark blue circles. The data are plotted above an image of the tomographic grid that was shown in Figure 2.10. The hollow yellow circles represent grid points while the blue triangles represent seismic stations. The $d v_{s}$ outlines a negative anomaly which resembles a magmatic reservoir and is aligned with the SW-NE regional maximum compressional axis. . . . . . . . 
$3.4-5 \%$ and $25 \% d v_{s}$ plotted with the locations of glomeroporphyritic scoria cones (cyan circles) and pilotaxitic scoria cones (yellow circles). These locations were obtained from the supplementary information in Schonwalder-Angel et al. (2018). The locations of 'Observed scoria cones (Google Earth)' are shown as dark blue circles. The figures are plotted over an image of the tomographic grid that was shown in Figure 2.10. The hollow yellow circles represent grid points in the map, while the blue triangles show the locations of seismic stations. . . . 76

3.5 A $35 \% d v_{s}$ plotted with the locations of volcano-tectonic (VT) events from 2009-2014 (as lime green circles) and the locations of VT events from 2015-2020 (shown as cyan circles). The locations of these VT events were provided by Dr. Luis Franco (OVDAS - SERNAGEOMIN). The location of Llaima's summit is indicated by a red triangle. The blue triangles on the map represent the locations of seismic stations. The hollow yellow circles represent the locations of grid points. . . . 77

3.6 A $35 \% d v_{s}$ plotted with the locations of volcano tectonic (VT) events between 2010-2019 from the perspective of a) an observer from the southwest and b) an observer from the northwest. Volcano tectonic events are binned by year and events corresponding to each year are plotted in varying shades of blue and green. The images show a dikelike structure that is surrounded by volcano tectonic events and links to a larger structure at depth in the SW quadrant of the study area. 
3.7 a) The $-16 \% d v_{s}$ plotted with the locations of long period (LP) events from 2009-2014 (lime green circles). b) The $-16 \%$ and $35 \% d v_{s}$ plotted with the locations of long period (LP) events from 2009-2014. Clusters of LP activity near the summit and along the SE flank appear to form a NW-SE alignment. The locations of these LP events were provided by Dr. Luis Franco (OVDAS - SERNAGEOMIN). The catalog does not include the depths of the LP events, and so these are plotted near the surface. Llaima's summit is indicated by a red triangle. The blue triangles on the map show the locations of seismic stations. The hollow yellow circles represent the locations of tomography grid points. . .

3.8 A map view of the $-16 \%$ and $35 \%$ shear wave velocity anomalies that are shown in Figure 3.7b plotted with the locations of long period (LP) events from 2009-2014. The locations of these long period events were provided by Dr. Luis Franco (OVDAS - SERNAGEOMIN). . . . . . 
A.1 A plot from Lesage et al. (2018) showing $v_{s}$ models for individual volcanoes (thin lines), laboratory measurements (symbols and dotted lines) and well-logs (dashed lines) for andesitic basaltic volcanoes. The thick lines represent averaged seismic models. The thick black line represents an average of the averaged models. Numbers in labels indicate references (1: Zamora et al. (1994); 2: Vinciguerra et al. (2006); 3: Stanchits et al. (2006); 4: Fortin et al. (2011); 5: Heap et al. (2014); 6,9: Lesage et al. (2018); 7: Kolzenburg et al. (2012); 8: Scheu et al. (2006); 10: Mora et al. (2006); 11: Métaxian et al. (1997); 12: Perrier et al. (2012); 13: La Rocca et al. (2000); 14: De Luca et al. (1997); 15: Saccorotti et al. (2003); 16: Saccorotti et al. (2004); 17: Ikeda et al. $(2008))$

A.2 Compressional wave velocities and shear-wave velocities of a) Columbia River Basalt and b) Mount Hood Andesite (Murase \& McBirney, 1973). Solid points are measured during cooling at a rapid rate $\left(200^{\circ} \mathrm{C}\right.$ per hour $)$, and open circles at a slower rate $\left(35^{\circ} \mathrm{C}\right.$ per hour $) . \quad$. . . . . . 103

B.1 Rayleigh 2-D group velocity map for a period of a) 4.2 s. b) 5.0 s. c) 8.2 s. Rayleigh wave paths for $2-\mathrm{D}$ group velocity tomography at $\mathrm{d}$ ) $4.2 \mathrm{~s}$. e) $5.0 \mathrm{~s}$. f) $8.2 \mathrm{~s}$. Rayleigh wave path densities for 2-D group velocity tomography for a period of g) $4.2 \mathrm{s.} \mathrm{h}) 5.0 \mathrm{~s}$. i) $8.2 \mathrm{s.} \quad \ldots 105$

B.2 Love 2-D group velocity map for a period of a) 4.2 s. b) 5.0 s. c) 8.2 s. Love wave paths for 2-D group velocity tomography for a period of d) $4.2 \mathrm{~s}$. e) $5.0 \mathrm{~s}$. f) $8.2 \mathrm{~s}$. Love wave path densities for 2-D group velocity tomography at g) $4.2 \mathrm{s.} \mathrm{h)} 5.0 \mathrm{s.}$ i) $8.2 \mathrm{s.} \ldots \ldots 106$ 
C.1 a) The best data fit for the grid point $(9,9)$ corresponding to observed Rayleigh wave group velocity dispersion. b) The best data fit for the grid point $(9,9)$ corresponding to observed Love wave group velocity dispersion. c) The 1-D shear wave velocity profile at the grid point $(9,9)$ that results from the BayHunter inversion. d) The best data fit for the grid point $(5,12)$ corresponding to observed Rayleigh wave group velocity dispersion. e)The best data fit for the grid point $(5,12)$ corresponding to observed Love wave group velocity dispersion. f) The 1-D shear wave velocity profile at the grid point $(5,12)$ that results from the BayHunter inversion. g) The best data fit for the grid point $(11,12)$ corresponding to observed Rayleigh wave group velocity dispersion. h) The best data fit for the grid point $(11,12)$ corresponding to observed Love wave group velocity dispersion. i) The 1-D shear wave velocity profile at the grid point $(11,12)$ that results from the BayHunter inversion. j) The best data fit for the grid point $(6,11)$ corresponding to observed Rayleigh wave group velocity dispersion. k) The best data fit for the grid point $(6,11)$ corresponding to observed Love wave group velocity dispersion. 1) The 1-D shear wave velocity profile at the grid point $(7,11)$ from the BayHunter inversion. . . . . . . . . . . 108 
C.2 a) The best data fit for the grid point $(7,13)$ corresponding to observed Rayleigh wave group velocity dispersion. b) The best data fit for the grid point $(7,13)$ corresponding to observed Love wave group velocity dispersion. c) The 1-D shear wave velocity profile at the grid point $(7,13)$ that results from the BayHunter inversion. d) The best data fit for the grid point $(7,11)$ corresponding to observed Rayleigh wave group velocity dispersion. e) The best data fit for the grid point $(7,11)$ corresponding to observed Love wave group velocity dispersion. f) The 1-D shear wave velocity profile at the grid point $(7,11)$ that results from the BayHunter inversion. g) The best data fit for the grid point $(11,9)$ corresponding to observed Rayleigh wave group velocity dispersion. h) The best data fit for the grid point $(11,9)$ corresponding to observed Love wave group velocity dispersion. i) The 1-D shear wave velocity profile at the grid point $(11,9)$ that results from the BayHunter inversion. j) The best data fit for the grid point $(5,9)$ corresponding to observed Rayleigh wave group velocity dispersion. k) The best data fit for the grid point $(5,9)$ corresponding to observed Love wave group velocity dispersion. 1) The 1-D shear wave velocity profile at the grid point $(5,9)$ from the BayHunter inversion. . . . . . . . . . . . . . 109

D.1 The velocity model that I constructed as input for the program srfker96 (Herrmann, 2013) to compute kernel sensitivities that are shown in Figure 2.29. The shear wave velocities in the $v_{s}$ model that correspond to materials at elevations above sea level have been omitted in this case. 111 
E.1 a) A 3-D isosurface from the BayHunter results (introduced in Section 2.8). The isosurface corresponds to a shear wave velocity of 2.1 $\mathrm{km} / \mathrm{s}$. The model has been corrected for elevations. b) A $-12 \% d v_{s}$ that was constructed through the normalization of the results obtained through BayHunter using the 1-D Vs model that is shown in the figure. 113

E.2 a) A $-12 \% d v_{s}$ that was constructed through normalization with the 1-D Vs model shown in the figure. b) A $-12 \% d v_{s}$ constructed through normalization with the 1-D Vs model that is shown in the figure. . . 113

F.1 a) Depth sensitivity kernels for the fundamental mode of Rayleigh group wave velocities for the 1-D $v_{s}$ model from Sielfeld et al. (2019) that was used to obtain final results in this thesis. b) Depth sensitivity kernels for the fundamental mode of Love wave group velocities. . . . 115

F.2 The model that was used to compute the kernel sensitivities shown in Figure F.1. Values of Vs correspond to the 1-D Vs model that was used to normalize results from BayHunter. I added $3 \mathrm{~km}$ to each depth in the 1-D Vs profile that was used for normalization to set the values of depths above to values below the surface of the volcano. . . . . . 116

G.1 a) A $-18 \% d v_{s}$. b) A $-5 \% d v_{s} \ldots \ldots \ldots \ldots \ldots \ldots \ldots$

G.2 a) A $25 \% d v_{s}$. b) A $45 \% d v_{s} . \ldots \ldots \ldots \ldots \ldots \ldots \ldots$

H.1 (a) Longitudinal wave velocity $\mathrm{v}_{p}$ and (b) shear wave velocity vs. versus liquid volume fraction $\phi$ from Yoshino et al. (2005). This is used to estimate melt fraction from changes in seismic velocities. . . . . . . 120 


\section{LIST OF TABLES}

1.1 Focal mechanisms of crustal seismic events near Llaima volcano between 2014-2015 computed by Sielfeld et al. (2019). The focal mechanisms are reported in the Aki and Richards convention (Richards \& Aki, 1980) in terms of longitude, latitude, depth, and magnitude, and strike, dip, and rake in degrees. The numbers denote the locations of corresponding beach balls that are shown in Figure 1.3. . . . . . . . 12

1.2 Stations in the temporary LL network (Lamb et al., 2020). . . . . . . 21

1.3 Permanent stations from the TC network. . . . . . . . . . . . 22

1.4 Seismic stations that were utilized from the $3 \mathrm{H}$ network. . . . . . . . 22

2.1 Parameters used for automated FTAN, where 'Vg' represents group velocity $(\mathrm{km} / \mathrm{s})$. ' $f$ ' represents frequency in $\mathrm{Hz}(1 /$ period). 'b' represents the change in the width of Gaussian filter over a linear spacing of 300 points. 'Amp. Min.' represents the amplitude percentage filter as a percent of the maximum amplitude. ' $\lambda$ ' represents wavelength. 
3.1 Melt fractions for different relationships between the shear wave velocity anomalies and what is expected of the shear wave velocity for given depths in the crust from the 1-D velocity profile that was used to normalize the model and is shown in Figure 2.32. 'A' refers to a fitting parameter for olivine-basalt systems which is given in Yoshino et al. (2005). This value is used to delineate liquid volume fraction $\phi$ from a plot of $v_{s} / v_{s_{0}}$ vs. liquid volume fraction from Yoshino et al. (2005), shown in Appendix H.1. . . . . . . . . . . . . . . . . . 71 


\section{LIST OF ABBREVIATIONS}

ANSWT ambient surface wave tomography

ANT ambient noise tomography

DEM digital elevation model

FTAN frequency time analysis

LOFS Liquiñe-Ofqui Fault System

LP long period

LVZ low velocity zone

McMC Markov chain Monte Carlo

OVDAS Volcano Observatory of the Southern Andes

PSDPDF power spectral density probability density function

PWS phase weighted stacking

SERNAGEOMIN The National Geology and Mining Service

VT volcano tectonic

xxix 


\title{
LIST OF SYMBOLS
}

\author{
$\lambda \quad$ Damping based on ray density \\ $\omega_{0} \quad$ Central frequency \\ $\sigma \quad$ Gaussian smoothing window width \\ $\sigma_{1} \quad$ Maximum compressional stress \\ $\sigma_{3} \quad$ Minimum compressional stress \\ ${ }^{\circ} \mathrm{C} \quad$ Celcius \\ $d v_{s} \quad$ Shear wave velocity anomaly in $\%$ \\ $m_{\omega} \quad$ Moment magnitude \\ $v_{p} \quad$ Compressional/P-wave velocity \\ $v_{s} \quad$ Shear wave velocity \\ $\alpha \quad$ Gaussian smoothing strength \\ $\beta \quad$ Damping strength \\ mGal Milligal \\ mPa Megapascal
}




\section{CHAPTER 1:}

\section{INTRODUCTION}

Llaima volcano is a glaciated, basaltic-andesitic stratocone in the South-Central Andes. It is one of the largest and most active volcanoes in Chile. While numerous geochemical and geophysical studies describe a crystalline mush and a system of vertical dikes beneath Llaima (Bouvet De Maisonneuve, 2011; Ruth et al., 2016), it is not possible to constrain the depths and geometry of structures, such as dikes or zones of magma accumulation, without a high-resolution, 3-D geophysical image that shows the locations and dimensions of Llaima's volcanic plumbing. To provide a structural framework for the interpretation of petrological and geochemical data, I apply ambient noise tomography (ANT) to three months of continuous seismic records from a selection of stations that surrounded Llaima in 2015. I jointly invert Rayleigh and Love wave group velocity dispersion curves to obtain an isotropic 3-D shear-wave velocity $\left(v_{s}\right)$ model. I show methods and results in Chapter 2 after an introductory discussion regarding the motivations of the project, datasets, and the study area in Chapter 1. Each section in Chapter 2 describes a processing step that was applied towards a final 3-D ambient noise tomography (ANT) v model. I follow each description by showing the results that were obtained for that step. In the final chapter

I bring together information from previous studies, such as the locations of seismic events, geochemistry, and gravity, to discuss structures in the resulting ANT models. 


\subsection{Motivation}

\subsubsection{Increased Eruptive Activity}

On January 1, 2008, Llaima ejected a $12.5 \mathrm{~km}$ ash plume from its main crater that sent ash travelling towards the Andes and into Argentina. Flights were cancelled, property was damaged, and hundreds of people were evacuated from nearby villages and the surrounding national park (Venzke, 2013). While lava and incandescent materials were initially confined to a crater at the summit, the eruption developed into a Strombolian phase that covered much of Llaima's glaciated peaks. Strombolian eruptions produce scoria cones, lava flows, and sometimes violent Strombolian "paroxysms" (Cashman \& Sparks, 2013; Vergniolle \& Jaupart, 1986). Eruptions at Llaima can take on effusive Hawaiian styles of activity, or even sub-Plinian activity (Naranjo \& Moreno, 1991). Glacial melting during eruptive periods can produce lahars, which fill the surrounding rivers and damage infrastructure such as roads and homes. Spatters from lava flows can result in forest fires (Mora-Stock et al., 2014).

There have been 46 eruptions since 1624 (Petit-Breuilh, 2004) with Volcanic Ex-

plosivity Indices (VEI) (Newhall \& Self, 1982) ranging between 2 and 3. While the eruptions are classified as moderate, they still pose a threat to nearby villages such as Melipeuco, Cherquenco, or Curacautín, or the populated touristic city of Temuco which is $76 \mathrm{~km}$ away from Llaima's summit. I show the years which there have been eruptions in Figure 1.1 with their VEI. Figure 1.1a shows 11 eruptive periods since 1980. Figure 1.1b shows a clear increase in eruptive activity since 1850. 
Volcanic Explosivity Index (VEI) by Year
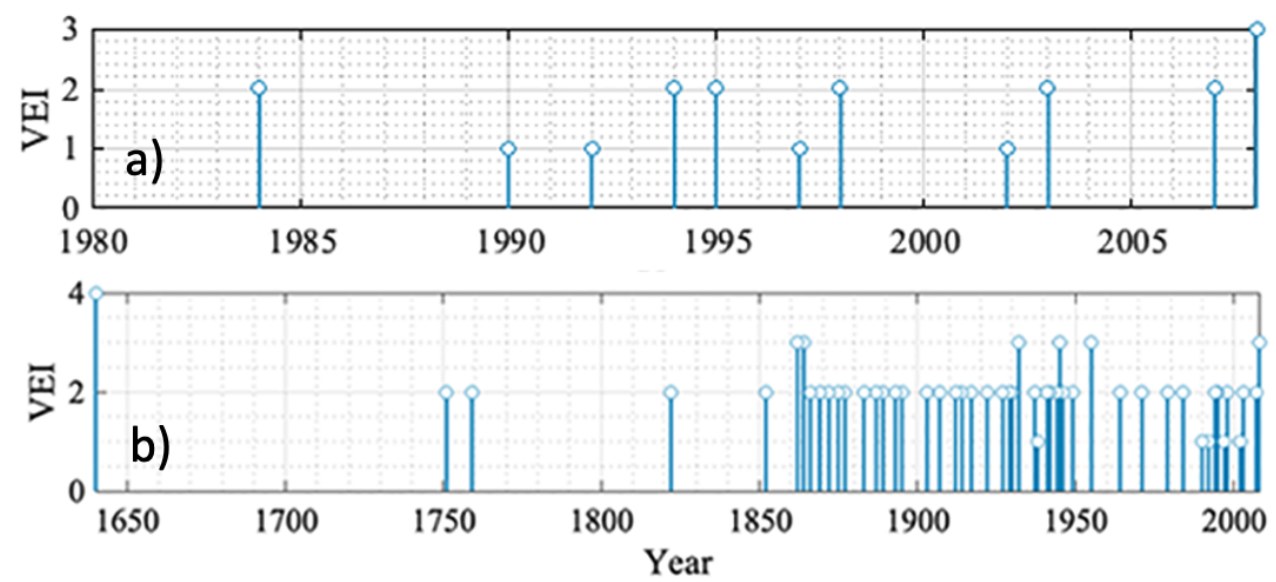

Figure 1.1: a) Eruptive activity at Llaima since 1980 showing the Volcanic Explosivity Indices (VEI) for eruptions during these years. b) Years of eruptions since 1650 vs. VEI showing an increase in activity since 1850 . This information was derived from Venzke (2013).

\subsubsection{Unknown Structural Architecture}

Despite being one of the most active volcanoes in Chile, the geometry of Llaima's volcanic system has not been fully constrained through geophysical means. We do not know the depths or orientation of magmatic storage beneath the surface. Geochemical evidence points towards the existence of a partially crystallized zone of magma storage in the upper $14 \mathrm{~km}$ beneath the surface that is fed by injections from a deeper reservoir (Ruth et al., 2016). Models by Bouvet De Maisonneuve (2011) show that upper magmatic storage may exist in the form of a crystalline plexus of anastomizing dikes where batches of magma are stored and undergo degassing and crystallization via cooling before being erupted. A goal of this project is to determine the dimensions and locations of magma accumulation beneath Llaima through a high-resolution image of crustal shear wave velocities which have been tomographically derived from 
the ambient seismic wavefield. Knowing the dimensions and locations of magma accumulation would strongly benefit efforts towards risk assessment and contribute to a greater understanding of the processes in Llaima's shallow magmatic reservoir.

\subsubsection{Developments in Ambient Noise Tomography}

In 1957, Keitti Aki proposed a spatial autocorrelation (SPAC) method to estimate surface-wave phase velocity from the correlation of ambient noise (Aki, 1957). While confirming the assertion that a diffuse acoustic field has correlations equal to the Green's function of the body, Lobkis \& Weaver (2001) cited evidence (e.g., Papanicolaou et al., 1996; Turner, 1998; Hennino et al., 2001) that seismic coda could reveal information on local stratigraphy. This work motivated studies by Campillo \& Paul (2003), Shapiro \& Campillo (2004), and Shapiro et al. (2005) which demonstrated that high-quality seismic tomography could be performed through the time-domain cross-correlation of the ambient seismic field. Ambient noise tomography has since then rapidly evolved as an irrefutably valuable tool for imaging the crustal structure in volcanic settings at local and regional scales (Masterlark et al., 2010; Huang et al., 2018; Yang \& Gao, 2020). More recent ANT studies in volcanic settings (e.g., Mordret et al., 2015; Obermann et al., 2016; Fallahi et al., 2017; González-Vidal et al., 2018) have been able to determine the distribution of shallow magmatic fluids.

In a more regional scale of Rayleigh wave ambient noise tomography in the Southern Central Andes, González-Vidal et al. (2018) observed high and low shear wave anomalies in the upper $3 \mathrm{~km}$ of the crust between $33^{\circ} \mathrm{S}$ and $38^{\circ} \mathrm{S}$. Negative (i.e. slow) shear wave velocity anomalies were interpreted as potentially representing sedimentary basins and magmatic bodies, while positive (i.e. fast) shear wave velocity anomalies were interpreted as intrusive bodies. The authors applied a method used in 
Delph et al. (2017) to estimate melt fraction from relationships between shear wave velocities (Takei, 2002; Yoshino et al., 2005). Using these methods, the maximum melt fraction estimated by Delph et al. (2017) was 22\% in the Cerro Galan Anomaly, which is the largest slow velocity anomaly that was imaged by this study. The lowest shear wave velocity obtained within this anomaly was $2.7 \mathrm{~km} / \mathrm{s}$, which is a $25 \%$ decrease from the expected $3.6 \mathrm{~km} / \mathrm{s}$ crustal $v_{s}$ of granite/granodiorite.

González-Vidal et al. (2018) speculated that -8\% shear-wave velocity anomalies in their model were due to partial melts, which represent shallow large-scale magmatic reservoirs. This regional model indicated that the magmatic plumbing system may span the crust, but the resolution of the model did not resolve small-scale features such as shallow reservoirs. I seek to resolve finer scale structure of magmatic reservoirs within the shallow crust beneath Llaima volcano by completing a local scale ANT.

\subsection{Geologic Setting}

Rising to an elevation of $3125 \mathrm{~m}$, Llaima is a double-peaked stratovolcano in the South-Central Andean volcanic arc. A stratovolcano is a steep-sided cone that is constructed from lava flows and pyroclastic deposits (Cashman \& Sparks, 2013). They are often surrounded by gently dipping flanks which are composed of lava flows and pyroclastic material themselves (Cashman \& Sparks, 2013). With its volume of $380 \mathrm{~km}^{3}$ (Schindlbeck et al., 2014), Llaima consists of one of the largest Holocene stratocone edifices in all of Chile with a NE-NNE trending field of parasite cones and vents (Melnick et al., 2006). The underlying crust consists of Tertiary diorite and granodiorite plutons (Reubi et al., 2011). A study by Araneda et al. (2003), which used passive seismic recordings and seismic refraction, estimated the lower boundary of the upper crust in this area to be around $15 \mathrm{~km}$. For the seismic refraction portion 


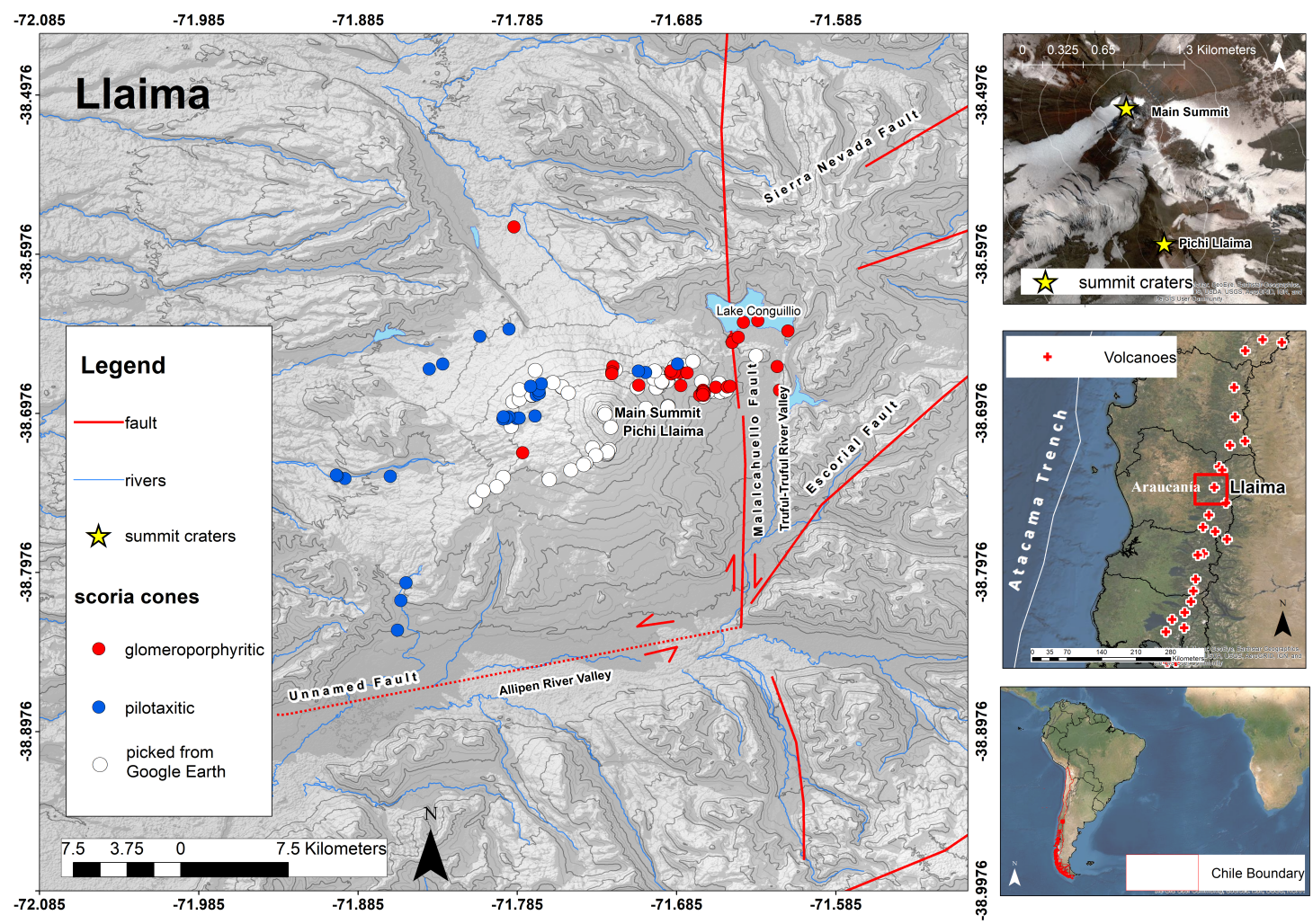

Figure 1.2: A map of Llaima (left) showing the locations of scoria cones on Llaima's flanks. The locations of glomeroporphyritic and pilotaxitic scoria cones were obtained from the supplementary information in SchonwalderAngel et al. (2018) and are shown as blue and red circles, respectively. The white circles represent the locations of scoria cones which were picked on 04/1/2021 using Google Earth imagery that was collected on 3/21/2021 by Image Landsat/Copernicus- CNES/Airbus. The inset maps at right of the main map show 1) a map of Llaima's summit, showing the main summit crater and Pichi Llaima 2) A map showing the location of Llaima within the Araucania region of Chile. Regions are outlined in black. The map shows the locations of volcanoes in Chile as red crosses, and the location of the Atacama (Peru-Chile) Trench as a white line in the Pacific Ocean, and 3) a map of South America where Chile is outlined in red. 
of this study, a chemical explosion was shot from a small lake in the Chilean Main Cordillera and from four shot points in the Pacific Ocean. This study used in situ Pwave velocity to compute temperature, density, and the velocity at normal pressures. The resulting density was used to model gravity along the transect, and a depth to the Moho of approximately $40 \mathrm{~km}$ was suggested to explain gravitational lows in sections of the profile which are located $220 \mathrm{~km}$ east of Llaima. Tassara et al. (2006) forward modeled Bouger gravity in a region that included the Pacific Ocean and the Andean margin between northern Peru and Patagonia. The models that resulted from this study show a depth to the Moho of approximately $40 \mathrm{~km}$ beneath Llaima.

Llaima is located at an intersection between a dextral strike-slip lineament of the margin-parallel Liquiñe-Ofqui Fault System (LOFS) and an unnamed sinistral strike slip fault along the Allipen River Valley at Llaima's southern edge (Melnick et al., 2006; Rosenau et al., 2006). The locations of these faults are shown in Figure 1.2. This figure shows the locations of the main summit and SE crater (Pichi Llaima), and of scoria cones along Llaima's flanks. The locations of the glomeroporphyritic and pilotaxitic cones were found within the supplementary information of SchonwalderAngel et al. (2018). These locations represent samples that were used for analysis in Schonwalder-Angel et al. (2018). The locations of 'Observed scoria cones' were picked in Google Earth on 04/1/2021 using imagery that was collected on 3/21/2021 by Image Landsat/Copernicus-CNES/Airbus. Several of the scoria cones that were picked in Google Earth match the locations of scoria cones that were shown in a map found in Schonwalder-Angel et al. (2018). Schonwalder-Angel et al. (2018) selected locations of scoria cones in a similar way using an ASTER image that was taken by NASA's Earth Observing 1 Satellite using the Advance Land Image (ALI) 
(Schonwalder-Angel et al., 2018), but did not provide the locations of these scoria cones in the supplementary information of their report as they were not sampled.

The NE-SW alignment of several scoria cones along Llaima's flanks corresponds to the regional state of stress which is interpreted as a maximum compressional stress $\left(\sigma_{1}\right)$ in the northeast direction and minimum compressional stress $\left(\sigma_{3}\right)$ in the northwest direction (Cembrano \& Lara, 2009; Rosenau et al., 2006).

\subsubsection{Geochemistry}

Schonwalder-Angel et al. (2018) described samples that were collected from scoria cones at Llaima to be either glomeroporphyritic or pilotaxitic. Glomeroporphyritic compositions are more primitive and reflect the mafic character of their source. These cones have been identified along Llaima's southwest and northeast flanks, within a NE-SW alignment that is parallel to the regional $\sigma_{1}$ and normal to $\sigma_{3}$.

The spatial distribution of pilotaxitic scoria cones along Llaima's NE, NW, and SW flanks suggests unimpeded dike intrusion controlled by local extension. There is not a clear trend for the distribution of pilotaxitic cones, but their radial distribution and compositions suggest that the propagation of the dikes sourcing these cones is affected by compressional stress from the load of the volcanic edifice (SchonwalderAngel et al., 2018; Roman \& Jaupart, 2014). Schonwalder-Angel et al. (2018) found that the feeder magmas of pilotaxitic cones could be derived from the source of melt for glomeroporphyritic cones and suggested similar magmatic origins.

Plagioclase phenocrysts and olivine hosted melt inclusions support similar mechanisms in that materials appear to originate from the same source, but vary due to the conditions in which they have been stored (Bouvet De Maisonneuve, 2011). Abrupt disruptions in the resorption zoning patterns of plagioclase suggest that most of these 
crystals experience frequent, but small volume recharge events. This kind of replenishment would be essential in preserving the bulk of many crystal-mush filled dikes at shallow depths. Scoria and tephra from the 2008 eruption are consistent with the prolonged residence of crystal-free, higher viscosity magmas (Ruth et al., 2018).

\subsubsection{Seismicity}

Seismicity at Llaima is telling of magma intrusion and volumetric deformation. Between 2009-2014, volcano tectonic (VT) events swarmed near Llaima's southern flank, while long period (LP) activity occurred in clusters at the summit and along the southeast flank. Volcano tectonic events are associated with the structural response of the volcanic edifice to an intrusion or withdrawal of fluids, while LP events are associated with disruptions in the underlying pressurization of magmatic and/or hydrothermal fluids (Chouet, 1996). The locations of VT and LP activity at Llaima are shown in the map in Figure 1.3. This map shows the locations of VT events between 2009-2014 as green circles. The locations of VT events from 2015-2020 are shown as pink circles. The locations of LP events from 2009-2014 are shown as red circles. Dr. Luis Franco (OVDAS - SERNAGEOMIN) provided the depths and/or coordinates of the VT and LP events that are shown in this map and discussed throughout this report.

Figure 1.3 also shows the locations of crustal seismic events which were derived through the Southern Andes Intra-Arc Seismicity (SAIAS) experiment (Sielfeld et al., 2019). This was a study of local seismicity based on 16 months of data from 34 seismic stations that were deployed along a $200 \mathrm{~km}$ stretch of the Southern Volcanic Zone (SVZ) between March 2014 and June 2015. The results describe crustal faulting

during a time and in an area that pertains to the focus of this thesis. Upper crustal seismic events shed light on instantaneous strain and instability along faults (Scholz, 
1988), particularly in active magmatic arcs in oblique convergent settings such as this, where margin-parallel rock weathering is enhanced by permanent heat flow that leads to transpressional partitioning (Sielfeld et al., 2019; Tikoff \& Teyssier, 1994).

The final catalog of the SAIAS experiment consists of 356 crustal seismic events. Sielfeld et al. (2019) computed the focal mechanism solutions of 36 of these crustal seismic events. Figure 1.3 presents seven of these focal mechanism solutions. The focal mechanisms are numbered in the map according to the order their parameters appear in Table 1.1. This table provides the locations, depths, dates, origin times, strikes, dips, and rakes of these events which were found in Sielfeld et al. (2019).

Each of the normal focal mechanisms in Figure 1.3 can be described as transtensional oblique-slip focal mechanisms (Dr. Gerd Sielfeld, personal communication), except for focal mechanism \#1, which represents reverse faulting. Reverse faulting can be associated with subduction, but the event corresponds to a depth of $12.3 \mathrm{~km}$, so it did not occur along the subduction boundary. Reversals from what is expected can also be related to the slightest amount of dike inflation (Roman \& Heron, 2007).

The depths of these focal mechanisms reveal that faulting generally occurs within the upper $15 \mathrm{~km}$ of the crust. The depth of the event that corresponds to focal mechanism \#5 however, is $19.4 \mathrm{~km}$. This event has the largest moment magnitude $\left(\mathrm{M}_{w}\right)$ in the SAIAS catalog. It was a $\mathrm{M}_{w} 3.4$ that occurred at the eastern tip of a ENE-oriented fissure on Llaima's NE flank (Sielfeld et al., 2019). It is consistent with this strike-slip setting where there is NE-trending maximum horizontal shortening. The alignment of glomeroporphyritic scoria cones along Llaima's flanks is observed as forming parallel to this orientation as well (Schonwalder-Angel et al., 2018). 


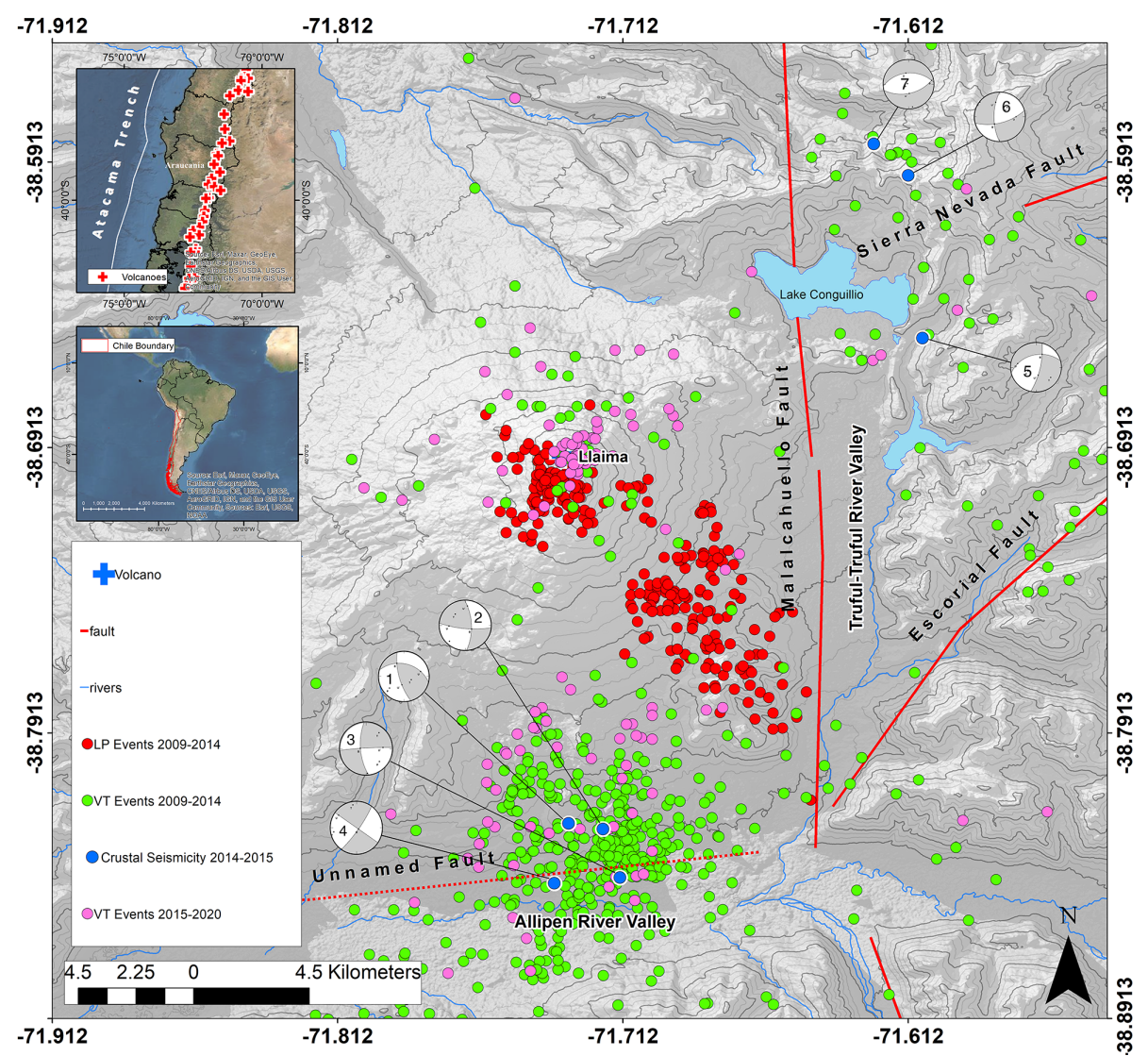

Figure 1.3: A map of the locations of VT events between 20092014, the locations of VT events between 2015-2020, the locations of LP events between 2009-2014, and crustal seismicity between 20142015 from the $3 \mathrm{H}$ network. The focal mechanisms are interpreted from Sielfeld et al. (2019), which provided values to plot focal mechanisms. The values were entered into a focal mechanism generator found at: https://demonstrations.wolfram.com/EarthquakeFocalMechanism/. They are numbered according to their order in Table 1.1. VT and LP events were provided by Dr. Luis Franco (OVDAS-SERNAGEOMIN.) 
Table 1.1: Focal mechanisms of crustal seismic events near Llaima volcano between 2014-2015 computed by Sielfeld et al. (2019). The focal mechanisms are reported in the Aki and Richards convention (Richards \& Aki, 1980) in terms of longitude, latitude, depth, and magnitude, and strike, dip, and rake in degrees. The numbers denote the locations of corresponding beach balls that are shown in Figure 1.3.

\begin{tabular}{|c|c|c|c|c|c|c|c|c|c|}
\hline$\#$ & Date & Origin time & Latitude & Longitude & Depth & Strike & Dip & Rake & $M_{w}$ \\
\hline 1 & 15.04 .15 & $08: 54: 30.00$ & -38.823 & -71.731 & 12.3 & 283.97 & 38.29 & 36.2 & 2.3 \\
\hline 2 & 11.07 .14 & $17: 36: 03.80$ & -38.825 & -71.719 & 15 & 95.1 & 75.52 & 26.57 & 1.5 \\
\hline 3 & 14.04 .15 & $12: 40: 52.00$ & -38.842 & -71.713 & 13.8 & 174.99 & 65.41 & -4.63 & 1.7 \\
\hline 4 & 10.09 .14 & $06: 39: 41.40$ & -38.844 & -71.736 & 11.8 & 125 & 90 & 10 & 2 \\
\hline 5 & 14.04 .15 & $09: 51: 12.20$ & -38.653 & -71.607 & 19.4 & 256.76 & 35.53 & -30.64 & 3.4 \\
\hline 6 & 10.09 .14 & $22: 03: 46.30$ & -38.596 & -71.612 & 9 & 75.6 & 62.12 & -28.45 & 2.6 \\
\hline 7 & 10.09 .14 & $07: 28: 14.90$ & -38.585 & -71.624 & 9 & 265.93 & 40.26 & -82.25 & 2.1 \\
\hline
\end{tabular}

\subsubsection{Regional Gravity}

Reduced gravity (Figure 1.4) shows a high in residual isostatic gravity south of Llaima's summit (in pink) in an area that is dominated by VT activity. This cluster of VT events has been analyzed in a paper by Mora-Stock et al. (2014) regarding the seismicity that followed the 2010 M8.8 Maule megathrust earthquake on 2010-0227. The isostatic residual gravity anomaly at this location is close to $15 \mathrm{mGal}$. The surrounding anomaly in yellow ranges between 2-4 mGal. Green represents values between -10 and $0 \mathrm{mGal}$. The presence of a positive gravity anomaly beneath Llaima is unique in comparison to the negative gravity anomalies beneath nearby volcanoes.

Anomalies in volcanic settings result from the density contrasts between intrusions and the surrounding country rock (Hinze, 1985). If the intrusion is more dense than the country rock, the result is a positive anomaly. If it is less dense than the country rock, then we would observe a low in gravity. The positive anomaly south of Llaima's summit could represent an anomalous mass that possibly formed from 
the solidification of the unerupted portions of magma injection that are thought to replenish the andesitic crystal mush at shallow depths beneath Llaima.

\subsection{Scientific Questions}

- Can ambient noise tomography be used to resolve a zone of crystalline mush to an adequate resolution to determine magma storage potential?

- Does the emplacement of dikes align with the trend of scoria cones?

- Is there an intrusion near the high in gravity high south of Llaima's summit?

\subsection{Hypothesis}

An analysis of the distributions and chemical compositions of scoria cones at Llaima by Schonwalder-Angel et al. (2018) shows that there are two groups of scoria cones along Llaima's flanks. One of these groups forms within an alignment that is parallel to the regional state of stress (with maximum compression in the NE direction). The other group of scoria cones forms within alignments that are radial to the summit. Products in the first group (defined as "glomeroporphyritic") are basaltic to basaltic andesitic with a $51-55 \%$ wt\% $\mathrm{SiO}_{2}$. Products in the second group (defined as "pilotaxitic") consist of calc-alkaline basalts and basaltic andesites with a 55-60\% wt\% $\mathrm{SiO}_{2}$. Basalts typically have a composition of $45-52 \%$ wt $\% \mathrm{SiO}_{2}$ (Philpotts \& Ague, 2009). I anticipate that the structures that are associated with glomeroporphyritic scoria cones will consist of shear wave velocities that are more similar to basalt.

Schonwalder-Angel et al. (2018) considered pressures of 50, 100, and $342 \mathrm{MPa}$ and temperatures between $1094-1233^{\circ} \mathrm{C}$ and $1109-1167^{\circ} \mathrm{C}$. Glomeroporphyritic samples were associated with basaltic compositions at each of these pressures. Basalts can have shear wave velocities near $3.2 \mathrm{~km} / \mathrm{s}$ at pressures between 200-1000 MPa (Christensen, 


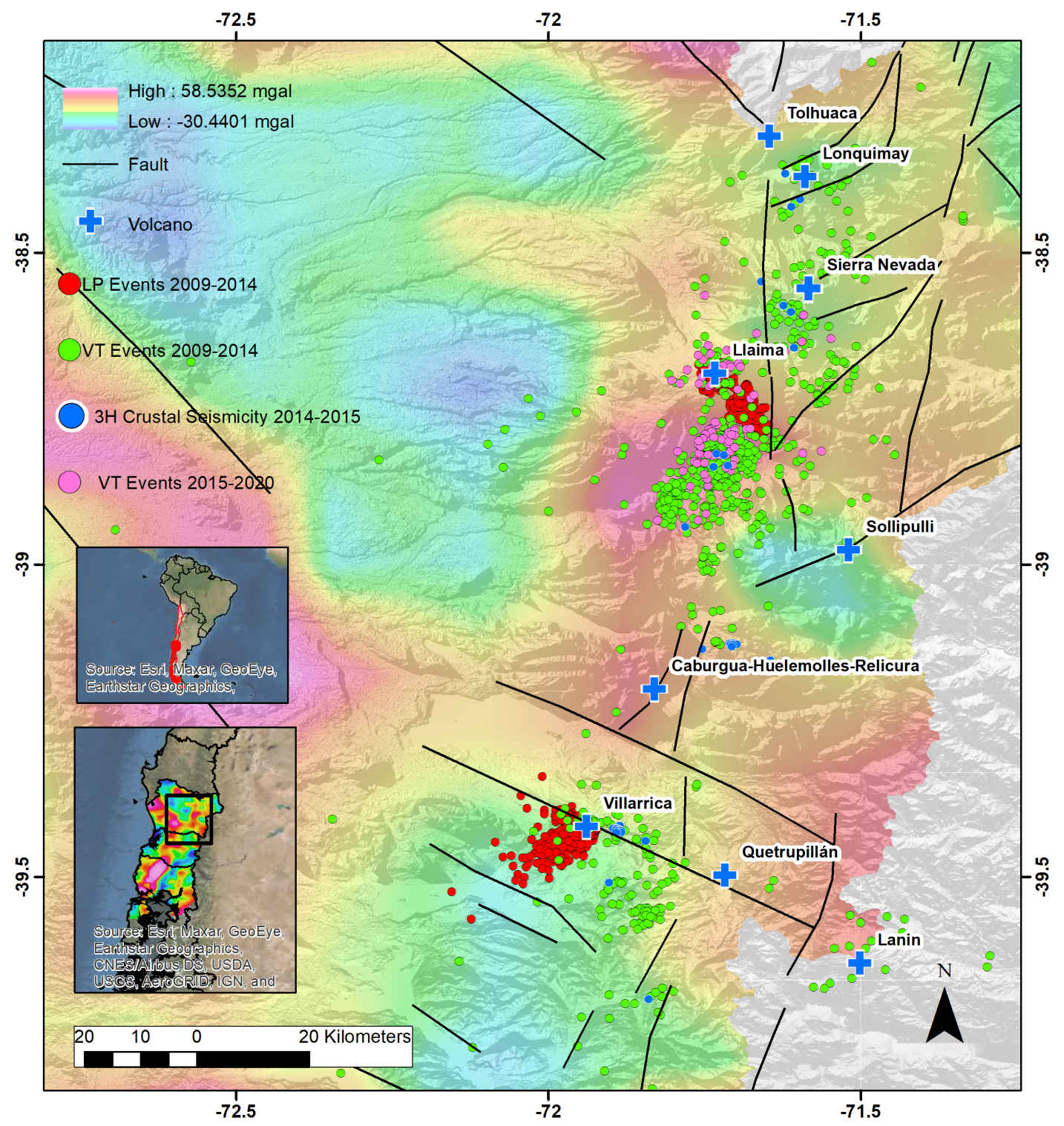

Figure 1.4: Isostatic residual gravity overlain by seismicity from Figure 1.3. The coordinates of VT and LP seismic events were provided by Dr. Luis Franco (OVDAS-SERNAGEOMIN). The coordinates of events associated with $3 \mathrm{H}$ crustal seismicity were computed by Sielfeld et al. (2019) as part of the SAIAS experiment. The gravity dataset was distributed by Schmidt \& Götze (2006). Gravitational lows are represented by cooler colors while gravitational highs are representedby warmer colors. The shapefile for this gravity model was found through: http://portalgeominbeta.sernageomin.cl. The underlying $30 \mathrm{~m}$ DEM of the Araucanía region was retrieved from: https://www.ide.cl/index.php/imagenes-y-mapas-base. 
1996). Basalts can have shear wave velocities of $2.7-3.1 \mathrm{~km} / \mathrm{s}$ between pressures of 0 to $200 \mathrm{MPa}$ (Tsuji \& Iturrino, 2008). The Llaima samples were found to contain approximately $0.9-1.2 \%$ wt $\% \mathrm{TiO}_{2}$ at pressures of 200 and $240 \mathrm{MPa}$, which can be associated with crystallization from a more evolved melt (Lissenberg \& Dick, 2008).

$\mathrm{Ti}$ is a slow diffusing element; it reflects high degrees of differentiation. In general these samples have higher $\mathrm{MgO}$ (approximately 5-6\% MgO wt\%). The combination of high $\mathrm{TiO}_{2}$ and high $\mathrm{MgO}$ contents can reflect an evolutionary history in which clinopyroxene-saturated melt percolated the troctolite glomerocrysts, and acquired a higher MgO through equilibriation of host olivine (Lissenberg \& Dick, 2008). Thus, I expect these scoria cones to be related to structures found at greater depths.

This contrasts from the range of depths that Schonwalder-Angel et al. (2018) describe for the piltaxitic group. These products can be derived from the glomeroporphyritic group through a fractionation that occurs in relatively shallow conditions (i.e. $100 \mathrm{MPa}$ or less) at temperatures in the range of $1150-1100^{\circ} \mathrm{C}$. This implies that fractionation must have occurred within the volcanic edifice/plumbing system because these products are more evolved. According to tables that are found in the supplementary information of Schonwalder-Angel et al. (2018), several of the samples that were defined as pilotaxitic often had more basaltic-andesitic compositions.

A calc-alkaline basaltic andesitic volcano such as Colima (with similarities to Llaima) has basaltic-andesite with shear wave velocities of approximately $3.1 \mathrm{~km} / \mathrm{s}$ between depths of 0 to $1500 \mathrm{~m}$ (Lesage et al., 2018). I show a plot from Lesage et al. (2018) that shows velocity models of different basaltic-andesitic volcanoes in Figure A.1 (Lesage et al., 2018; Zamora et al., 1994; Stanchits et al., 2006; Fortin et al., 2011; Heap et al., 2014; Kolzenburg et al., 2012; Scheu et al., 2006; Mora et al., 
2006; Métaxian et al., 1997; Perrier et al., 2012; La Rocca et al., 2000; De Luca et al., 1997; Saccorotti et al., 2003, 2004; Ikeda et al., 2008). While the authors do not describe depths past $1500 \mathrm{~m}$, we may assume from the downward trend of the curve that velocity will continue to approach $3.1 \mathrm{~km} / \mathrm{s}$ as depth increases.

When basalt is heated, its shear wave velocity rapidly decreases from approximately $2.5 \mathrm{~km} / \mathrm{s}$ at temperatures between $800-1000^{\circ} \mathrm{C}$ to $1 \mathrm{~km} / \mathrm{s}$ at temperatures near $1100^{\circ} \mathrm{C}$ (Murase \& McBirney, 1973). When andesite is heated, its shear wave velocity rapidly decreases from approximately $2.5 \mathrm{~km} / \mathrm{s}$ at temperatures between $800-$ $1200^{\circ} \mathrm{C}$ to $1 \mathrm{~km} / \mathrm{s}$ near $1200^{\circ} \mathrm{C}$ (Murase \& McBirney, 1973). I show the plot from which this information is derived from in Figure A.2. I expect shear wave velocities of less than $2.5 \mathrm{~km} / \mathrm{s}$ to be associated with partial melt. As Llaima's crust is thought to consist of Tertiary diorite and granodiorite plutons (Reubi et al., 2011), these materials may have shear wave velocities near 3.6-3.7 km/s (Christensen, 1970).

Llaima's location next to conjugate strike-slip faults leads to extension in the NWSE direction, and compression in the SW-NE direction (Schonwalder-Angel et al., 2018; Rosenau et al., 2006). I hypothesize that the overall geometry of structures in my final model will support these kinematics. However, I expect to find radially distributed, eruptible lenses of melt near the locations of piltoxitic scoria cones, which have formed as a result of the upward buoyancy of melt in combination with the load of the edifice, as proposed by Schonwalder-Angel et al. (2018). In these locations, the stress field may be sensitive to surficial load of the edifice (Roman \& Jaupart, 2014). As one of the largest volcanic edifices in Chile, the Llaima stratocone has a volume of $380 \mathrm{~km}^{3}$ (Schindlbeck et al., 2014). This may prevent dense primitive melts from erupting in the focal area and divert these products radially. 
There are two factors that limit the resolution and depth of ambient noise tomography models. One is the range of frequencies that are present in the ambient field. The other is the interstation distance between station pairs. Larger interstation distances and larger periods increase model sensitivities to greater depths. Smaller interstation distances and shorter periods optimize the resolution of the array.

All but one of the stations that are used in this study are equipped to record a 3-component broadband signal. Multiple stations are equipped with Trillium 120PAs, which have a long-period corner of 120 s. Stations with Guralp CMG-3T and Meridian sensors also have a corner period of $120 \mathrm{~s}$. It is possible that signals will be recorded up to $120 \mathrm{~s}$ in this study; however, most natural seismic energy occurs within the secondary microseism band of 1-10 s (Mordret et al., 2015). Surface waves within these periods are mostly sensitive to the upper tens of kilometers of the crust.

\subsection{Seismic Networks}

I describe the seismic networks and stations that were used to retrieve waveforms for ambient noise tomography in this section. The locations of the stations are shown in the map in Figure 1.5. Network LL was temporarily deployed to bolster the stations within the TC seismic network that are permanently installed to monitor Llaima. Network 3H was deployed as part of the SAIAS experiment (Sielfeld et al., 2019).

\subsubsection{Network LL}

Network LL was temporarily deployed between January and March 2015 through the coordinated efforts of researchers at Boise State University and the University of North Carolina (UNC) in Chapel Hill. Members of OVDAS-SERNAGEOMIN aided the deployment of network LL and made the study entirely possible. The stations were 


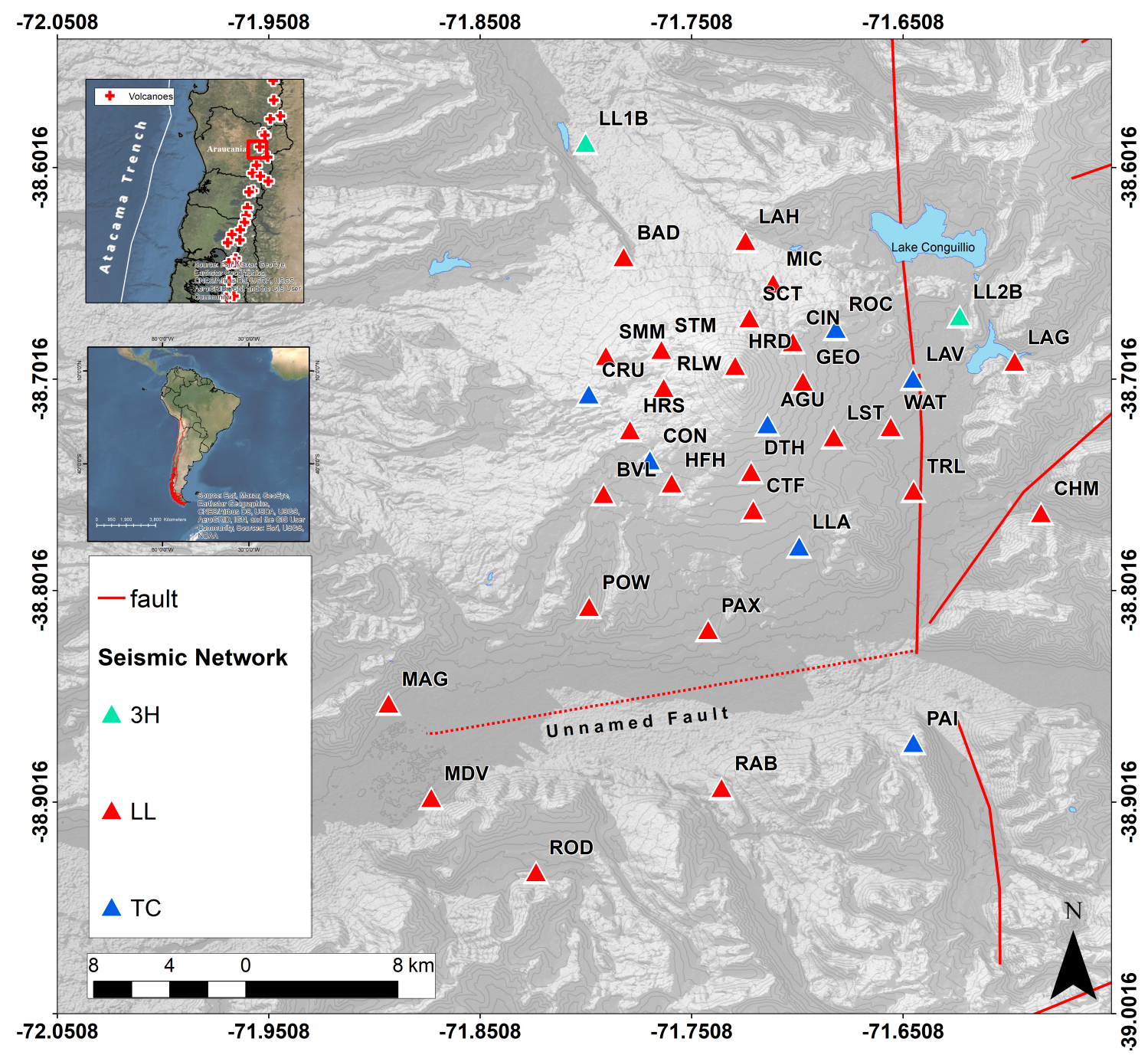

Figure 1.5: A map of the stations used from the LL, TC, and $3 H$ networks. The locations of the two seismic stations that were used from the 3H network are shown as teal triangles. The locations of seismic stations from the LL network are shown as red triangles. The locations of seismic stations in the TC network are shown as blue triangles. Solid red lines denote the locations of nearby faults. A dotted red line denotes the location of an unnamed fault that was inferred from Schonwalder-Angel et al. (2018) and Melnick et al. (2006). The $30 \mathrm{~m}$ DEM was retrieved from https://www.ide.cl/index.php/imagenes-y-mapas-base. 
installed within a $20 \times 25 \mathrm{~km}$ area surrounding Llaima volcano. They were equipped with a variety of broadband seismometers and digitizers that are listed in Table 1.2.

Bishop et al. (2018) applied a receiver function analysis using the same dataset which I am applying ANT towards. This study highlighted crustal boundary layers beneath Llaima by depicting P-to-SV wave conversions at impedance contrasts across boundaries. The author picked P-wave phase arrivals from 16 well-recorded teleseismic events to compute $\mathrm{P}$-wave receiver functions. They estimated crustal thickness using an H- $\kappa$ stacking technique (Zhu \& Kanamori, 2000). Upper crustal geometry was imaged using a Common Conversion Point (CCP) stacking approach (Dueker \& Sheehan, 1997; Gilbert et al., 2003). The results of this study showed higher $\mathrm{v}_{p} / \mathrm{v}_{s}$ ratios than what has previously been suggested for the region (1.75 by Bohm et al. (2002)). The authors found a range between 1.75-1.97, with the average being 1.86 . I use the $\mathrm{v}_{p} / \mathrm{v}_{s}$ ratio of 1.86 in my final inversions for shear wave velocity structure.

The crustal thickness beneath station CRU was found to be $55 \mathrm{~km}$, but this was 9-17 km deeper than the crustal thickness beneath other stations (Bishop et al., 2018). The results showed low velocity SV-P anomalies near $10 \mathrm{~km}$ depth under stations AGU, DTH, CTF, LST, and TRL. SV-P anomalies are identified from the deconvolutions of the vertical components of seismograms from their radial components (Heeszel et al., 2016). They can be used to estimate the depth which phase conversions between P- to SV- waves occur (Bishop et al., 2018).

A high-to-low velocity transition zone was observed near $20 \mathrm{~km}$ depth. The higher $\mathrm{v}_{p} / \mathrm{v}_{s}$ ratios were interpreted to have resulted from magmatism. The resolution of near surface structure was limited in this study, as the initial P-wave pulse of the receiver functions is almost $2 \mathrm{~s}$ long. Structure shallower than approximately $6 \mathrm{~km}$ 
was not resolved, but is possible to resolve through ambient noise tomography.

\subsubsection{Network TC}

I use recordings from stations in the TC seismic network, which is permanently monitored by OVDAS-SERNAGEOMIN. OVDAS-SERNAGEOMIN is an entity of the Chilean government that monitors the most dangerous volcanoes in Chile. There are nine seismic stations permanently installed at Llaima in the TC network. They are all equipped with 3-component broadband seismometers, except for station LAJ which is equipped with a $1-\mathrm{Hz}$ passive vertical seismometer. I list the seven stations from which waveforms were retrieved and their recording properties in Table 1.3.

\subsubsection{Network $3 \mathrm{H}$}

The stations that are used from network $3 \mathrm{H}$ were deployed as part of the SAIAS experiment (Sielfeld et al., 2019). The stations and their properties are listed in Table 1.4. Both of the stations were equipped with broadband seismometers, and they are two of the stations from the $3 \mathrm{H}$ network that were closest to Llaima. 
Table 1.2: Stations in the temporary LL network (Lamb et al., 2020).

\begin{tabular}{|c|c|c|c|c|c|c|}
\hline Station & X & Y & Altitude $(\mathrm{m})$ & SPS & Datalogger & Sensor \\
\hline BAD & -71.7829 & -38.6440 & 1258 & 100 & Trillium & Trillium 120PA \\
\hline BVL & -71.7925 & -38.7560 & 1478 & 100 & Meridian & Meridian \\
\hline CHM & -71.5856 & -38.7650 & 840 & 100 & Taurus & Trillium 120PA \\
\hline CIN & -71.7029 & -38.6843 & 1934 & 100 & REFTEK 130 & Trillium 120PA \\
\hline CTF & -71.7216 & -38.7636 & 1473 & 100 & Meridian & Meridian \\
\hline DTH & -71.7227 & -38.7456 & 1720 & 100 & Meridian & Meridian \\
\hline GEO & -71.6981 & -38.7029 & 1933 & 100 & REFTEK 130 & Trillium 120PA \\
\hline HFH & -71.7602 & -38.7510 & 1621 & 100 & Meridian & Meridian \\
\hline HRD & -71.7302 & -38.6954 & 3080 & 100 & Meridian & Meridian \\
\hline HRS & -71.7799 & -38.7258 & 1810 & 100 & Meridian & Meridian \\
\hline LAG & -71.5980 & -38.6935 & 998 & 100 & Guralp & Guralp 3T \\
\hline LAH & -71.7253 & -38.6364 & 1183 & 100 & Guralp & Guralp 3T \\
\hline LST & -71.6836 & -38.7292 & 1486 & 100 & Meridian & Meridian \\
\hline MAG & -71.8941 & -38.8551 & 501 & 100 & Taurus & Trillium 120PA \\
\hline MDV & -71.8740 & -38.8997 & 613 & 100 & Taurus & Trillium 120PA \\
\hline MIC & -71.7123 & -38.6565 & 1411 & 100 & REFTEK 130 & Guralp 40T \\
\hline PAX & -71.7429 & -38.8203 & 712 & 100 & Guralp & Guralp 3T \\
\hline POW & -71.7993 & -38.8094 & 777 & 100 & REFTEK 130 & Guralp 3T \\
\hline RAB & -71.7367 & -38.8949 & 732 & 100 & Taurus & Trillium 120PA \\
\hline RLW & -71.7640 & -38.7059 & 1975 & 100 & REFTEK 130 & Trillium 120PA \\
\hline ROD & -71.8244 & -38.9347 & 821 & 100 & Centaur & Trillium 120PA \\
\hline SCT & -71.7234 & -38.6729 & 1934 & 100 & REFTEK 130 & Guralp 40T \\
\hline SMM & -71.7914 & -38.6908 & 1711 & 100 & Guralp & Guralp 3T \\
\hline STM & -71.7651 & -38.6879 & 1970 & 100 & Centaur & Trillium 120PA \\
\hline TRL & -71.6458 & -38.7544 & 882 & 100 & Guralp & Guralp 3T \\
\hline WAT & -71.6567 & -38.7243 & 1027 & 100 & Centaur & Trillium 120PA \\
\hline
\end{tabular}


Table 1.3: Permanent stations from the TC network.

\begin{tabular}{|c|c|c|c|c|c|c|}
\hline Station & X & Y & Altitude $(\mathrm{m})$ & SPS & Datalogger & Sensor \\
\hline AGU & -71.7150 & -38.7230 & 2150 & 100 & Trillium & Guralp 6TD \\
\hline CON & -71.7705 & -38.7090 & 1706 & 100 & REFTEK 151 & 30 \\
\hline CRU & -71.7995 & -38.6843 & 1934 & 100 & Trillium & $120 \mathrm{P}$ \\
\hline c LAJ & -71.6962 & -38.7550 & 1466 & 100 & & L-4C \\
\hline LAV & -71.6461 & -38.7015 & 1077 & 100 & Trillium & $120 \mathrm{P}$ \\
\hline LLA & -71.7000 & -38.7808 & 1091 & 100 & Guralp & Guralp 6TD \\
\hline PAX & -71.6459 & -38.8737 & 1127 & 100 & Trillium & $120 \mathrm{P}$ \\
\hline ROC & -71.6826 & -38.6779 & 1694 & 100 & Trillium & $120 \mathrm{P}$ \\
\hline
\end{tabular}

Table 1.4: Seismic stations that were utilized from the $3 \mathrm{H}$ network.

\begin{tabular}{|c|c|c|c|c|c|c|}
\hline Station & $\mathrm{X}$ & $\mathrm{Y}$ & Altitude $(\mathrm{m})$ & SPS & Datalogger & Sensor \\
\hline LL1B & -71.801 & -38.590 & 743 & 100 & DiGOS CUBE & Trillium-Compact \\
\hline LL2B & -71.624 & -38.672 & 1054 & 100 & DiGOS CUBE & Trillium-Compact \\
\hline
\end{tabular}




\section{CHAPTER 2:}

\section{METHODS}

\subsection{Summary}

I follow a standard procedure for ambient noise tomography that is shown in Figure 2.1. This workflow begins with the pre-processing of continuous seismic records to compute cross-correlations between all station pairs and selected components. I compute cross-correlations between the vertical components (ZZ) and the transverse components (TT). This results in two separate datasets that are jointly combined to estimate an isotropic shear wave velocity model that satisfies both of these important wave types at the same time. ZZ refers to a measure between Rayleigh waves, and TT refers to a measure between Love waves. I measure group travel times from the negative and positive components of the ZZ and TT correlations via frequency time analysis (FTAN). FTAN results in a set of group velocity dispersion curves which are regionalized through 2-D surface wave group velocity tomography. A set of frequency-dependent Rayleigh and Love wave group velocity maps is obtained. The maps represent local spatial averages of group velocity at each grid point on the map and summarize large amounts of surface-wave dispersion data (Barmin et al., 2001). The group velocity dispersion curves that were obtained through FTAN are regionalized through the 2-D group velocity inversion for a 1-D Markov chain Monte Carlo 
(McMC) transdimensional Bayesian inversion for shear wave velocity with depth. The results are combined for a final 3-D $v_{s}$ model. I use the Python package MSNoise (Lecocq et al., 2014) for the steps in Figure 2.1 up to 2-D group velocity tomography. I then use the Python package BayHunter (Dreiling \& Tilmann, 2019) for 1-D McMC transdimensional Bayesian inversion. I normalize the results using a regional 1-D $v_{s}$ model that resulted from the Southern Andes Intra-Arc Seismicity experiment (SAIAS) (Sielfeld et al., 2019). I correct the results for elevation using values that were derived from a $30 \mathrm{~m}$ digital elevation model (DEM) of the region (retrieved from: https://www.ide.cl/index.php/imagenes-y-mapas-base).

\subsection{Introduction}

The ambient seismic field constitutes the background seismicity of the Earth (Nakata et al., 2019). The laws of physics imprint a hidden coherent structure on this wavefield that can be extracted through the computation of correlations between pairs of stations (Curtis et al., 2006). When averaged over long enough periods of time, the correlation approximates the wavefield that would be recorded at one receiver if an impulse source had acted at the other. Assuming the noise source distribution is homogeneous around the stations (Lobkis \& Weaver, 2001), the cross-correlation of wave forms travelling between station pairs over time yields the Green's function of the medium between the two stations. Surface waves dominate the Green's function approximation between station pairs (Shapiro et al., 2005), as their energy is concentrated near the Earth's surface (Stein \& Wysession, 2009).

The arrivals of earthquakes interfere during cross-correlation such that the estimates of arrival times no longer relate to the Green's function between the stations. To achieve the best approximation to the Green's function, ambient seismic data are 


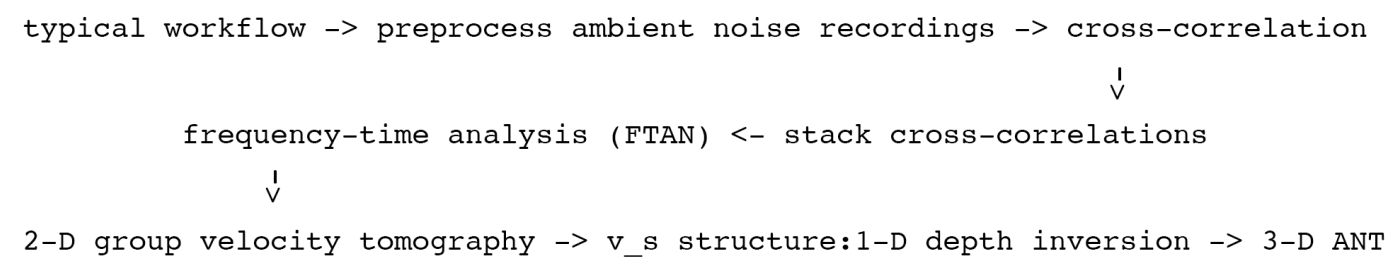

Figure 2.1: A standard workflow for ambient noise tomography.

pre-processed to balance seismic amplitudes and normalize the waveforms.

\subsection{Single Station Data Preparation}

Pre-processing is a part of the workflow that I apply through MSNoise. I select configurations through a user interface in MSNoise, and the configurations are applied by MSNoise prior to the computation of cross-correlations. Pre-processing involves the time removal of instrument response, de-meaning, de-trending and bandpass filtering of each seismogram (Bensen et al., 2007). I applied instrumental corrections using dataless response files for each station. Data was downsampled from 100 to $20 \mathrm{~Hz}$ to reduce the storage and computation time of cross-correlations. I applied a bandpass filter between .01-10 Hz. I use this wider bandwidth to preserve a larger spectral range for the purpose of FTAN. Several studies in volcanic settings have analyzed the spectral range between 1 and $10 \mathrm{~s}$ to successfully image volcanic edifices at a local scale (Brenguier et al., 2007; Masterlark et al., 2010; Stankiewicz et al., 2010; Mordret et al., 2014). A second band pass filter of 1-30 s is applied during frequency time analysis. Measurements can then be obtained within the 1-10 s range or greater.

Figure 2.2 shows the spectral characteristics of the signals recorded by station LL.BVL.HHZ. These images were created using PQLX (McNamara \& Boaz, 2010), which is a software tool to evaluate seismic station performance based on the power 
spectral density probability density function (PSDPDF). The first image (Figure 2.2a) shows the variation of the spectrum recorded by station BVL over the months of February and March 2015. We see that the most energetic parts of the spectrum were recorded between 1 and $10 \mathrm{~s}$, and that there were bursts of energetic signal at periods less than $1 \mathrm{~s}$. Signals were recorded at all periods between .021-100 s.

Figure 2.2b shows the PDF for station LL.BVL.HHZ showing the highest probability levels of the recorded signal relative to baselines which are set by the Peterson Low Noise Model (LNM) and the Peterson High Noise Model (HNM) (Peterson, 1993). These bounds were proposed from the background noise of seismic stations that were installed on hard, competent, basement rock (Richards \& Aki, 1980). This image shows that the most energetic parts of the signal were recorded between 1 and $10 \mathrm{~s}$ within a range that corresponds to ambient noise. The strongest and most probable amplitudes (with a probability near 12\%) were recorded between 1-10 s. The peaks at approximately 5 and 14 s are due to ocean waves (Richards \& Aki, 1980).

I applied spectral whitening and one-bit normalization (Bensen et al., 2007). Spectral whitening normalizes the signals at the selected range of frequencies, corresponding to the bandpass filter of .01-10 Hz. It is performed by taking the square-root of the single-station power spectral density (Seats et al., 2012). One-bit normalization is a method of temporal normalization that allows us to disregard amplitudes completely, so that we do not overweight the most energetic parts of the noise (Shapiro \& Campillo, 2004). This is one of the most aggressive methods to identify and remove earthquakes and other contaminants, as it retains only the sign of the raw signal by replacing all positive amplitudes with a 1 and all negative amplitudes with a -1 . 

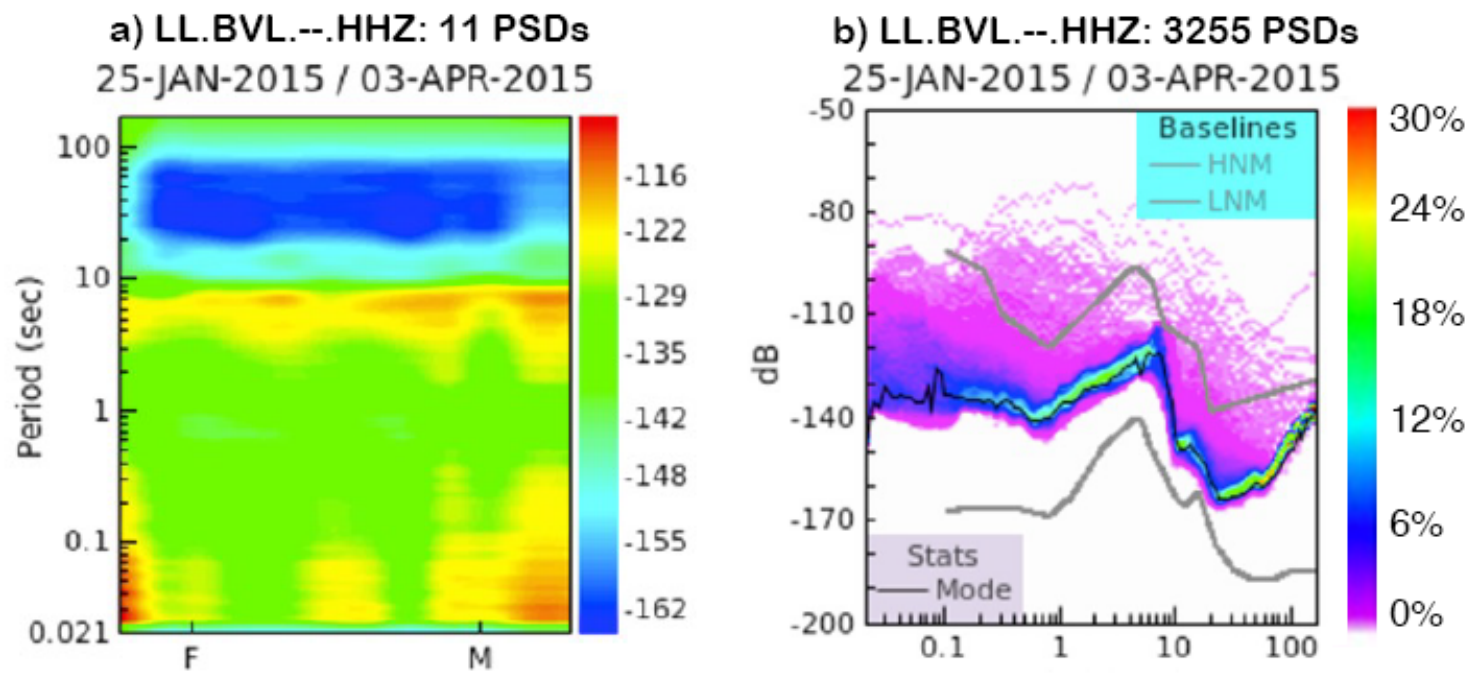

Figure 2.2: Noise models computed by the ambient noise data analysis software PQLX (McNamara \& Boaz, 2010) showing (a) Spectral variations of seismic noise recorded January through April 2015 at station BVL, and (b) The probabilistic power spectral density recorded by the vertical component (HHZ) of station LL.BVL between January to April 2015.

\subsection{Cross-Correlation}

Cross-correlations are computed in the frequency domain. A cross-correlation function is returned for each station pair containing data for time lags in the acausal (negative lags) and causal (positive lags) parts. As a mathematical operation, crosscorrelation can be thought of as a sliding dot product. It is similar to a convolution, but for a cross-correlation, we reverse one of the signals such that

$$
a[n] \cdot b[-n]=c[n]
$$

(Smith, 1997). Each of the positions in c[n] is obtained by multiplying the values at corresponding points in the two signals and then summing the results. The result 
is a sequence of values for various positions of lag. Random noise is attenuated in this process and coherent frequencies sum constructively. The result is a measure of how much each signal resembles the other at different lags in time (Smith, 2003).

I computed separate cross-correlations between Rayleigh waves and between Love waves. I set the analysis to use waveforms that were recorded between 2015-01-01 to 2015-05-01. This selection ensured that recordings from all available days were taken into account. Not every station was deployed or decommissioned on the same day. The greatest amount of days that were recorded by any of the stations was between 76-80 days. Eighty days amounts to 2.6 months of continuous recordings. I used an overlapping window of $75 \%$ and a correlation window of $3600 \mathrm{~s}$. These were found to be the most optimal settings for ambient noise correlation by Seats et al. (2012).

The maximum lag of the cross-correlation computations was set to $100 \mathrm{~s}$. As we see in Figure 2.3, the arrivals of Love or Rayleigh waves at the maximum interstation distance of approximately $37 \mathrm{~km}$ do not arrive at lags of more than $15 \mathrm{~s}$. By setting the max lag to $100 \mathrm{~s}$, the impulse arrivals that result from cross-correlating the signals of each interstation pair are padded with additional zeros. Adding zeros increases the length of the period in the time domain, while increasing the resolution in the frequency domain by making the samples more finely spaced (Smith, 1997).

\subsection{Phase Weighted Stacking}

After cross-correlations are computed in the frequency domain, they are returned to the time domain and added to one another through a process known as stacking. Like the results from cross-correlation, the returns of this process are two-sided time functions with both positive and negative correlation lags (Bensen et al., 2007). I applied a time-domain phase weighted stacking (PWS) method (Schimmel \& Paulssen, 
1997) to the second power. PWS is a non-linear stacking technique in which an amplitude-unbiased coherency measure is designed based on the instantaneous phase.

Figure 2.3 shows the stacked cross-correlations for each station pair. The crosscorrelations are plotted as a function of time and offset. Offset refers to the interstation distance between pairs of stations. ZZ refers to a cross-correlation between Rayleigh waves. TT refers to the cross-correlation between Love waves.

The results of cross-correlation contain information about the signals of surface waves which travel in opposite directions along interstation paths which link the stations (Yang et al., 2007). The arrivals of these two oppositely travelling signals occur at the positive and negative lag. While the two signals travel within the same materials, the sources of noise in the opposing directions may be different. It is common to see asymmetric cross-correlations, from which two signals contain differing spectral contents (Yang et al., 2007). We see that the arrival times of the Rayleigh wave (ZZ) arrivals increase linearly as interstation distance increases up to distances that approach $37 \mathrm{~km}$. The arrivals of Love waves (TT) exhibit a similar linear behavior.

\subsection{Frequency Time Analysis}

I use the results from cross-correlation and stacking to measure group velocity as a function of period through FTAN. Surface waves do not suffer from the same type of decay through geometric spreading as body waves (Stein \& Wysession, 2009). The energy of body waves spreads three-dimensionally and decays with a distance $\mathrm{r}^{-2}$ away from their source, while the energy of surface waves spreads two-dimensionally and decays with a distance $\mathrm{r}^{-1}$ (Stein \& Wysession, 2009). Thus we can expect Green's function approximations between stations to be dominated by surface waves that are propagating away from a source (Richards \& Aki, 1980). The transverse-transverse 

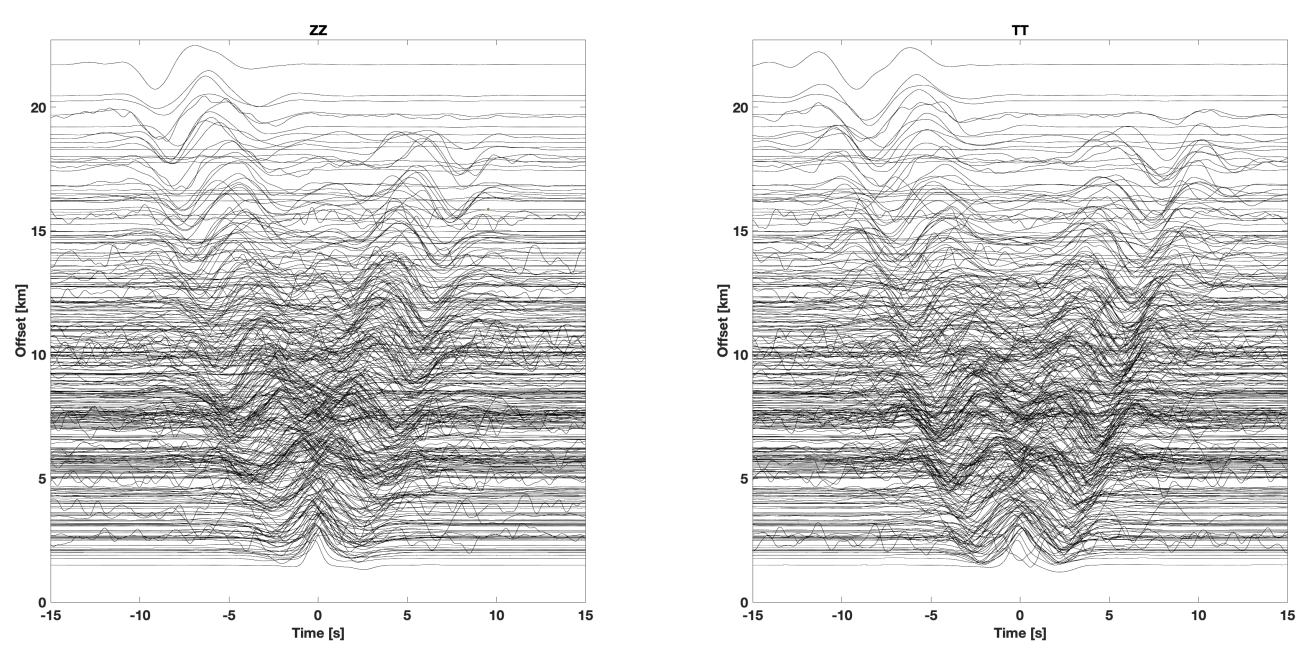

Figure 2.3: The 0.01-10 $\mathrm{Hz}$ bandpassed filtered, stacked cross-correlation functions for the Rayleigh (ZZ) and Love (TT) waves recorded by the available waveforms from seismic stations in the LL, TC, and $3 \mathrm{H}$ networks.

component of correlations of the Green's function tensor consists of a sum of Love waves modes, and the radial-radial and vertical-vertical components consist of a sum of Rayleigh wave modes. Thus, Love waves can be measured using the transverse components of seismometers, and Rayleigh waves can be measured using either the vertical or radial components. The vertical components are preferred because transverse and radial components of are often more noisy than vertical components.

The velocities of surface waves vary according to the range of depths which are sampled by each period. For Love waves, this dispersion depends on shear wave velocity. For Rayleigh waves, this dispersion depends on shear wave velocity and compressional wave, or P-wave, velocity $\left(v_{p}\right)$ (Stein \& Wysession, 2009). Because of their dispersive nature, we can decompose surface waves through FTAN. FTAN is a version of a Fourier analysis in which we can measure the phase or group velocities of surface waves to obtain information about the Earth's structure at different 
frequencies, but it is easiest to obtain group velocity.

Group velocities reflect the amplitudes of the envelopes in which packets of surface waves propagate. They can be measured by dividing the distance between station pairs by the arrival time of the surface wave energy. These envelopes are superimposed on carrier waves which move with phase velocities. The estimation of phase velocities assumes a term for intrinsic ambiguity and involves a term for the source ambiguity or 'initial phase' (Lin et al., 2008). This value arises from the uncertainty of the ambient source distribution. To circumvent the difficulty in constraining this source phase ambiguity factor, and its introduction of error, I estimate group velocity to invert for shear wave velocity structure and neglect phase velocity in this study.

In FTAN, instantaneous spectral amplitudes are calculated from a seismogram through a filtration with a band-pass filter that has been centered about each corresponding period (Dziewonski, 1979). This multiple filter technique is used to study the variations of amplitude within a multiply dispersed signal as a function of velocity in the time domain and period in the frequency domain. We pass an array of narrow band-pass filters over a signal to measure group velocity from the peak envelope amplitudes of Rayleigh or Love waves as a function of period and velocity.

I use the MSNoise plug-in 'MSNoise-TOMO' to compute FTAN in two steps. I first select parameters in a Graphical User Interface (GUI) and view the effects of the parameter choices on a FTAN diagram. The GUI produces a FTAN image from the waveform traveling between two stations. This energy diagram is defined by the envelopes of a series of narrow-band filtered versions of the results from crosscorrelation and stacking. It is produced by displaying the logarithm of the square of the envelope of the signal, $\log \left\|A\left(t, \omega_{0}\right)^{2}\right\|$ (Bensen et al., 2007), in which $t$ is time and 
$\omega_{0}$ is the center frequency. These envelope functions are arranged vertically on a grid of different values of $\omega_{0}$ to produce a matrix that is displayed as the FTAN image. The maximum amplitudes are picked automatically in each vertical array to form a dispersion ridge that is tracked as a function of period for a group speed curve.

The GUI offers a way to visually validate FTAN configurations as well as the cross-correlations between stations. Through this analysis, I detected signals with abnormally smaller and noisier amplitudes than those of the other station pairs which were associated with cross-correlations involving the station LL.WAT. I removed all waveforms that resulted from cross-correlations with LL.WAT from the dataset.

Figure 2.4 shows the MSNoise FTAN GUI for the cross-correlations between the station pairs LL.HFH-TC.MIC. The GUI plots the trace of the cross-correlation between the station pair above the FTAN diagram. The portion of the waveform that is being analyzed is plotted in the trace as a red line segment. The width of this segment is defined by a user set range of group velocities. For this analysis, I selected a minimum group velocity of $1.0 \mathrm{~km} / \mathrm{s}$, and a maximum group velocity of $4.8 \mathrm{~km} / \mathrm{s}$. This range made it so that FTAN captured significant components of the surface wave arrivals, while ensuring that most picks were selected within a range of group velocities that increased with period. In general, surface waves with the longest periods travel the fastest and are the first to arrive (Stein \& Wysession, 2009).

Configurations such as the minimum and maximum velocity applied to construct group velocity dispersion curves are shown in each panel. These values correspond to the final configurations used in the automated FTAN procedure. The group velocity dispersion curves are depicted as connected black points in the energy diagram, while period-velocity measurements larger than one wavelength are highlighted with green 

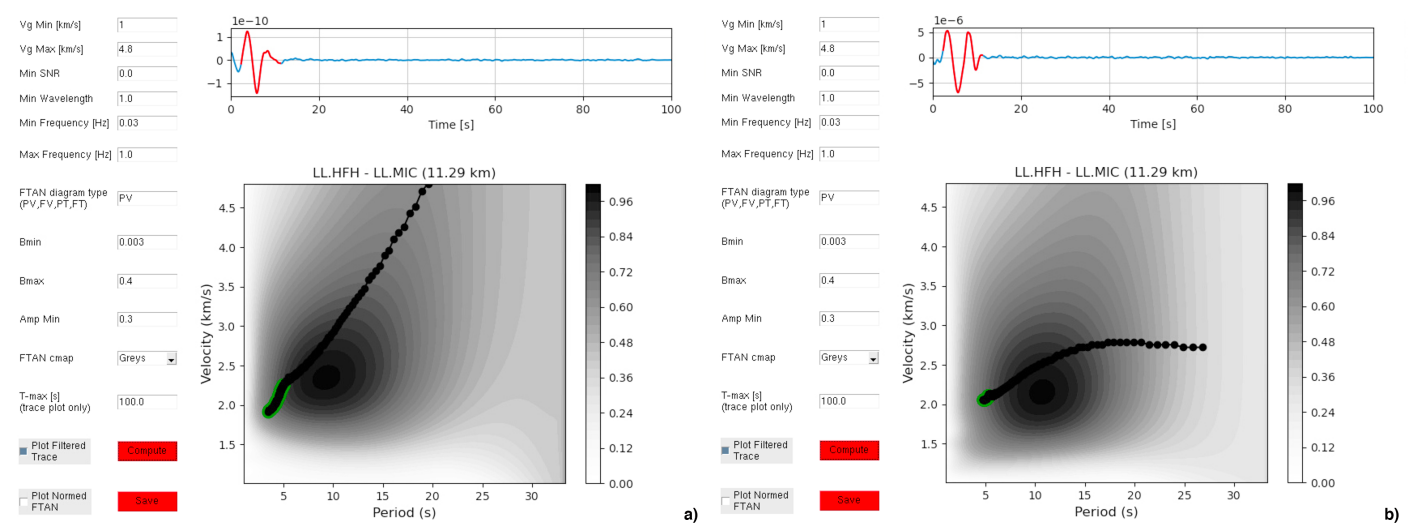

Figure 2.4: a) The MSNoise FTAN GUI for the cross-correlation of Rayleigh waves travelling between the stations $\mathrm{HFH}$ and MIC, showing values that were selected for automated FTAN (i.e.: Vg min. and max., min. signal-to-noise-ratio (SNR), min. wavelength, min. and max. frequency, Bmin, Bmax, and amp. min.). b) The FTAN GUI for the crosscorrelation of Love waves travelling between $\mathrm{HFH}$ and MIC.

outlines. I set a one wavelength criteria to construct group velocity dispersion curves from measurements that are within interstation distances of 1 wavelength or greater. The analysis was limited to periods from 1 to $33 . \overline{33} \mathrm{~s}$ (which is $0.03-1 \mathrm{~Hz}$ ).

After running an automated FTAN procedure, I removed all dispersion curves which did not increase with period. While my initial FTAN parameter settings could obtain reliable dispersion curves for some interstation pairs, the same settings could not obtain reliable results between other stations, i.e. some results did not increase with period or were not measured at all. Because of this, I ran the automated FTAN procedure again using using a different set of parameters on cross-correlations for pairs which had been removed after the first run of FTAN. I show the parameters and an example of the FTAN diagram for the station pair LL.HRD-TC.AGU in Figure 2.5. These stations are $3.33 \mathrm{~km}$ apart. I repeated this process until having obtained 533 Rayleigh wave group velocity dispersion curves and 507 Love wave group velocity 

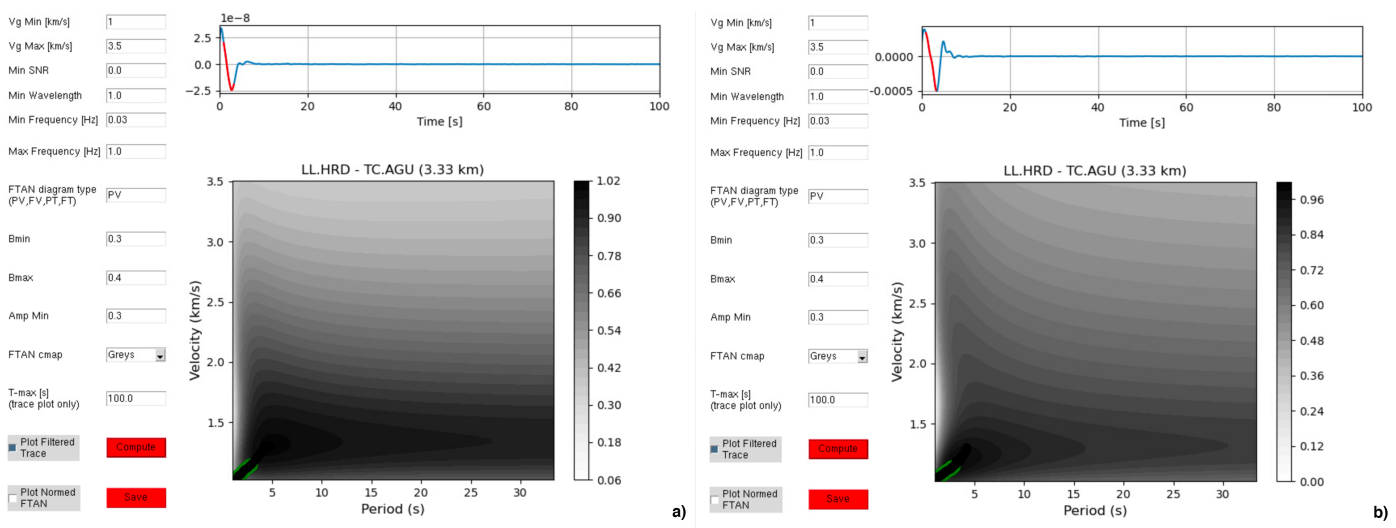

Figure 2.5: a) Configurations for a second automated run of FTAN shown in a) the FTAN GUI for the cross-correlation of Love waves travelling between stations HRD and AGU, and b) the FTAN GUI for the crosscorrelation of Love waves travelling between stations HRD and AGU.

dispersion curves. Parameters that were used to run FTAN are shown in Table 2.1.

Figure 2.6 shows the FTAN picked group velocity dispersion curves. The analysis was set to select measurements within periods of $1-33 . \overline{33} \mathrm{~s}$ using a one wavelength criteria. The results yielded values that were measured between periods of 1-10 s. Studies show that results obtained by setting the interstation distance cut-off to one wavelength are consistent with the results of studies that obtain dispersion measurements using distances longer than three wavelengths (Luo et al., 2015). Dispersion measurements obtained with short-path dispersion measurements are useful towards constraining smaller velocity anomalies in ANT (Ekström, 2014).

The group velocity measurements fall within similar ranges for both Rayleigh and Love waves. The values range between group velocities of $1.0-3.2 \mathrm{~km} / \mathrm{s}$. Compared to Love waves, we see that the amount of measurements for group velocities that are less than $1.5 \mathrm{~km} / \mathrm{s}$ is relatively sparse for Rayleigh waves. Histograms of the distributions of Rayleigh and Love wave group velocities are shown in Figure 2.7. The distributions 
Table 2.1: Parameters used for automated FTAN, where 'Vg' represents group velocity $(\mathrm{km} / \mathrm{s})$. ' $f$ ' represents frequency in $\mathrm{Hz}(1 /$ period $)$. ' $b$ ' represents the change in the width of Gaussian filter over a linear spacing of 300 points. 'Amp. Min.' represents the amplitude percentage filter as a percent of the maximum amplitude. ' $\lambda$ ' represents wavelength.

\begin{tabular}{|c|c|c|c|c|c|c|c|c|}
\hline & Run 1 & Run 2 & Run 3 & Run 4 & Run 5 & Run 6 & Run 7 & Run 8 \\
\hline Min. $f(\mathrm{~Hz})$ & 0.03 & 0.03 & 0.03 & 0.03 & 0.03 & 0.03 & 0.03 & 0.03 \\
\hline Max. $f(\mathrm{~Hz})$ & 1.0 & 1.0 & 1.0 & 1.0 & 1.0 & 1.0 & 1.0 & 1.0 \\
\hline Min. Vg $(\mathrm{km} / \mathrm{s})$ & 1.0 & 1.0 & 1.8 & 1.0 & 1.8 & 1.5 & 1.5 & 0.1 \\
\hline Max. Vg (km/s) & 4.8 & 3.5 & 2.3 & 3.5 & 3.0 & 3.3 & 2.0 & 1.4 \\
\hline Min. $\lambda$ & 1.0 & 1.0 & 1.0 & 1.0 & 1.0 & 1.0 & 1.0 & 1.0 \\
\hline b Min. & 0.003 & 0.3 & 0.04 & 0.06 & 0.1 & 0.8 & 0.08 & 0.09 \\
\hline b Max. & 0.4 & 0.4 & 0.8 & 0.2 & 0.4 & 0.87 & 0.87 & 0.9 \\
\hline Amp. Min. & 0.3 & 0.0 & 0.0 & 0.1 & 0.0 & 0.4 & 0.4 & 0.4 \\
\hline
\end{tabular}

of group velocities with the Rayleigh wave dataset show that these measurements were less sensitive to group velocities that are less than $2.0 \mathrm{~km} / \mathrm{s}$. However, a count of group velocity measurements within each period for both Rayleigh and Love waves shows more measurements have been collected for Rayleigh waves at periods of less than approximately $2 \mathrm{~s}$. I show the count of measurements that were picked within each period for FTAN of both Rayleigh and Love waves in Figure 2.8.

The increase of group velocities with period is a trend that has been observed in ANT studies of other volcanoes (Mordret et al., 2015; Obermann et al., 2016, 2019) for periods of less than $20 \mathrm{~s}$. This indicates an upper crustal structure in which periods sample material whose velocity increases with depth (Stein \& Wysession, 2009).

\section{$2.7 \quad$ 2-D Group Velocity Tomography}

Group velocity measurements are used to invert for 2-D tomographic group velocity distributions at each period. This is computed through the ambient surface wave tomography (ANSWT) algorithm in MSNoise-TOMO, which applies the ray-theory 

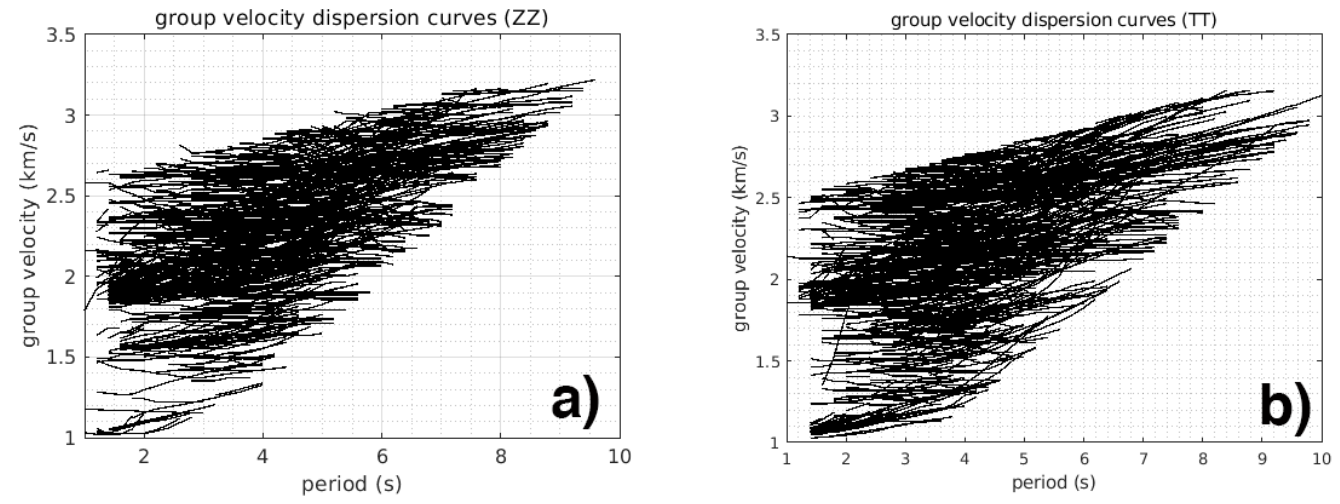

Figure 2.6: a) FTAN picked Rayleigh group velocity dispersion curves for periods 1-10 s b) FTAN picked Love wave group velocity dispersion curves.
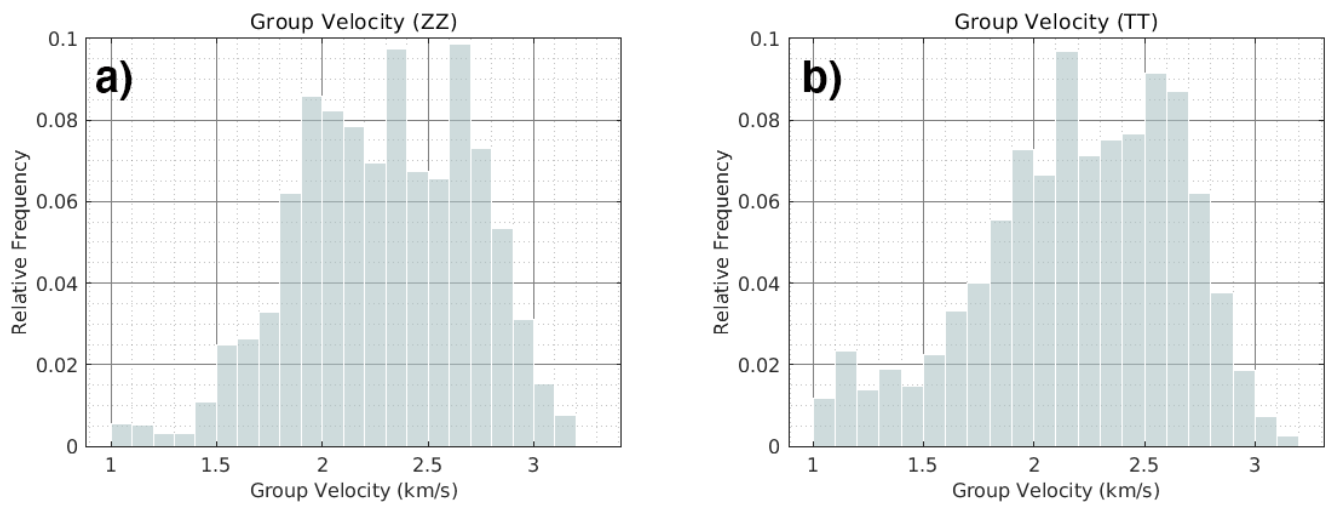

Figure 2.7: a) The relative density of a) Rayleigh wave group velocities within periods of 1-10 s, and of b) Love wave group velocities within 1-10 s. These distributions correspond to the velocities in Figure 2.6. 

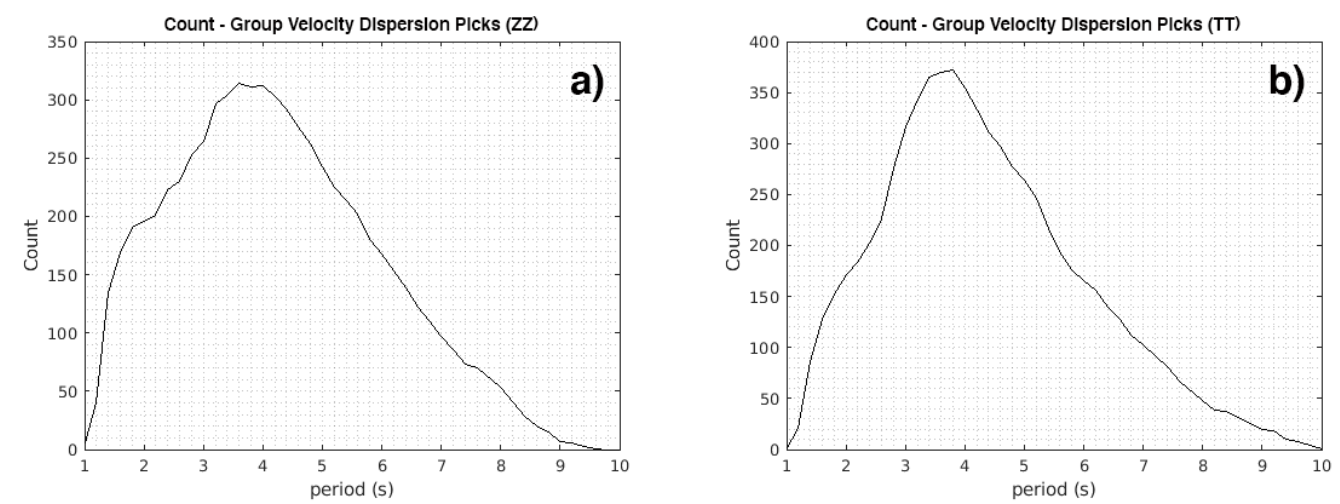

Figure 2.8: The number of group velocity dispersion picks within each period from 1-10 s via FTAN corresponding to the dispersion picks shown in Figure 2.6v for a) Rayleigh wave dispersion and b) Love wave dispersion.

based inversion presented by Barmin et al. (2001). Barmin's inversion assumes a spherical geometry within a scaled region that is defined by a simple closed curve. It is a surface-wave inversion so we use surface-wave data to constrain the structure of the crust. This kind of inversion is advantageous because surface-wave dispersion maps summarize a great deal of data in a compact form while remaining close to a true model (Barmin et al., 2001). A disadvantage is that dispersion maps contain only some of the information regarding the Earth structure that is contained by the seismogram. As these maps are obtained through inversion, they contain uncertainties from observational and theoretical errors (Barmin et al., 2001).

Because of the nature of the earth's structure, surface-wave tomographic inversion problems are invariably ill-posed. This means that there is an insufficient number of linearly independent constraints to be able to determine a solution. Barmin's inversion accounts for this by applying a regularization scheme through Gaussian smoothing. This involves a penalty function that consists of a spatial smoothing function with a correlation length that is set by the user (Barmin et al., 2001). This 
method places constraints on the amplitudes of perturbations in the reference state to keep the resulting models close to the starting models, with the goal of estimating the model $\mathbf{m}$ from the observed travel time residuals. We place constraints on the following penalty function, which is explicitly minimized to find the model $\mathbf{m}$ :

$$
(\mathbf{G}(\mathbf{m})-\mathbf{d})^{T} \mathbf{C}^{-1}(\mathbf{G}(\mathbf{m})-\mathbf{d})+\alpha^{2}\|F(\mathbf{m})\|^{2}+\beta^{2}\|H(\mathbf{m})\|^{2},
$$

(Barmin et al., 2001). The first term represents the misfit of the data. The second term contains the regularization parameter alpha $(\alpha)$, which is a spatial smoothing condition based on the matrix $F . F$ contains the regularization parameter sigma $(\sigma)$, which is the spatial smoothing width or correlation length. The third term places a damping constraint that penalizes the weighed norm of the model with the parameter beta $(\beta)$ (Mordret et al., 2013). This constrains the amplitudes of perturbations depending on the local path coverage, denoted lambda $(\lambda)$, at any single grid node. An effect of this term is that the amplitudes of the perturbations are automatically overdamped into a background reference state in locations where there is low path density (Barmin et al., 2001). Path density refers to the number of paths which intersect a circle of a fixed radius that is centered about a point on the grid.

\subsubsection{Grid Size}

I generate a grid of discrete nodes on which I can evaluate the model by using a local Cartesian coordinate system so that I can determine distances between points of interest (Barmin et al., 2001). I parameterize the model on a $0.025^{\circ} \times 0.025^{\circ}$ pixel grid. This results in 19 grid points in the longitudinal direction, and 12 grid points in the latitudinal direction. The size of each cell corresponds to $2.8 \times 2.8 \mathrm{~km}$. This grid size was selected to allow for a higher resolution within a $10 \mathrm{~km}$ circle surrounding 

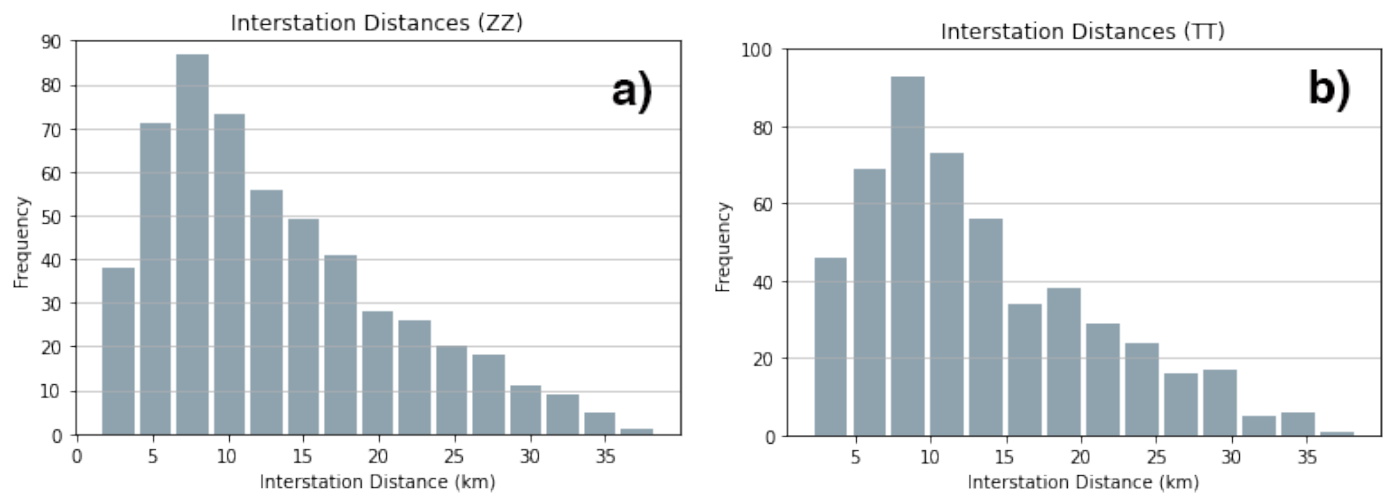

Figure 2.9: Histograms showing the distribution of distances between station pairs travelled by a) Rayleigh waves and b) Love waves. The distributions correspond to the group velocity picks in Figure 2.6.

Llaima's summit where the density of seismic stations is the greatest. The tomography will not be as well constrained by the density of ray paths outside of this area, but the data from these additional stations will still be able to add information about the surrounding structure. I show histograms of the interstation distances for which measurements were retrieved in Figure 2.9. These distributions correspond to the group velocity measurements that were picked through FTAN (shown in Figure 2.6). Nearly 40 Rayleigh wave group velocity dispersion curves correspond to interstation distances that are less than $5 \mathrm{~km}$, while more than 40 Love wave group velocity dispersion curves correspond to interstation distances that are less than $5 \mathrm{~km}$.

\subsubsection{Regularization Parameters}

I use a method of choosing parameters for regularization that is similar to the method of using an L-curve to select parameters for Tikhonov regularization, in which we control the complexity of models by selecting parameters that are closer to zero while deciding an optimal trade-off between two values (Widman, 2002). Figure 2.11 shows the values of root mean square (RMS) error and variance reduction for different peri- 


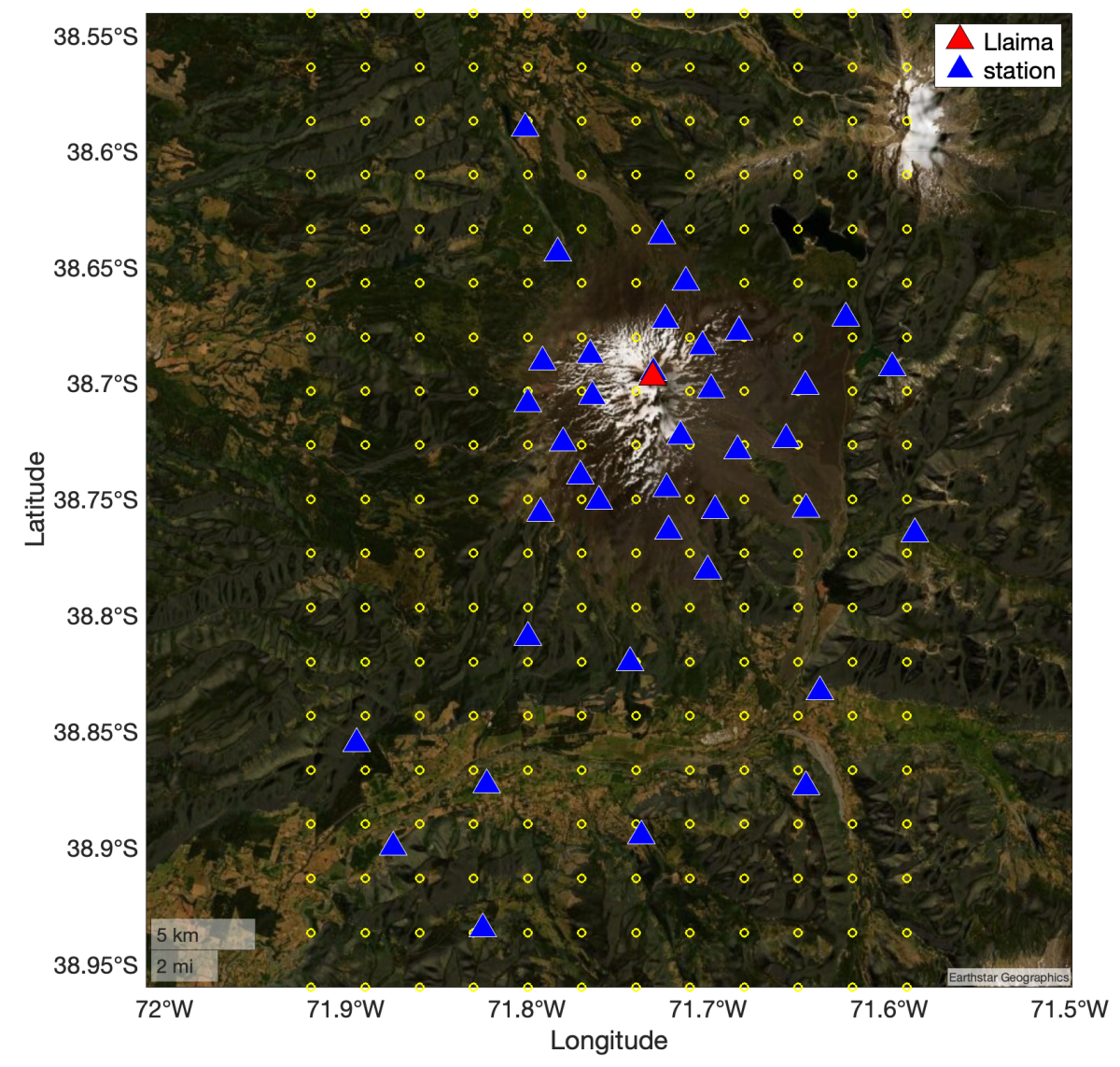

Figure 2.10: The tomography grid for both Love and Rayleigh waves. Grid points are shown as hollow yellow circles, resulting in a 12 x 19 grid. Each grid spacing is equivalent to $2.8 \mathrm{~km}$. Llaima's summit is indicated by a red triangle. Blue triangles represent the locations of seismic stations. 

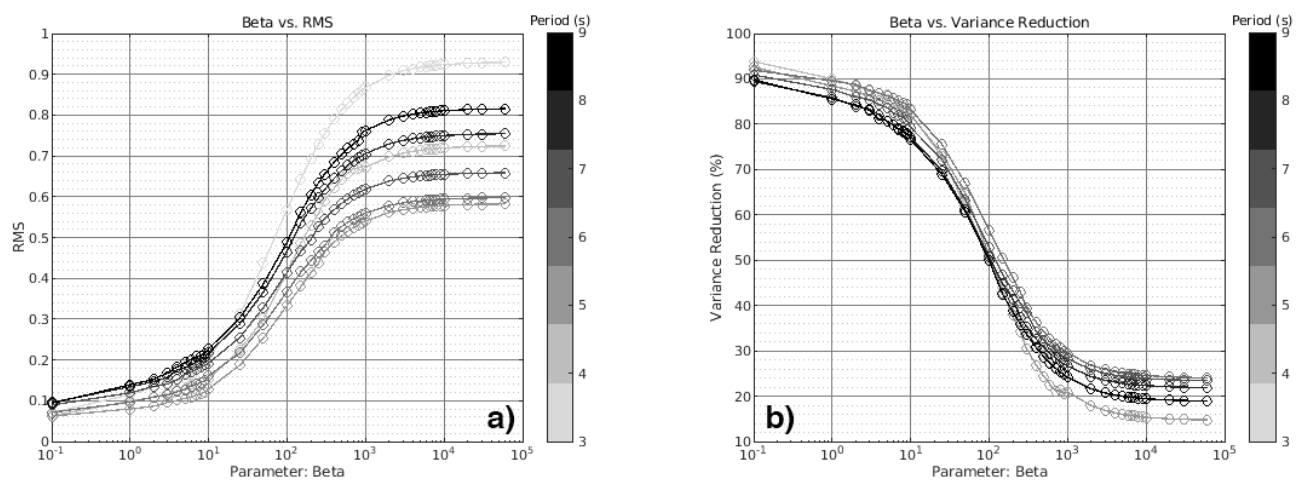

Figure 2.11: a) The root mean square (RMS) data fit and b) the variance reduction while varying the regularization parameter beta. The measurements for each period are represented by hollow circles that are connected with a line. Each line corresponds to the measurements for a different period between 3-9 s. The lines are colored by varying shades of grey, where the lightest shade of grey represents the measurements for a period of $3 \mathrm{~s}$ and the darkest shade represents measurements at $9 \mathrm{~s}$.

ods while varying the regularization parameter during Rayleigh wave group velocity tomography. I do not show the results of this process for Love wave tomography because the results are very similar - both Rayleigh and Love waves are mostly sensitive to the shear wave velocity. This figure is produced from the results of 2-D group velocity tomography with MSNoise for increasing values of $\beta$. root mean square error is computed from the standard deviation of model residuals. Variance reduction is computed from the variances of the final and background velocity models. I selected 10 for beta $(\beta)$. The root mean square error at 10 is below 0.3 for periods between 3-9 s. The variance reduction is greater than 70\%. Variance reduction represents the ratio of the data variance from the resulting models to the data variance of a homogeneous initial model (Pourpoint et al., 2018). Variance reductions greater than $50 \%$ indicate that the results fit the data reasonably well (Mordret et al., 2015).

Figure 2.12 shows the results of this process to obtain $\alpha$ (with $\beta=10, \sigma=1, \lambda=0$ ). 

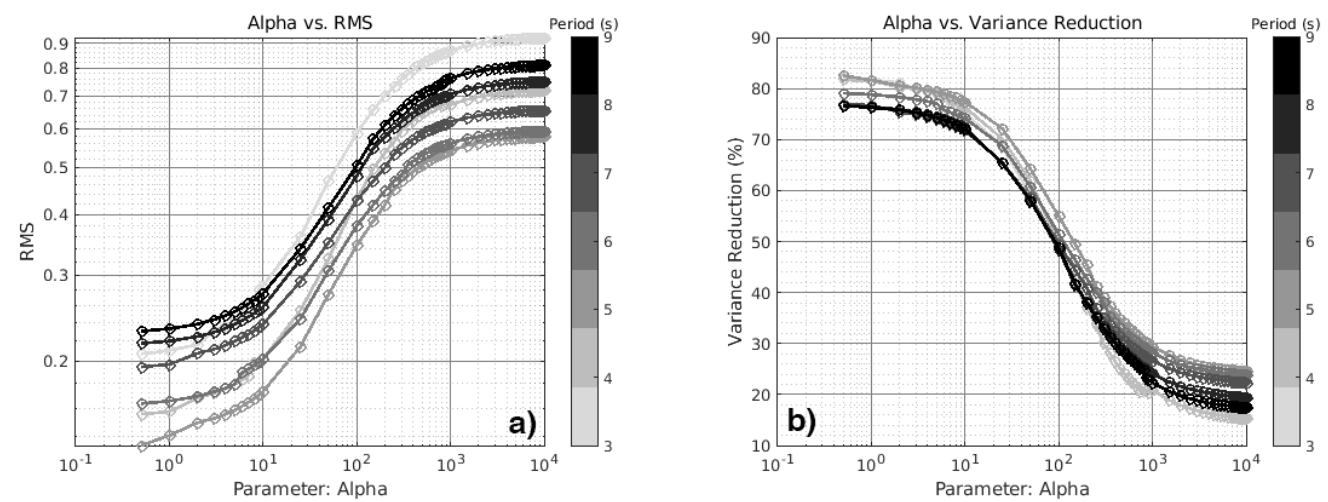

Figure 2.12: a) RMS for periods 3-9 s while varying the regularization parameter alpha. b) Variance reduction for periods 3-9 s while varying alpha. The measurements for each period are represented by hollow circles that are connected with a line. Each line corresponds to the measurements for a different period between 3-9 $\mathrm{s}$. The lines are colored by varying shades of grey, where the lightest shade of grey represents the measurements for a period of $3 \mathrm{~s}$ and the darkest shade represents measurements at $9 \mathrm{~s}$.

Figure 2.13 shows the results for sigma $(\sigma)$. Sigma sets a spatial smoothing width that can decrease the size of dataless gaps in resulting tomography maps. It can also reduce the degree of resolution within areas of the map that have been measured. I selected a value of 1 for sigma, and solved for lambda $(\lambda)$. Lambda has the smallest effect on the resulting variance reduction (see: Figure 2.14), but it is optimal to choose values that are greater than 0.5 . I selected a value of 1 for lambda, and used the obtained parameter selections to compute 2-D group velocity tomography. I then customized the parameters by increasing or decreasing the values in order to eliminate streaking or other undesirable results from the resulting tomography maps based off of subjective criteria, while objectively maintaining values of variance reduction that are greater than $60 \%$. The final parameter selections to compute 2-D tomography using Rayleigh waves were $\alpha=65, \beta=40, \lambda=1$, and $\sigma=5$. The final parameter selections to compute 2-D tomography using Love waves were $\alpha=50, \beta=30, \lambda=1$, and $\sigma=5$. 

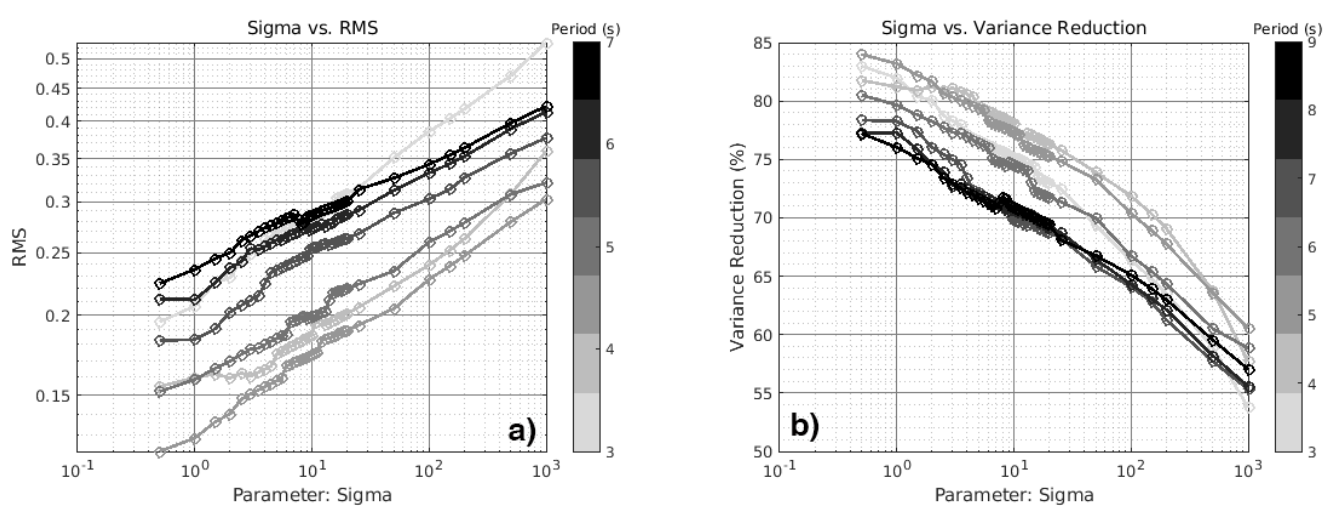

Figure 2.13: a) RMS for periods 3-9 s vs. the regularization parameter sigma. b) Variance reduction for periods 3-9 $\mathrm{s}$ while varying sigma. The measurements for each period are represented by hollow circles that are connected with a line. Each line corresponds to the measurements for a different period between 3-9 s. The lines are colored by varying shades of grey, where the lightest shade of grey represents the measurements for a period of $3 \mathrm{~s}$ and the darkest shade represents measurements at $9 \mathrm{~s}$.
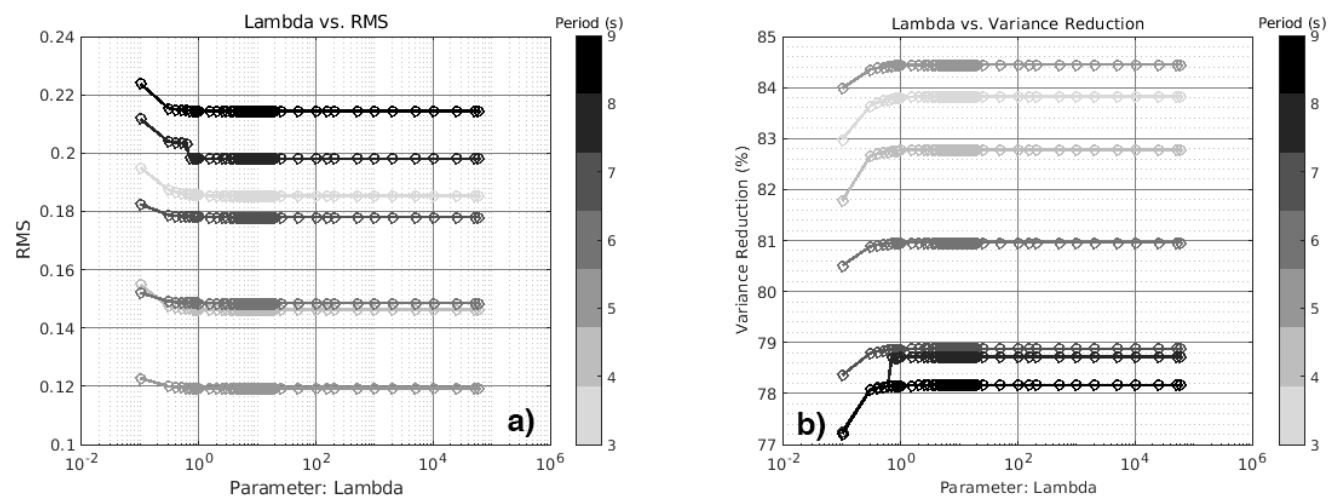

Figure 2.14: a) RMS for periods 3-9 s vs. the regularization parameter lambda. b) Variance reduction for periods 3-9 s while varying lambda. The measurements for each period are represented by hollow circles that are connected with a line. Each line corresponds to the measurements for a different period between 3-9 s. The lines are colored by varying shades of grey, where the lightest shade of grey represents the measurements for a period of $3 \mathrm{~s}$ and the darkest shade represents measurements at $9 \mathrm{~s}$. 


\subsubsection{Group Velocity Maps}

The group velocity dispersion curves that were picked via FTAN are regionalized into group velocity maps at periods between $1-10 \mathrm{~s}$ periods within $0.2 \mathrm{~s}$ intervals. This resulted in $452-\mathrm{D}$ group velocity maps. I discuss and show the resulting maps from a period of 3.2 and $9 \mathrm{~s}$ within this section. I show additional maps that were output by MSNoise as part of the 2-D group velocity tomography process for Rayleigh and Love waves, along with accompanying maps of ray path coverage, in Appendix B.

Figure 2.15 shows the Rayleigh and Love ray paths that were computed to obtain 2-D group velocity maps for a period of 3.2 s. Figure 2.16 shows the Rayleigh and Love ray paths that were computed to obtain 2-D group velocity maps for a period of

$9 \mathrm{~s}$. A red triangle in each of the figures denotes the location of station LL.HRD which was installed at Llaima's summit. The ray path coverage is the most dense within the area that contains Llaima's main edifice (within a $10 \mathrm{~km}$ radius of the summit). Multiple paths show group velocities of less than $1.6 \mathrm{~km} / \mathrm{s}$ within this range. These low velocities represent negative $v_{s}$ anomalies which are interpreted as a presence of magmatic fluid accumulation. Outside of this region, the ray paths with the longest interstation distances sample materials with higher velocities. These higher velocities are interpreted as a more solid material. We see an increase in the amount of ray paths from 3.2 to $9 \mathrm{~s}$, and that the area of coverage is larger in the maps for $9 \mathrm{~s}$.

Figure 2.17 shows the ray path densities for Rayleigh and Love wave group velocity tomography within a period of 3.2 s. Figure 2.17 shows the ray path densities for Rayleigh and Love wave group velocity tomography within a period of $9.0 \mathrm{~s}$. The pixels are colored according to the number of rays per a pixel, with the most brightly colored regions being the areas that are most resolved by ray path coverage. 

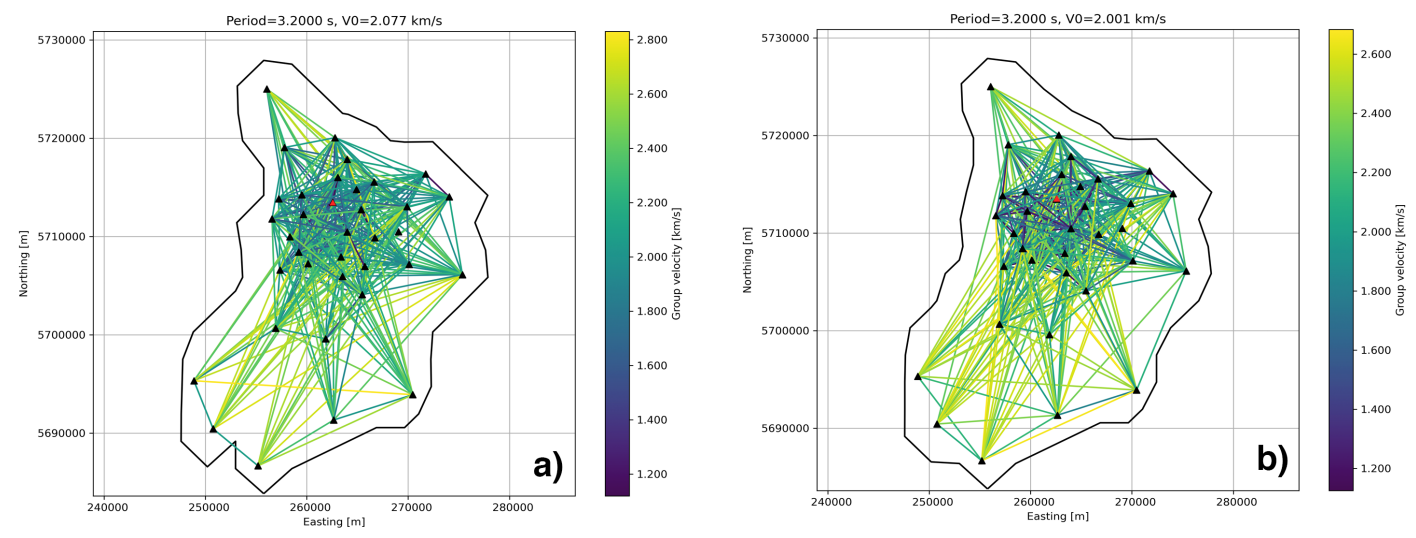

Figure 2.15: Ray paths computed from group velocities and periods for 2-D group velocity tomography for a period of $3.2 \mathrm{~s}$ for a) Rayleigh wave tomography and b) Love wave tomography. The color bar represents group velocities with cooler shades representing lower group velocities and warmer shades representing higher group velocities. Black triangles represent seismic stations. Red triangles represent Llaima's summit.
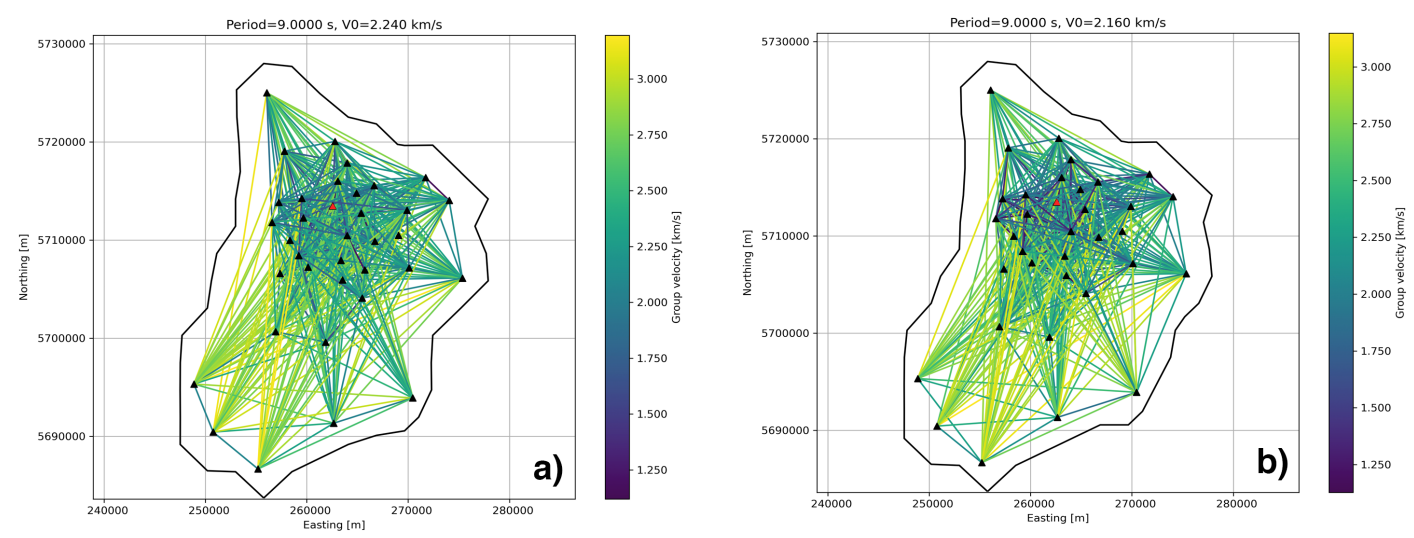

Figure 2.16: Ray paths computed from group velocities and periods for 2-D group velocity tomography for a period of $9.0 \mathrm{~s}$ for a) Rayleigh wave tomography and b) Love wave tomography. The color bar represents group velocities with cooler shades representing lower group velocities and warmer shades representing higher group velocities. Black triangles represent seismic stations. Red triangles represent Llaima's summit. 

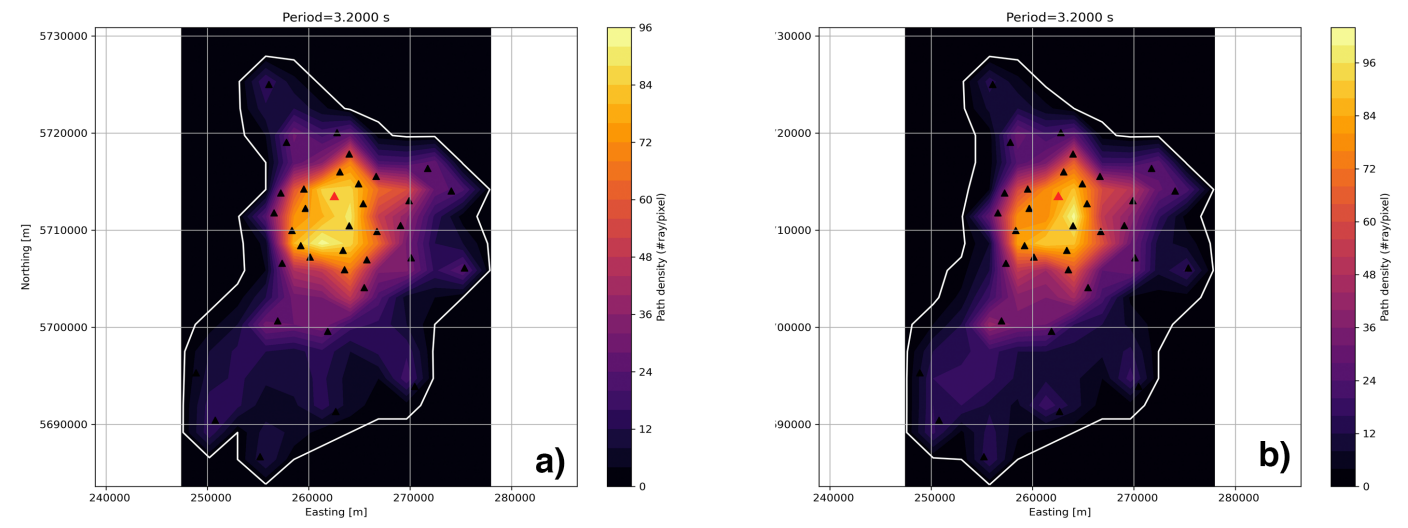

Figure 2.17: Ray path densities for 2-D group velocity tomography at a period of $3.2 \mathrm{~s}$ for a) Rayleigh wave group velocity tomography and b) Love wave group velocity tomography. Black triangles represent the locations of seismic stations, while the red triangles represent Llaima's summit. The brightest areas represent the most densely covered areas.
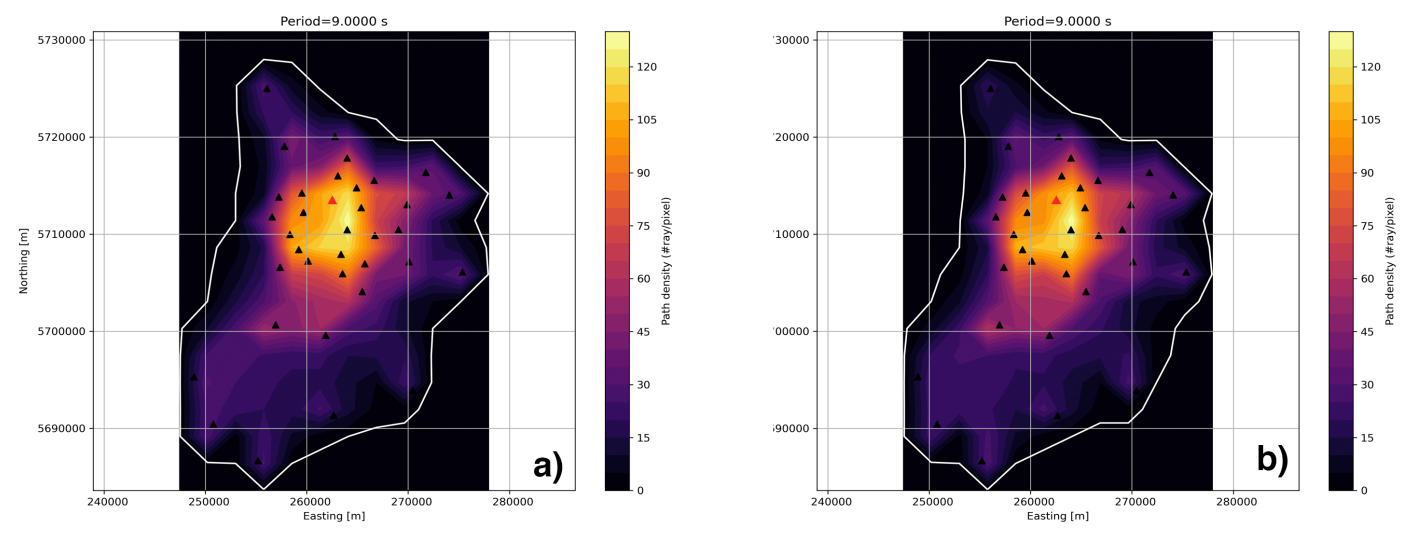

Figure 2.18: Ray path densities for 2-D group velocity tomography at a period of $9.0 \mathrm{~s}$ for a) Rayleigh wave group velocity tomography and b) Love wave group velocity tomography. Black triangles represent the locations of seismic stations, while the red triangles represent Llaima's summit. The brightest areas represent the most densely covered areas. 


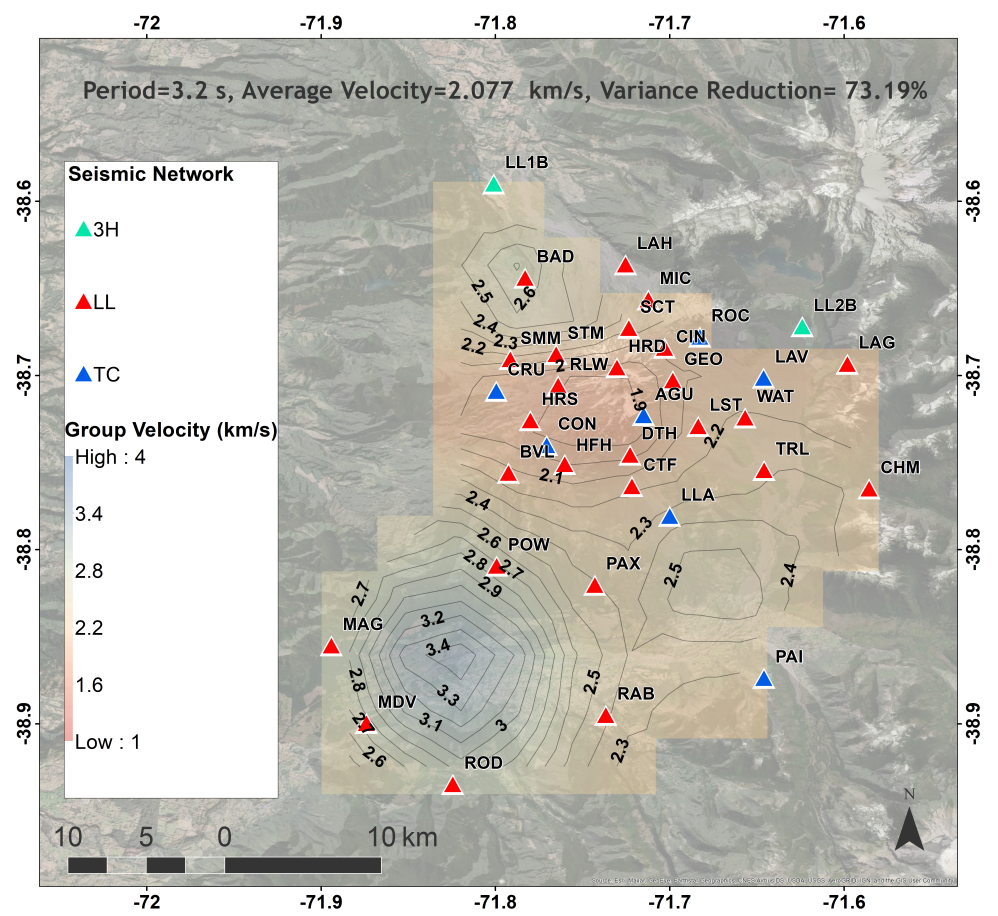

Figure 2.19: A map of Rayleigh wave group velocity distributions at a period of $3.2 \mathrm{~s}$. The color bar ranges between shear wave velocities of 1.0$4.0 \mathrm{~km} / \mathrm{s}$. Warmer shades represent locations where materials have lower group wave velocities. Cooler shades represent locations where materials have higher group wave velocities. Grey contours are labelled according to group velocity between $0.1 \mathrm{~km} / \mathrm{s}$ intervals. Bilinear interpolation has been applied. Llaima's summit is located at (-38.697407, -71.730445).

The Rayleigh and Love wave group velocity maps that correspond to the information shown in Figures 2.15, 2.16, 2.17, and 2.18 (for periods of $3.2 \mathrm{~s}$ and $9.0 \mathrm{~s}$ ) are shown in Figures 2.19, 2.20, 2.21, and 2.22. We observe a low velocity zone (LVZ) directly underneath Llaima's summit in each of the maps. The shape of this LVZ appears slightly elliptical, with a minor axis that is oriented slightly NE-SW.

Figure 2.23 shows the regionalized group velocity dispersion curves that were obtained through the 2-D group velocity inversion of the dispersion curves that resulted from FTAN. Rather than being dispersion curves which represent group velocities 


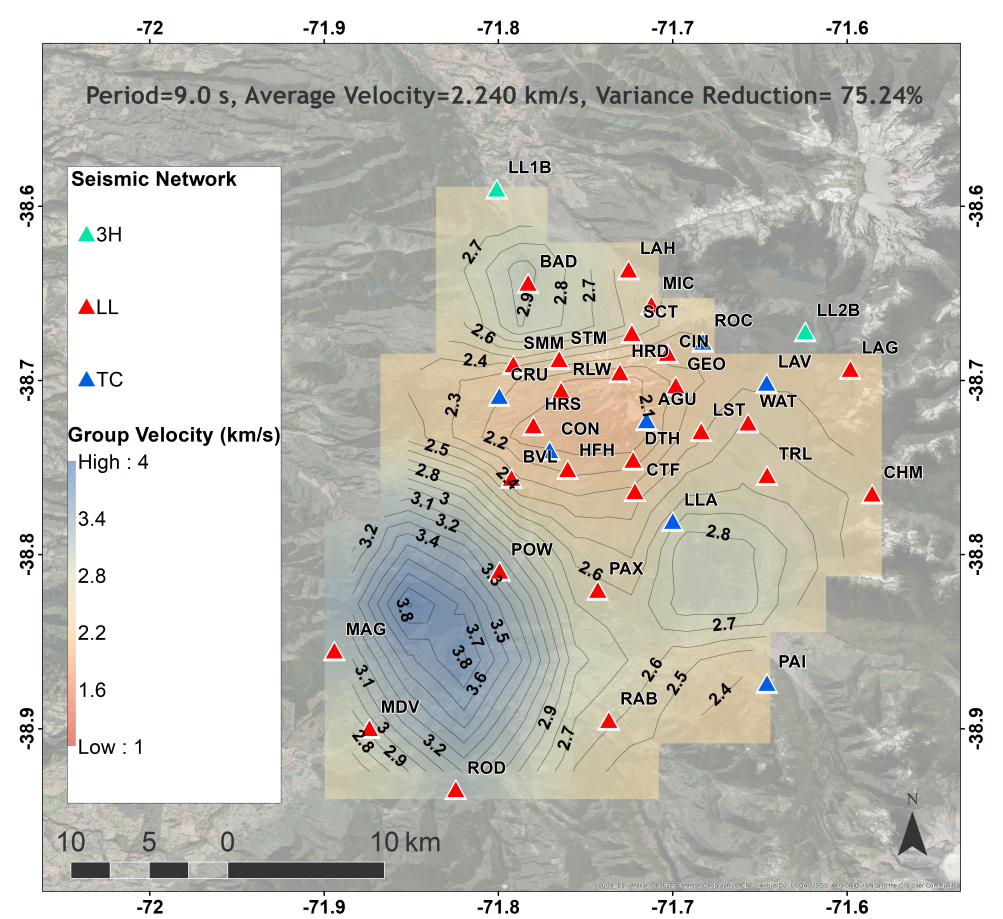

Figure 2.20: A map of Rayleigh wave group velocity distributions at a period of $9.0 \mathrm{~s}$. The color bar ranges between shear wave velocities of 1.0$4.0 \mathrm{~km} / \mathrm{s}$. Warmer shades represent locations where materials have lower group wave velocities. Cooler shades represent locations where materials have higher group wave velocities. Grey contours are labelled according to group velocity between $0.1 \mathrm{~km} / \mathrm{s}$ intervals. Bilinear interpolation has been applied. Llaima's summit is located at $(-38.697407,-71.730445)$. 


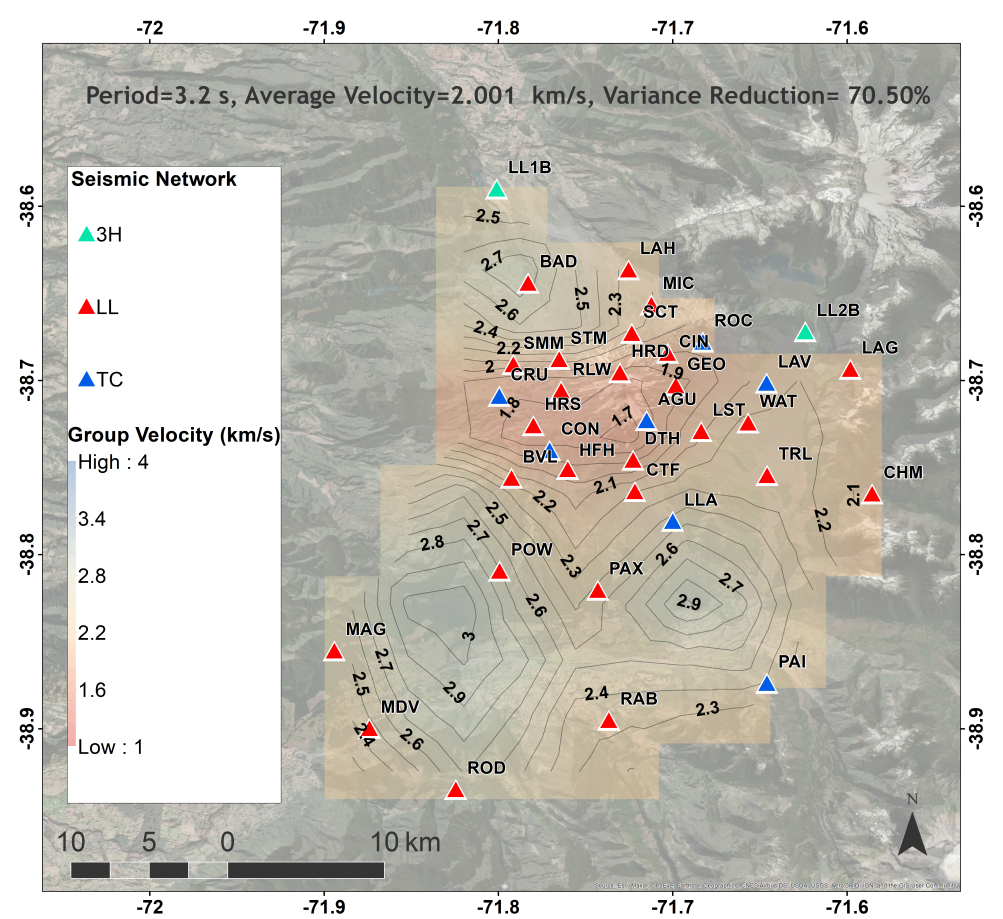

Figure 2.21: A map of Love wave group velocity distributions at a period of $3.2 \mathrm{~s}$. The color bar ranges between shear wave velocities of 1.0-4.0 $\mathrm{km} / \mathrm{s}$. Warmer shades represent locations where materials have lower group wave velocities. Cooler shades represent locations where materials have higher group wave velocities. Grey contours are labelled according to group velocity between $0.1 \mathrm{~km} / \mathrm{s}$ intervals. Bilinear interpolation has been applied. Llaima's summit is located at $(-38.697407,-71.730445)$. 


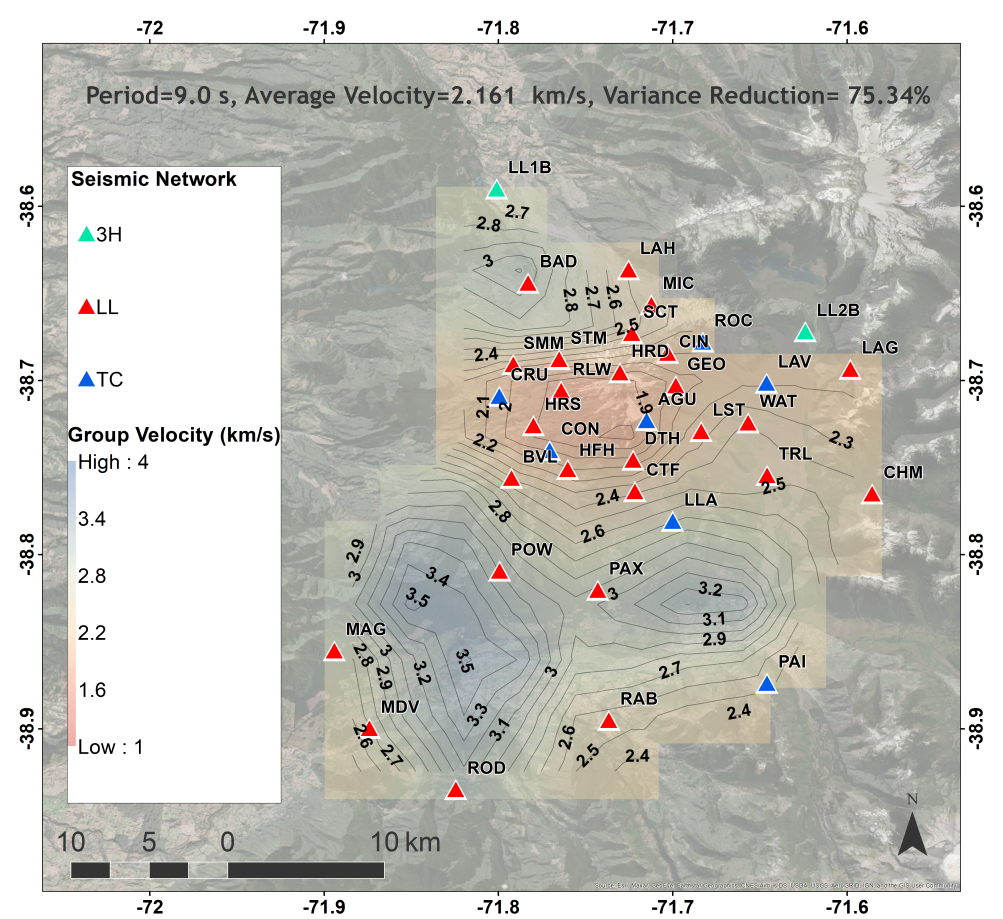

Figure 2.22: A map of Love wave group velocity distributions at a period of $9.0 \mathrm{~s}$. The color bar ranges between shear wave velocities of 1.0-4.0 $\mathrm{km} / \mathrm{s}$. Warmer shades represent locations where materials have lower group wave velocities. Cooler shades represent locations where materials have higher group wave velocities. Grey contours are labelled according to group velocity between $0.1 \mathrm{~km} / \mathrm{s}$ intervals. Bilinear interpolation has been applied. Llaima's summit is located at $(-38.697407,-71.730445)$. 
between each station pair, these curves represent the measurements for single $(\mathrm{x}, \mathrm{y})$ locations in the tomography grid. The group velocities that result from the inversion are affected by the damping constraints that were placed through regularization. I fit constraints to obtain group velocities that were generally less than $3.7 \mathrm{~km} / \mathrm{s}$, under the assumption that the highest shear wave velocities in the upper crust beneath Llaima would be that of granodiorite or diorite (roughly $3.6-3.7 \mathrm{~km} / \mathrm{s}$ (Christensen, 1970), however some of the measurements in the Rayleigh wave tomography approach $4 \mathrm{~km} / \mathrm{s}$ at periods greater than $7 \mathrm{~s}$. Green dotted lines denote the minimum group velocities in each data set, while blue dotted lines denote the maximum group velocities. The lowest velocities in the Rayleigh wave dataset range from $1.8 \mathrm{~km} / \mathrm{s}$ to $2 \mathrm{~km} / \mathrm{s}$. The minimum of group velocities in the Love wave dataset shows measurements of lower velocities with a minimum range between approximately $1.55 \mathrm{~km} / \mathrm{s}$ to $1.8 \mathrm{~km} / \mathrm{s}$. Maximum velocities in the Rayleigh wave dataset range between $3.5 \mathrm{~km} / \mathrm{s}$ to $3.9 \mathrm{~km} / \mathrm{s}$. Those of the Love wave dataset range between $3.15 \mathrm{~km} / \mathrm{s}$ to $3.65 \mathrm{~km} / \mathrm{s}$. The standard deviations of the Rayleigh and Love wave measurements increase with period. The hollow blue circles represent the mean of the measurements. The means of the regionalized Rayleigh and Love wave group velocity measurements each deviate about an axis of $2.5 \mathrm{~km} / \mathrm{s}$. They range between group velocities that are slightly lower than $2.5 \mathrm{~km} / \mathrm{s}$, and increase to values that are above $2.5 \mathrm{~km} / \mathrm{s}$ at a period of $5 \mathrm{~s}$. The deviance of the mean from $2.5 \mathrm{~km} / \mathrm{s}$ is greater in the Rayleigh wave dataset.

Higher velocities at longer periods indicate a presence of higher velocity materials at greater depths. This may be related to crystallization, compaction, or cooling conditions (Janiszewski et al., 2019). The lowest velocities at all periods may be related to the production of melt, which is expected within a volcanic setting. Lower 

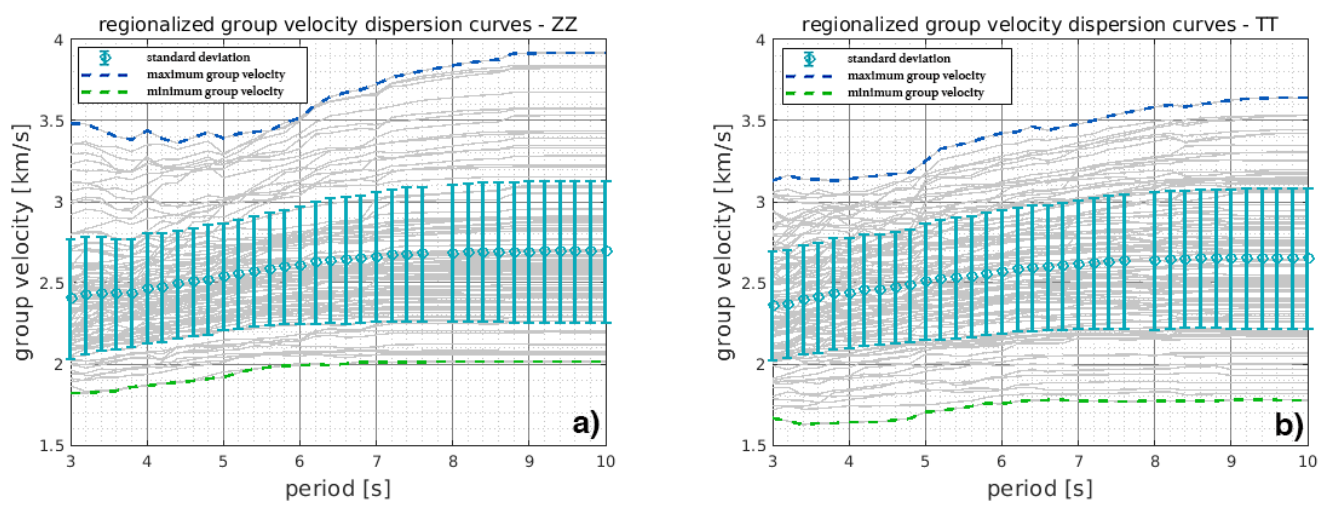

Figure 2.23: Regionalized group velocity dispersion curves for a) Rayleigh waves and b) Love waves. The curves correspond to (x,y) locations in each of the period maps obtained through 2-D group velocity tomography. The mean measurements at each period and their standard deviations are shown as teal hollow circles with error bars. The minimum group velocities at each period are represented by a dashed green line. The maximum group velocities are represented by a dashed blue line.

velocities can also be related to sediment distribution or fracturing. The velocities of rocks like basalt or diabase decrease when the materials are fractured (Carlson, 2014). Studies show that the heating of volcanic rocks extends pre-existing microcracks by small increments, while contraction during cooling from high temperatures results in the extension of larger and more tensile microcracks) (Browning et al., 2016). However, for many rocks, there is a critical point in the confining pressure at which cracks begin to close and velocities begin to rapidly increase. For crystalline rocks, this is typically near 100-250 Mpa. This range occurs near $4 \mathrm{~km}$ depth (Birch, 1961).

\subsection{1-D Vs-Depth Inversion}

I use the Python tool BayHunter (Dreiling, 2020) for McMC transdimensional Bayesian inversion of surface wave dispersion. This solves for the $v_{s}$-depth structure, the number of layers, and the noise parameters. We find an optimal solution by jointly 
combining observations (from our ZZ and TT dispersion curves), models, and their respective errors by applying Bayes' theorem. A joint inversion with both Rayleigh and Love wave dispersion curves obtains structures that each set is sensitive to.

If we denote the observed data as $d_{o b s}$ and a model $m$, the probability of observing $d_{o b s}$ given $m$ is written $p\left(d_{o b s} \mid m\right)$. The probability for $m$ given $d_{o b s}$ is written $p\left(m \mid d_{o b s}\right)$. Both occurrences are dependent on the probabilities of $m$ and $d_{o b s}$, written as $p(m)$ or $p\left(d_{o b s}\right)$, respectively (Dreiling, 2020). Bayes theorem states that the posterior distribution of the model given the data $\left(p\left(m \mid d_{o b s}\right)\right.$ is equal to the product of the prior knowledge $p(m)$ and the data likelihood $p\left(d_{o b s} \mid m\right)$ over a normalization factor. The inverse conditional probability of both events occurring is:

$$
p\left(d_{o b s} \mid m\right) p(m)=p\left(m \mid d_{o b s}\right) p\left(d_{o b s}\right)
$$

Because we know $d_{o b s}$, Bayes theorem can be rewritten as:

$$
p\left(m \mid d_{o b s}\right) \propto p\left(d_{o b s} \mid m\right) p(m)
$$

BayHunter solves for a posterior probability distribution for each model parameter that is consistent with the data and the model priors. The model priors are values that are set by the user before running the inversion. I set the model prior $v_{p} / v_{s}$ ratio to a constant 1.86. 1.86 was the average $\mathrm{v}_{p} / \mathrm{v}_{s}$ ratio found by Bishop et al. (2018) (which used waveforms from the LL and TC networks). I set the number of layers to range between 1-25, and shear wave velocities to range between $0.5-4 \mathrm{~km} / \mathrm{s}$.

I set a depth of the model to range between 0 and $30 \mathrm{~km}$. I set the surface wave dispersion correlation to 0 , because we assume that the noise in the surface wave 
dispersion curves is uncorrelated. The noise of synthetic surface wave dispersion was set to range between $1 \mathrm{e}-5$ to $0.001 \mathrm{~km} / \mathrm{s}$. I applied a setting which ensured that each layer was over $0.25 \mathrm{~km}$ thick. I also applied settings so that there could not be an increase of more than $30 \%$ between two shear wave velocities in adjacent layers.

The model priors are obtained from the regionalized group velocity dispersion curves that were obtained through 2-D group velocity tomography. I jointly invert the group velocity dispersion curves of both Rayleigh and Love waves for a more robust inversion that uses information from both of these important wave types.

BayHunter applies a Markov chain Monte Carlo sampling algorithm which uses multiple independent Markov chains and a random Monte Carlo sampling to find the $v_{s}$-depth models with the highest likelihood. Each inversion was performed with 50 chains. Each chain performed 150,000 iterations, with a 2:1 ratio for the burn-in and exploration phase. Each Markov chain contains a current model that is sampled through an exploration phase that is defined by a number of iterations. In each iteration, a model is proposed and accepted based on the prior, the proposal, and the posterior ratios from the proposed to current model. The model is accepted if it has a probability that is equal to the acceptance probability. I set the acceptance probability to range between $20-25 \%$. When a proposed model is accepted, it replaces the current model. Each accepted model is saved as a chain model. The chain models represent the posterior probability distribution for each parameter of the model.

Figure 2.24 shows the results of the McMC sampling scheme for a single group velocity dispersion curve. This curve corresponds to the grid point $(7,12)$ in the $12 \times 19$ tomography grid. This grid point has nearly the same coordinates as Llaima's summit and is at the center of the area of interest. It is located at the latitude and longitude 
(-38.6973, -71.7317). The graphs show 50 chains progressing independently through the parameter space during the burn-in and exploration phases. The optimization process is based on likelihood. A chain can initially begin with a lower likelihood, which improves as iterations increase. Some chains reach a final likelihood plateau in the burn-in phase, while others fail to converge. The figure shows the development of the joint misfit, and noise $(\sigma)$ for Love and Rayleigh wave group velocity dispersion.

Figure 2.25 shows the $v_{s}$ structure and synthetic group dispersion curves of each chain. The last panel shows the final $v_{s}$-depth structure, which was computed from 100,000 models of five chains. The rest of the chains were declared as outliers. BayHunter selects outliers based on the median likelihood of each chain during the exploration phase. All chains that did not reach a median likelihood of $95 \%$ were rejected.

Figures 2.26a through $2.26 \mathrm{c}$ show the results of the inversion for the grid point $(9,10)$, which is located on Llaima's SSE slope. Figures 2.26a and 2.26b show the modelled fits of the group velocity dispersion curves at this location. Each of the group velocity dispersion curves increase with period. But we see that after about 10 $\mathrm{km}$, the modelled shear wave velocity in Figure 2.26c begins to rapidly decrease after reaching a value near $2.75 \mathrm{~km} / \mathrm{s}$ near a depth of $9 \mathrm{~km}$. The shear wave velocities do not continue to change very much with depth after about $13 \mathrm{~km}$. The area containing this grid point is just outside of the most well-resolved region of the map (which is shown by the path density in Figures 2.17 and 2.18). Whereas the path density for the grid point that corresponds to the BayHunter results shown in Figures 2.24 and 2.25 is located in the most well resolved areas of the map. I show additional 1-D shear wave velocity-depth curves that resulted from BayHunter in Appendix C.

Figure 2.26d shows the shear wave velocity profiles that were obtained for every 

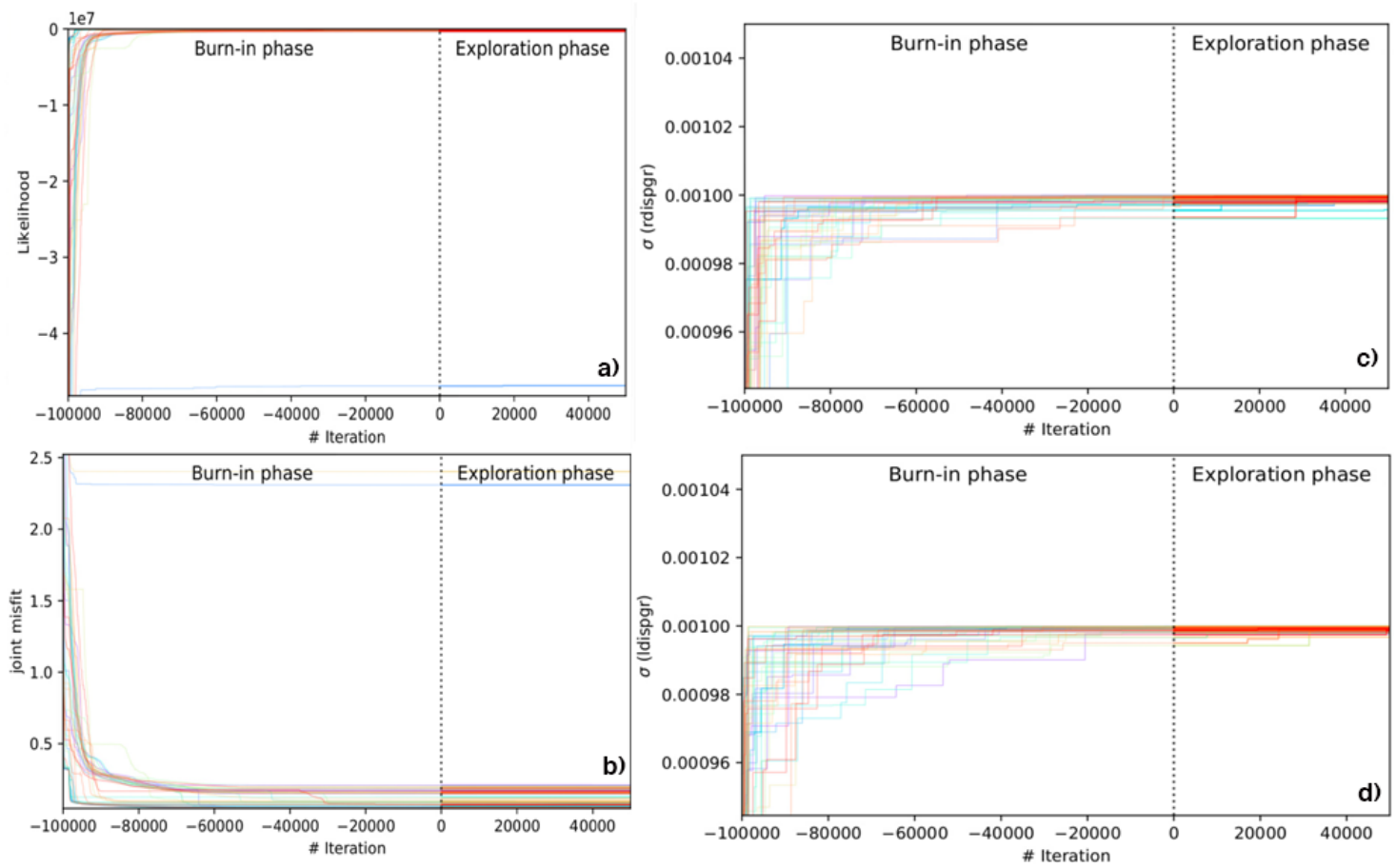

Figure 2.24: a) The development of likelihood over an iteration for 50 chains. This starts in a burn in phase and ends in the exploration phase. b) The development of joint misfit. c) The development of noise for Love wave dispersion. d) The development of noise for Rayleigh wave dispersion.

grid point with a plot of the mean of these values shown as a thick black line. The inversion computes the density of each layer within each chain using the equation $\rho=0.77+0.32 * \mathrm{v}_{p}$ (Berteussen, 1977). $\mathrm{v}_{p}$ in this case was assumed from a user set $\mathrm{v}_{p} / \mathrm{v}_{s}$ ratio of 1.86 , but the inversion can also be used to explore different $\mathrm{v}_{p} / \mathrm{v}_{s}$ values within a given range. The inversion was set to compute shear wave velocities between $0.5-4 \mathrm{~km} / \mathrm{s}$, while the range of shear wave velocities in the results is $1.5-4$ $\mathrm{km} / \mathrm{s}$. The range of the mean is approximately $1.7-3.7 \mathrm{~km} / \mathrm{s}$. We see that multiple shear wave velocity profiles do not continue to update after depths of about $10 \mathrm{~km}$. 

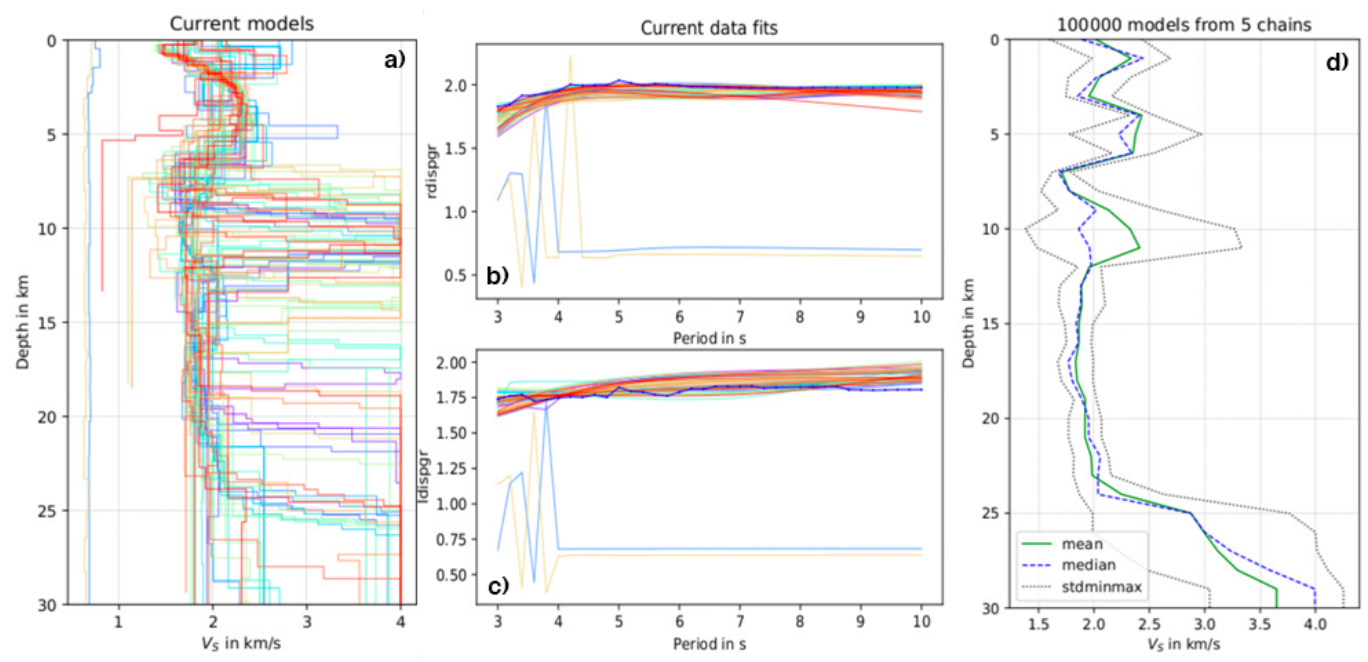

Figure 2.25: a) The development of $v_{s}$ structure with depth over 50 chains. b) The development of the modeled data fit using Rayleigh group dispersion. The blue curve is the observed dispersion curve for the grid point $(9,12)$. c) The development of the modeled fit using the observed Love group dispersion curve. d) The final $v_{s}$ model from the best chains.
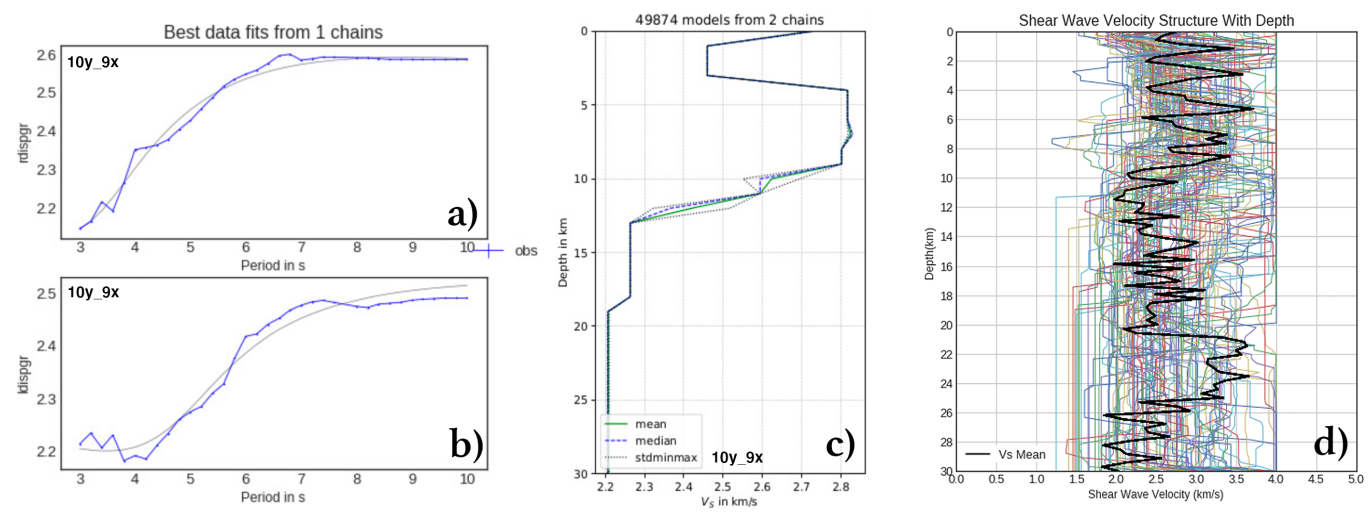

Figure 2.26: a) The best data fit for the grid point $(9,10)$ corresponding to a) observed Rayleigh wave group velocity dispersion and b) observed Love wave group velocity dispersion. c) The 1 -D shear wave velocity profile at the grid point $(9,10)$ that results from the BayHunter inversion. d) Each of the shear wave velocity profiles from the BayHunter inversion. The mean shear wave velocity is shown as a black curve. 


\section{$2.9 \quad 2-\mathrm{D}$ Vs structure with depth}

The inversion with BayHunter results in a set of 1-D $v_{s}$ profiles with depth for each point in the grid (shown in Figure 2.26d). I combine these 1-D models to obtain 2-D and 3-D representations of $v_{s}$ structure with depth. Figure 2.27 shows $v_{s}$ structure as horizontal slices with depth between $0.9-8.9 \mathrm{~km}$ prior to the application of bilinear interpolation. Figure 2.28 shows $v_{s}$ structure as horizontal slices between $0.9-8.9 \mathrm{~km}$ after the application of bilinear interpolation. The color scale ranges between 1.5-4.0 $\mathrm{km} / \mathrm{s}$. The horizontal slices show a negative $v_{s}$ anomaly, or LVZ, slightly west of Llaima's summit (shown as a red triangle) at depths up to $7 \mathrm{~km}$. The size of this LVZ increases with depth. There is a high velocity zone in the SW quadrant at all depths. The structure of the model does not change very much past $9 \mathrm{~km}$, which is an indication of a loss of sensitivity by the surface waves near this depth.

To consider the depth sensitivity of my model, I used an open source software to compute sensitivity kernels (Herrmann, 2013) for fundamental Rayleigh and Love waves sampling periods of 1-10 s. I assumed an elastic shear wave velocity structure and assumed values from the 1-D $v_{s}$ model for the Liquiñe-Ofqui Fault System (LOFS) which had the lowest RMS of any of the resulting models from Sielfeld et al. (2019). The model used to compute sensitivity kernels is shown in Appendix D. $v_{p}$ in the table were computed from $v s$, while assuming a $v_{p} / v_{s}$ ratio of 1.86 (1.86 was the average value of $v_{p} / v_{s}$ that was determined by (Bishop et al., 2018). I constructed the values

for density $(\rho)$ by assuming that density is equal to $\rho=v_{p} * 0.32+0.77$ (Berteussen, 1977) (which is the equation used by BayHunter to compute density).

I show the resulting sensitivity kernels in Figure 2.29. We see that shorter periods of Rayleigh waves (such as 1 or $2 \mathrm{~s}$ ) are most sensitive to depths in the crust that are 

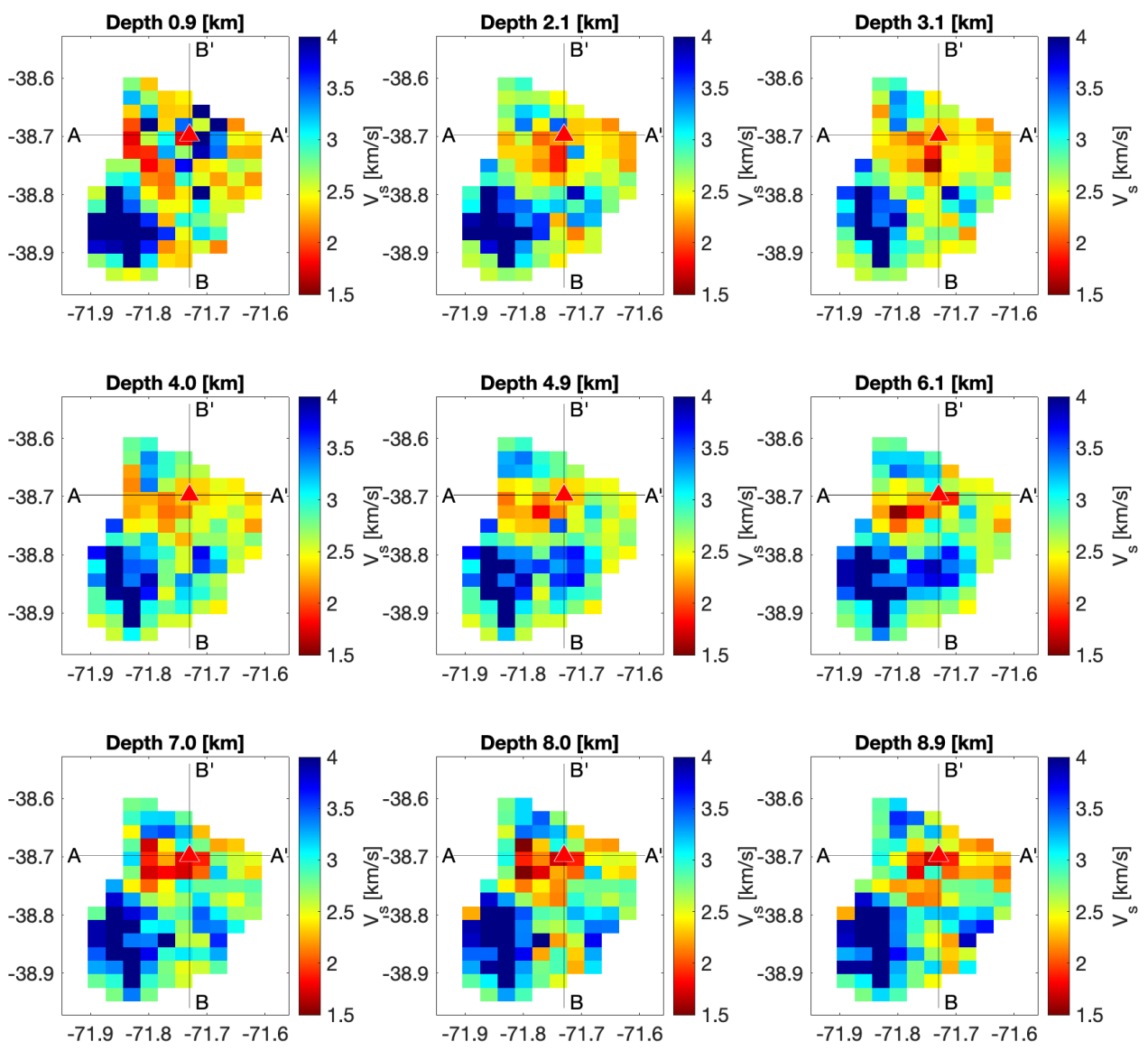

Figure 2.27: Horizontal slices of $v_{s}$ distributions at depths of $0.8-24.8 \mathrm{~km}$. The color bar scale represents $v_{s}$ and is set to range between $1.5-4.0 \mathrm{~km} / \mathrm{s}$. The red triangle corresponds to the coordinates of Llaima's summit. 

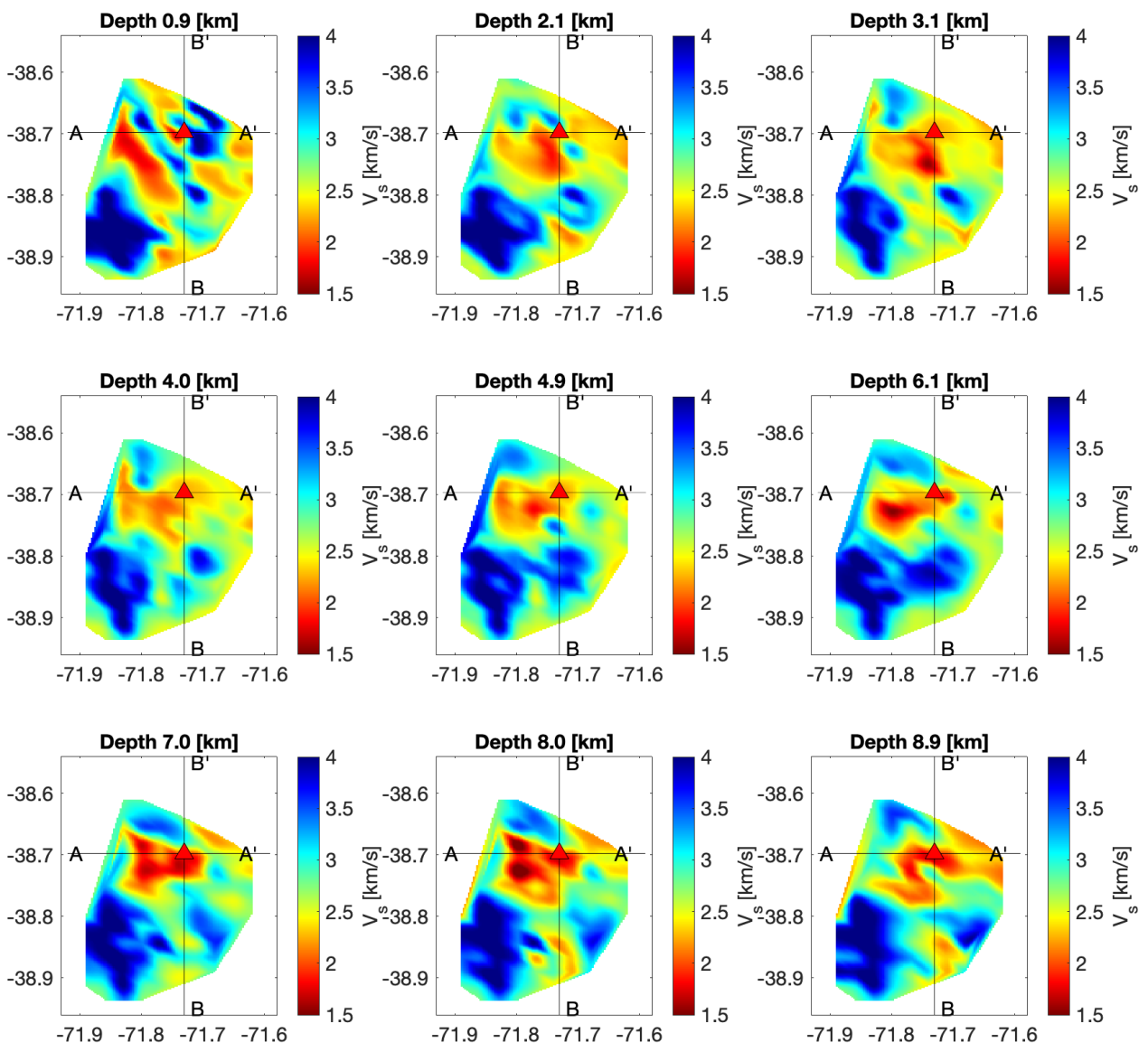

Figure 2.28: Horizontal slices of $v_{s}$ distributions at depths of $0.8-24.8 \mathrm{~km}$. The color bar scale represents $v_{s}$ and is set to range between $1.5-4.0 \mathrm{~km} / \mathrm{s}$. The red triangle corresponds to the coordinates of Llaima's summit. 

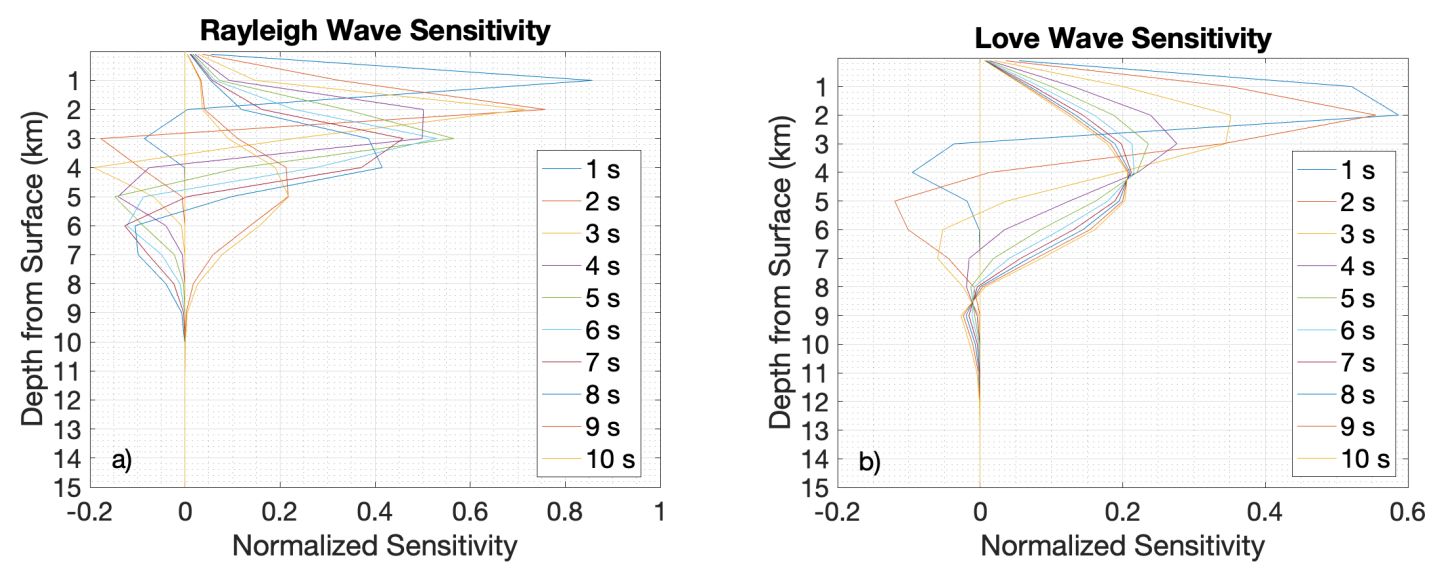

Figure 2.29: a) Depth sensitivity kernels for the fundamental mode of Rayleigh wave group velocities. I used the $1-\mathrm{D}$ average $v_{s}$ model from Sielfeld et al. (2019) with the lowest RMS as input. b) The depth sensitivity kernels for the fundamental mode of Love wave group velocities.

within the upper $1.5 \mathrm{~km}$ below sea level. At $2 \mathrm{~km}$ below sea level, the most sensitive period of Rayleigh waves is $2 \mathrm{~s}$. This pattern is visible at a depth of $3 \mathrm{~km}$, where the most sensitive Rayleigh waves correspond to a period of $3 \mathrm{~s}$. This continues until about $5 \mathrm{~km}$ (where Rayleigh waves that correspond to a period of $5 \mathrm{~s}$ are the most sensitive). The sensitivity of Rayleigh waves within each of the periods decreases with depth. It decreases sharply at $10 \mathrm{~km}$ to 0 and remains at this value thereafter.

The most sensitive Love waves at both $1 \mathrm{~km}$ and $2 \mathrm{~km}$ below the sea level correspond to a period of $1 \mathrm{~s}$. Love waves travelling at periods of $1 \mathrm{~s}$ become the least sensitive at depths that are greater than $2 \mathrm{~km}$. Love waves that correspond to 2 and $3 \mathrm{~s}$ are the most sensitive to a a depth of $3 \mathrm{~km}$. Near $4 \mathrm{~km}$ depth, Love waves between periods of 3-10 s are approximately equal in being the most sensitive to this depth. The sensitivity of Love waves generally decreases with depth. This sensitivity reaches values that are nearly 0 near a depth of $8.5 \mathrm{~km}$, and reaches 0 at a depth near $12 \mathrm{~km}$.

I show the transects that correspond to the lines A-A' and B-B' in Figures 2.30 

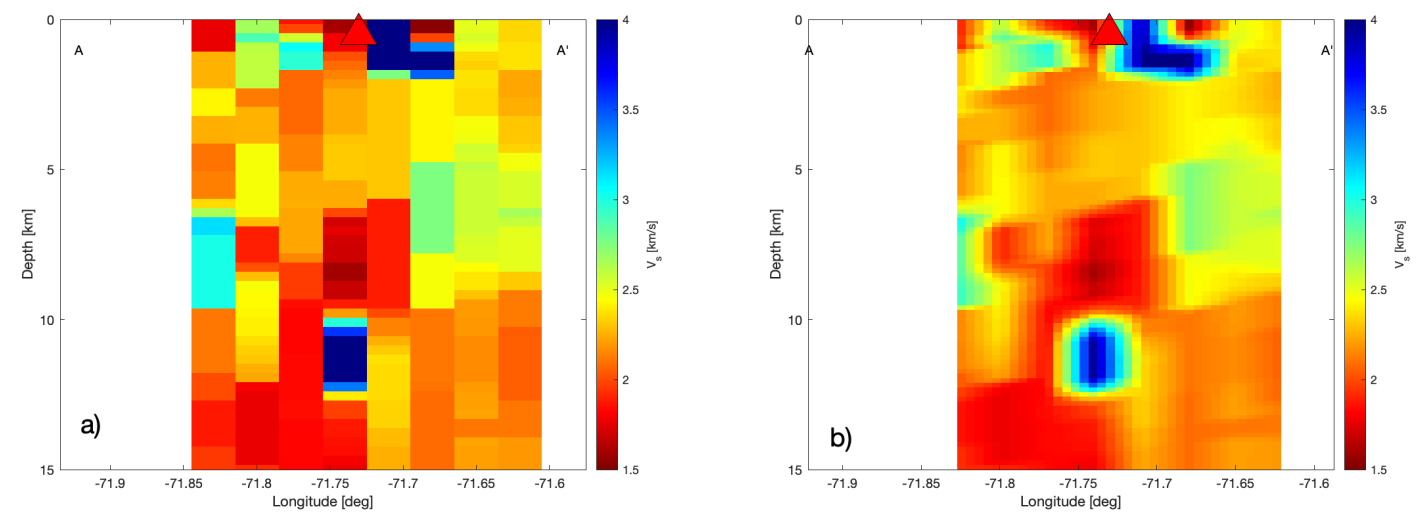

Figure 2.30: The A-A' transect corresponding to the A-A' line in Figure 2.27, plotted in a) without interpolation applied, and b) with a bilinear interpolation applied. The color scale ranges between $v_{s}$ of $1.5-4.0 \mathrm{~km} / \mathrm{s}$. The red triangle corresponds to the coordinates of Llaima's summit.

and 2.31. Each figure shows the transects with and without bilinear interpolation applied. The transect for A-A' shows a wide LVZ which takes up most of the transect and has a shape with similarities to that which is expected for a magma reservoir. There is a high velocity zone east of Llaima's summit in the upper $3 \mathrm{~km}$ of the crust. In contrast, the transect for B-B' shows a thinner LVZ beneath Llaima's summit.

\section{$2.10 \quad 3-\mathrm{D}$ Vs structure with depth}

The combination of $1-\mathrm{D}$ shear wave velocity profiles results in a 3-D matrix that can be plotted in 3-D using MATLAB. The computation in MSNoise assumes that each of the stations are at sea level, so I corrected the shear wave velocity profiles with depth using the elevations at each grid point in the model. The elevations were extracted at each grid point from a DEM using ArcMap. I then normalized the results using values of shear wave velocity that have been modelled for this region. The values are results from the Southern Andes Intra-Arc Seismicity (SAIAS) experiment (Sielfeld 

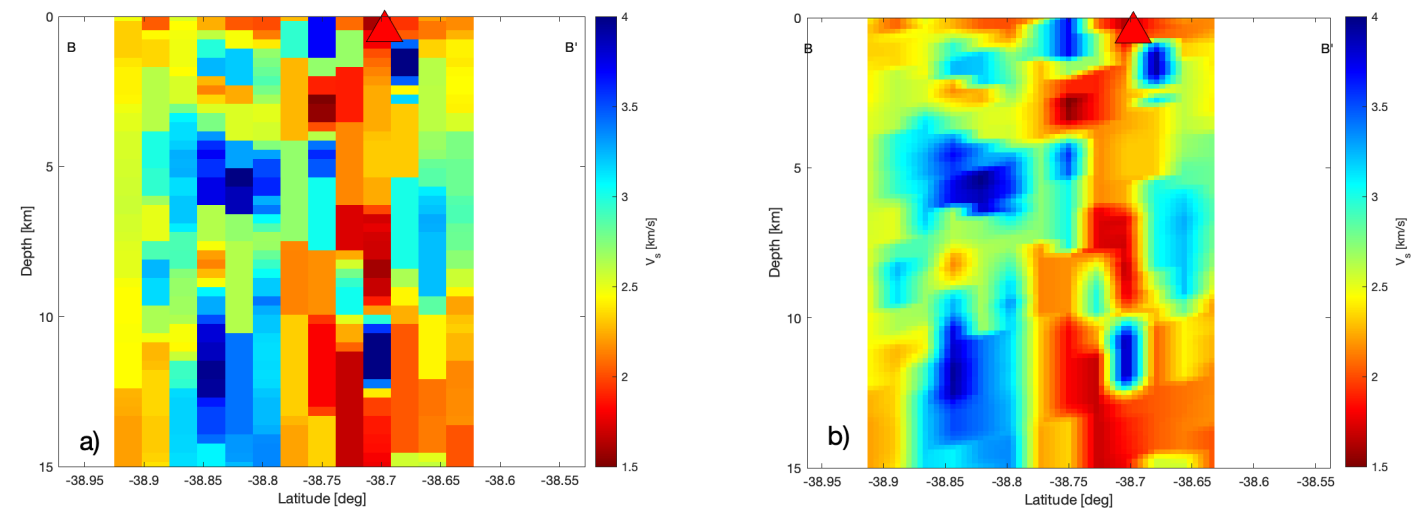

Figure 2.31: The B-B' transect corresponding to the B-B' line in Figure 2.27, plotted in a) without interpolation applied, and b) with a bilinear interpolation applied. The color scale ranges between $v_{s}$ of $1.5-4.0 \mathrm{~km} / \mathrm{s}$. The red triangle corresponds to the coordinates of Llaima's summit.

et al., 2019), which is a study that was discussed in Chapter 1. I use waveforms from two of the stations that were deployed through SAIAS, so the 1-D velocity models are related to the dataset I use for ANT. Furthermore, SAIAS took place during a time frame which describes the conditions during the time the LL network was deployed.

The values of shear wave velocity (as well as $v_{p}$ and RMS) were provided by Dr. Gerd Sielfeld through personal communication. These models were constructed by using travel times to compute one-dimensional layered velocity models using the program VELEST (Kissling et al., 1995). This program inverts 1-D velocity models from the times of phase arrivals using an initial model (Sielfeld et al., 2019; Kissling, 1988; Kissling et al., 1995). The input for this inversion was 95 well-constrained earthquakes which had a minimum of $8 \mathrm{P}$ - and 4 S-phase arrivals and event residuals (RMS) that were smaller than $0.3 \mathrm{~s}$. The inversion assumed a $v_{p} / v_{s}$ range of 1.5-2.1.

I tested each of the $601-\mathrm{D} v_{s}$ models of varying RMS that resulted from Sielfeld et al. (2019) to normalize the values in my 3-D matrix of shear wave velocities. This 
normalization obtains $v_{s}$ anomalies as percentages $\left(d v_{s}\right)$ that are relative to what is expected in the crust based on the model that is used for normalization. This can smooth the geometries of artifacts in the original model which have $v_{s}$ that are close to the expected values in the crust. I examined the structure that resulted from each of the 1-D Vs models corresponding normalization. I selected a 1-D shear wave velocity model for normalization based off results which constructed structures that resembled those of the original model reasonably well. Each of the profiles could be used for normalization and still retrieve structure that was similar to that of my original model, however some results were noisier than others. I show the 1-D shear wave velocity models that best retrieved structure in Figure 2.32a.

I sought out the smoothest results which could be achieved for the smallest negative percentages of $d v_{s}$ (i.e. the smallest deviations from my original model)- as I expect that a structure that resembles a volcanic system consisting of a magma chamber and/or magma reservoir would be outlined by negative shear wave velocity anomalies. My final selection was based off of a $-12 \% d v_{s}$ for the $1-\mathrm{D}$ velocity model that is shown in Figure 2.32b. The 1-D Vs model that was used for normalization did not have the lowest RMS of the dataset from Sielfeld et al. (2019). This could be due to observational and theoretical uncertainties in my model which have resulted from the inversions for 2-D group velocity or 1-D shear wave velocity structure. It could be because the 1-D $v_{s}$ models result from a more regional study, and there are differences that surround each volcano- as we see through magnetotellurics (Díaz Alvarado et al., 2020; Pavez et al., 2020; Held et al., 2016) or regional gravity (See: Figure 1.4).

I show the original 3-D $v_{s}$ model prior to normalization and examples of the results of normalization for different 1-D $v_{s}$ models in Appendix E. Because the shear wave 
velocity profile that was used for normalization differs from that which was used to compute sensitivity in Figure 2.29, I show the sensitivity kernels and $v_{s}$ model that correspond to the $v_{s}$ model that has been used for normalization in Appendix F.

I show a $-17 \% d v_{s}$ in Figure 2.32b, along with the 1-D shear wave velocity profile that was used to normalize this structure. At this percentage of negative shear wave anomaly, we observe a structure that resembles a magma reservoir for which the highest point is located near $500 \mathrm{~m}$ above sea level, and the lowest point is located near $2000 \mathrm{~m}$ below sea level. At depths above sea level, the expected shear wave velocity from the 1-D $v_{s}$ profile shown in the figure is near $2.46 \mathrm{~km} / \mathrm{s}$. A -17 \% decrease from this value is approximately $2.05 \mathrm{~km} / \mathrm{s}$. From depths of 0 to $3000 \mathrm{~m}$ below sea level, the expected shear wave velocity is $2.58 \mathrm{~km} / \mathrm{s}$. A $-17 \%$ decrease from this value is approximately $2.15 \mathrm{~km} / \mathrm{s}$. From depths of 6000-9000 m below sea level, the expected shear wave velocity is $2.58 \mathrm{~km} / \mathrm{s}$. A $-17 \%$ decrease from this value is approximately $2.15 \mathrm{~km} / \mathrm{s}$. Shear wave velocities that are less than $2.5 \mathrm{~km} / \mathrm{s}$ can correspond to basaltic or andesitic melt (Murase \& McBirney, 1973) (See: Figure A.1). However, at pressures of less than $20 \mathrm{MPa}$, shear wave velocities that are less than $2.5 \mathrm{~km} / \mathrm{s}$ may also correspond to heat treated granodiorite (Wang et al., 2013). The locations of these materials may correspond to the locations of scoria cones along Llaima's flanks. This would suggest a basaltic or basaltic-andesitic composition.

To examine changes in structure, I plotted the $3-\mathrm{D} d v_{s}$ dataset within a loop that plotted shear wave velocity anomalies for percentages between -70\% to 50\%. Directly south of the summit, and northwest of the summit, the transition from negative to positive anomalies reveals a vertical, dike-like structure. SW of the summit, this transition reveals an outline of a larger structure which links to the dike-like structure. 

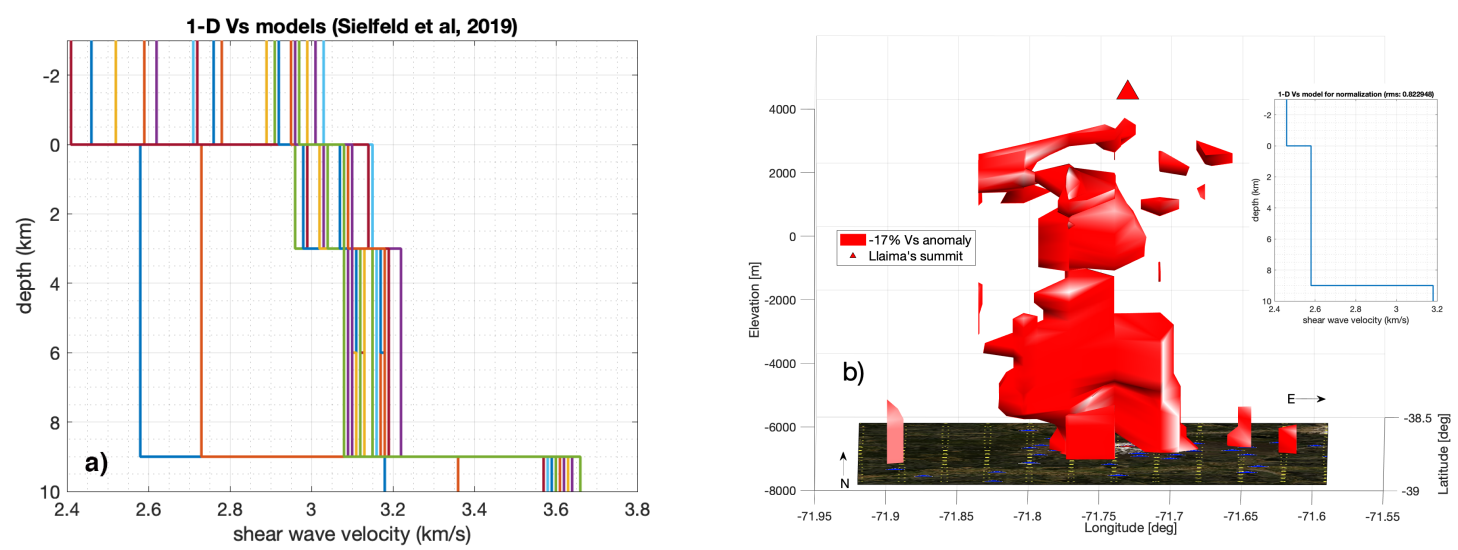

Figure 2.32: a) 1-D shear wave velocity profiles that are best able to resolve structure that was found in the original $3-\mathrm{D}$ shear wave velocity model which resulted from BayHunter. The values for these profiles were provided by Dr. Sielfeld through personal communication and result from Sielfeld et al. (2019). b) A $-17 \% d v_{s}$ showing the 1-D shear wave velocity profile that was used for normalization.

These 3-D $v_{s}$ anomalies are shown in Figure 2.33 in terms of their $d v_{s}$ representations. They are located in the same area containing the gravitational high south of Llaima's summit that was discussed in Chapter 1 and is shown in Figure 1.4.

I show the $3-\mathrm{D}$ structure for a $35 \% d v_{s}$ in Figure $2.33 \mathrm{~b}$. This image reveals higher shear wave velocity materials that would be contained by the surfaces shown in Figure 2.33a. There is a dike-like structure south of Llaima's summit, which is linked to the positive anomaly in the SW quadrant of the study area. There is a positive shear wave velocity anomaly under Llaima's summit (that is also observed in Figure 2.30 and Figure 2.28) at elevations between approximately 200-2000 m. I show the 3-D structures for additional values of shear wave anomalies in Appendix G. 

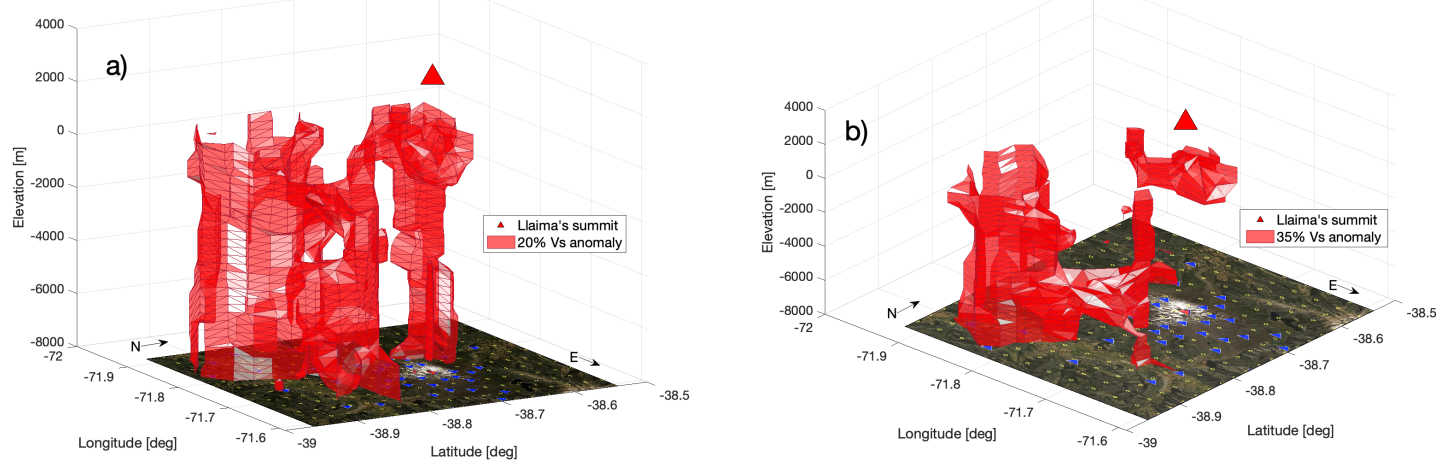

Figure 2.33: a) A 20\% $d v_{s}$ showing dike-like structures NW and south of Llaima's summit (shown as a red triangle), as well as a transition towards a high shear wave anomaly southwest of Llaima's summit. b) A $35 \%$ shear wave velocity anomaly which outlines a positive $d v_{s}$ SW of Llaima's summit. The figures are plotted over an image of the topographic grid that was shown in Figure 2.10. The hollow yellow circles represent grid points, while the blue triangles represent locations of seismic stations. 


\section{CHAPTER 3:}

\section{DISCUSSION}

I have used 2.6 months of continuous seismic records from an array of seismic stations that surrounded Llaima volcano in 2015 to create a high-resolution 3-D ambient noise tomography model (ANT). After normalizing the 3-D shear wave velocity $\left(v_{s}\right)$ model that resulted from an inversion of group velocity dispersion curves with a 1-D shear wave velocity model that represents crustal structure for the region (Sielfeld et al., 2019), I obtained a model in which shear wave velocities within negative anomalies decrease towards central minimums. Values decrease towards the centers of shapes that resemble magma reservoirs. This indicates that the fraction of melt increases towards central minimums within negative shear wave velocity anomalies, and that materials become stiffer towards the centers of positive shear wave anomalies.

\subsection{Magma Storage}

I present a shear wave velocity anomaly as a percentage $\left(d v_{s}\right)$ of $-30 \%$ in Figure $3.1 \mathrm{a}$, and a $d v_{s}$ of $-20 \%$ in Figure $3.1 \mathrm{~b}$. The $-20 \% d v_{s}$ surrounds the $-30 \% d v_{s}$ such that we observe gradients towards central minimums. The diameter of the smaller spherical structure observed at a depth near $700 \mathrm{~m}$ is approximately $2.5-3.0 \mathrm{~km}$ at its greatest extent. The diameter of the structure that surrounds it in Figure $3.1 \mathrm{~b}$ is $\approx 3.5 \mathrm{~km}$. At depths between 0 and $9000 \mathrm{~m}$, shear wave velocities are $\approx 1.8 \mathrm{~km} / \mathrm{s}$ and $\approx 2.1 \mathrm{~km} / \mathrm{s}$ 

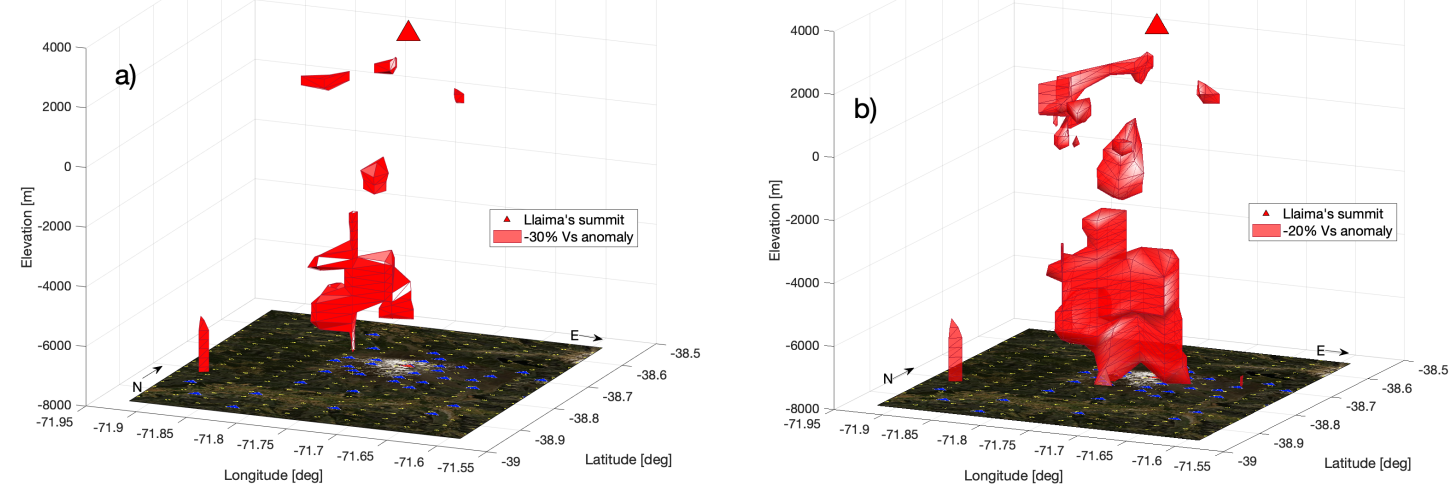

Figure 3.1: a) A $-30 \% d v_{s}$ showing low shear wave anomalies beneath Llaima's summit (shown as a red triangle). b) A $-20 \% d v_{s}$ showing low shear wave anomalies beneath Llaima's summit (shown as a red triangle).

for the $-30 \%$ and $-20 \% d v_{s}$, respectively. At depths of 9000-12,000 m, shear wave velocities are $\approx 2.2 \mathrm{~km} / \mathrm{s}$ and $\approx 2.5 \mathrm{~km} / \mathrm{s}$ for the $-30 \%$ and $-20 \% d v_{s}$, respectively.

The lower zone of magma accumulation that is contained by the $-30 \% d v_{s}$ has a geometry of vertically connected lenses of melt that is similar to what would be expected of a vertically extensive crystalline mush (Paulatto et al., 2019) in which melt is transferred from mid to upper crustal levels through vertically stacked lenses (Cashman et al., 2017). A crystalline mush is thought of as the uneruptible portion of partially molten rock in a magmatic system (Cashman \& Sparks, 2013).

I show another perspective of negative shear wave anomalies for values of $-14 \%$ and $-13 \%$ in Figure 3.2. From the perspective of an onlooker that is standing in the southwest, we see how the spherical structure branches off from the central conduit for a $-14 \% d v_{s}$, and how the $-13 \% d v_{s}$ encompasses the structure shown in Figure 3.2a. 

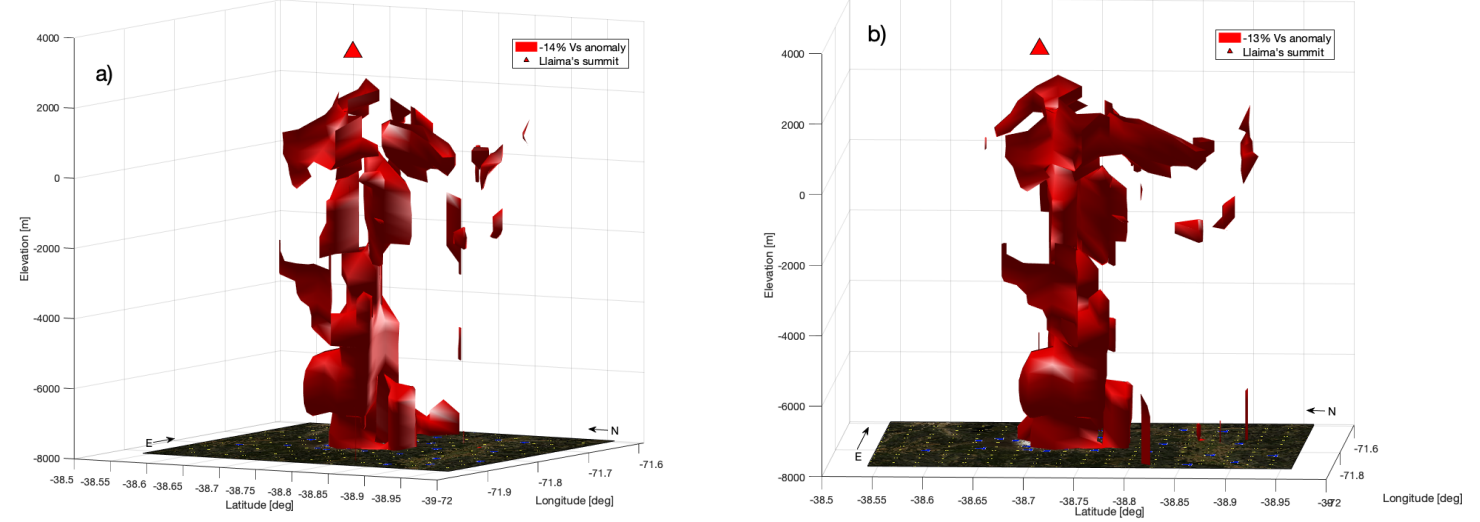

Figure 3.2: a) A $-14 \% d v_{s}$ and b) a $-13 \% d v_{s}$ showing low shear wave anomalies beneath Llaima's summit (indicated by a red triangle).

\subsubsection{Melt Fraction}

Studies have used shear wave velocity anomalies to estimate fractions of melt (Delph et al., 2017) through a relationship between shear wave velocity and melt fraction (Yoshino et al., 2005). I show estimates of melt fraction that correspond to the normalized shear wave velocity anomalies at varying levels of the crust within my model in Table 3.1. These have been computed using the shear wave velocities that correspond to different $d v_{s}$ as well as the shear wave velocities $\left(v_{s_{0}}\right)$ that are expected from the 1-D $v_{s}$ profile that was used for normalization. I compute $v_{s} / v_{s_{0}}$ from these values and use a plot of $v_{s} / v_{s_{0}}$ vs. liquid volume fraction $(\phi)$ from Yoshino et al. (2005) to estimate values for melt fraction. I show the plot that is used for this estimation in Appendix H.1. This model assumes that the ratio of the bulk moduli between solid and fluid material is 5 , and that the ratio between the densities of the fluid and solid materials is 0.92 . It assumes that the fitting parameter ' $\mathrm{A}$ ' is equal to 2.3. This value is given in Yoshino et al. (2005) as the fitting parameter for olivine- 
basalt systems. It assumes that the partially molten region is in textural equilibrium and that the value of $\mathrm{d} \ln v_{s} / \mathrm{d} \ln v_{p}$ is no larger than 1.5. Takei (2002) estimated that the value of $\mathrm{d}$ for texturally equilibrated partially molten rocks must be 1-1.5. Assuming a $v_{p} / v_{s}$ ratio of 1.86 , the values of $\mathrm{d} \ln v_{s} / \mathrm{d} \ln v_{p}$ for shear wave velocities between $2.1-4 \mathrm{~km} / \mathrm{s}$, and for values of $\mathrm{d}$ between 1-1.5, never exceed a value of 0.7.

Table 3.1: Melt fractions for different relationships between the shear wave velocity anomalies and what is expected of the shear wave velocity for given depths in the crust from the 1-D velocity profile that was used to normalize the model and is shown in Figure 2.32. 'A' refers to a fitting parameter for olivine-basalt systems which is given in Yoshino et al. (2005). This value is used to delineate liquid volume fraction $\phi$ from a plot of $v_{s} / v_{s_{0}}$ vs. liquid volume fraction from Yoshino et al. (2005), shown in Appendix H.1.

\begin{tabular}{|c|c|c|c|c|c|}
\hline $\begin{array}{c}\text { Depths } \\
(\mathrm{m})\end{array}$ & $\begin{array}{c}d v_{s} \\
(\%)\end{array}$ & $\begin{array}{c}v_{s} \\
(\mathrm{~km} / \mathrm{s})\end{array}$ & $\begin{array}{c}v_{s_{0}} \\
(\mathrm{~km} / \mathrm{s})\end{array}$ & $v_{s} / v_{s_{0}}$ & $\begin{array}{c}\phi \\
(\%)\end{array}$ \\
\hline$-3000-0$ & -5 & 2.34 & 2.46 & 0.95 & 3 \\
\hline$-3000-0$ & -10 & 2.21 & 2.46 & 0.90 & 5 \\
\hline$-3000-0$ & -20 & 1.97 & 2.46 & 0.80 & 9 \\
\hline$-3000-0$ & -25 & 1.85 & 2.46 & 0.75 & 13 \\
\hline $0-3000$ & -5 & 2.45 & 2.58 & 0.95 & 3 \\
\hline $0-3000$ & -10 & 2.32 & 2.58 & 0.90 & 5 \\
\hline $0-3000$ & -20 & 2.06 & 2.58 & 0.80 & 9 \\
\hline $0-3000$ & -25 & 1.94 & 2.58 & 0.75 & 13 \\
\hline $3000-6000$ & -5 & 2.45 & 2.58 & 0.95 & 3 \\
\hline $3000-6000$ & -10 & 2.32 & 2.58 & 0.90 & 5 \\
\hline $3000-6000$ & -20 & 2.06 & 2.58 & 0.80 & 9 \\
\hline $3000-6000$ & -25 & 1.94 & 2.58 & 0.75 & 13 \\
\hline
\end{tabular}

\subsection{Scoria Cone Distribution}

I show the locations of glomeroporphyritic and pilotaxitic scoria cones in Figure 3.3 with the $-19 \% d v_{s}$. I chose to show a $-19 \% d v_{s}$ with the locations of scoria cones because this shows slightly more low velocity structure that can be related to these locations than was shown by the $-20 \% d v_{s}$ in Figure $3.1 \mathrm{~b}$. I additionally show plots 


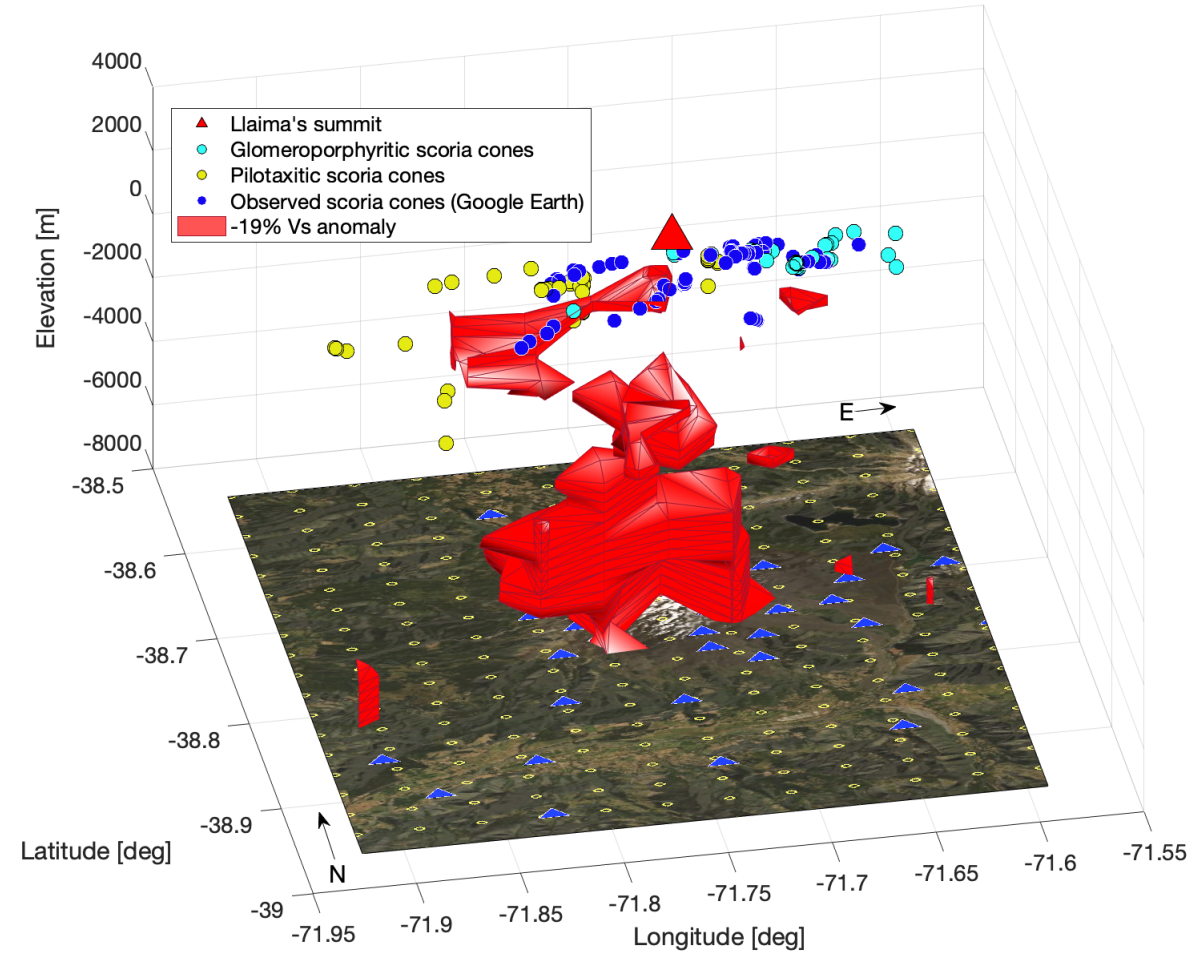

Figure 3.3: A $-19 \% d v_{s}$ plotted with the locations of glomeroporphyritic (cyan circles) and pilotaxitic scoria cones (yellow circles). These locations were obtained from the supplementary information in Schonwalder-Angel et al. (2018). The locations of scoria cones that are denoted as 'Observed scoria cones (Google Earth)' are shown as dark blue circles. The data are plotted above an image of the tomographic grid that was shown in Figure 2.10. The hollow yellow circles represent grid points while the blue triangles represent seismic stations. The $d v_{s}$ outlines a negative anomaly which resembles a magmatic reservoir and is aligned with the SW-NE regional maximum compressional axis. 
of different $d v_{s}$ within this chapter, Section 2.10, and Appendix G to offer different perspectives of the changes that have been retrieved by different $d v_{s}$ through normalization. The locations of glomeroporphyritic and pilotaxitic scoria cones were obtained from the supplementary information in Schonwalder-Angel et al. (2018).

The figure also shows the locations of scoria cones which I picked from Google Earth. Several of my picks align with the locations of scoria cones that are shown in a map in Schonwalder-Angel et al. (2018), but the supplementary information only provides the coordinates of scoria cones from which samples were derived. Rather than georeferencing the map by Schonwalder-Angel et al. (2018), I used Google Earth to select the locations of scoria cones that I could observe using satellite data that was collected on 3/21/2021 by Image Landsat/Copernicus- CNES/Airbus. Some of my picks align with the locations of glomeroporphyritic or pilotaxitic cones that were provided by Schonwalder-Angel et al. (2018). Schonwalder-Angel et al. (2018) used the same method to select the locations of scoria cones using an ASTER image that was collected by NASA's Earth Observing 1 Satellite using the Advance Land Image (ALI) on April 16th, 2009 (https://earthobservatory.nasa. gov/IOTD/view.php?id=38271).

Schonwalder-Angel et al. (2018) suggested that glomeroporphyritic scoria cones in this setting tend to align with the regional maximum compressional axis, which is oriented SW-NE. I infer that the products of scoria cones that were picked in Google Earth which align with the maximum compressional stress have undergone the same processes as products from the glomeroporphyritic scoria cones. Several of these picks are located close to the summit. Schonwalder-Angel et al. (2018) identified products from the main edifice as compositionally and chemically identical to products from the glomeroporphyritic group. The products of glomeroporphyritic cones were identified 
as being more primitive in that they reflected the mafic character of their source by having higher concentrations of $\mathrm{MgO}, \mathrm{Ni}$, and $\mathrm{Cr}$ (Schonwalder-Angel et al., 2018). These scoria cones align with the trend of structures shown by negative $d v_{s}$ such as that in Figure 3.3, which are inferred as representing central magmatic reservoirs. If the crust is expected to have a $v_{s}$ of $2.46 \mathrm{~km} / \mathrm{s}$ at elevations which are greater than sea level (from the $v_{s}$ model that was used to normalize the results from BayHunter), then the $v_{s}$ of this $-19 \% d v_{s}$ is $\approx 2.0 \mathrm{~km} / \mathrm{s}$. In this setting, it is possible that the $v_{s}$ of $\approx 2.0 \mathrm{~km} / \mathrm{s}$ may correspond to a partially molten state of basalt or andesite.

Schonwalder-Angel et al. (2018) state that there is not a clear orientation for the pilotaxitic scoria cones, but suggest from their spatial distribution that the feeder dikes which source these cones form in a pattern that is radial to the edifice. The vesicles of samples from the pilotaxitic group are elongated and seemingly interconnected (Angel, 2015), which could be the result of rapid magma ascent and degassing. Analyses of the most primitive glomeroporphyritic samples with rhyolite-MELTS (Schonwalder-Angel et al., 2018; Gualda et al., 2012) showed a trend between the pilotaxitic and glomeroporphyritic groups at pressures of less than $100 \mathrm{MPa}$ and temperatures of $1150-1100^{\circ} \mathrm{C}$. This implies that the fractionation which generates pilotaxitic melts occurs at shallow depths (Schonwalder-Angel et al., 2018).

Figure 3.3 does not show an obvious link to the locations of pilotaxitic scoria cones, but several of their locations border the edges of the $-5 \% d v_{s}$ in Figure 3.4. This single $d v_{s}$ is shown in Appendix $\mathrm{G}$ in Figure G.1b. I plot this anomaly with the $25 \% d v_{s}$ in Figure 3.4 to show the spatial relationship between these two anomalies as we see what appears to be a dike emerging between edges of the $-5 \% d v_{s}$ that are surrounded by pilotaxitic scoria cones. The pilotaxitic scoria cones in the SW 
quadrant of the map occur near this positive $d v_{s}$ as well. A $10 \%$ increase from the expected $v_{s}$ of $2.46 \mathrm{~km} / \mathrm{s}$ is $\approx 2.7 \mathrm{~km} / \mathrm{s}$, while a $60 \%$ increase is $\approx 3.9 \mathrm{~km} / \mathrm{s}$.

\subsection{Geophysical Constraints}

I plot the $35 \% d v_{S}$ with the locations of volcano-tectonic (VT) events in Figure 3.5. This figure shows VT events from 2009-2014 as lime green circles, and volcano tectonic events from 2015-2020 as cyan circles. The locations of these events were provided by Dr. Luis Franco (OVDAS - SERNAGEOMIN). This positive shear wave anomaly reveals a dike-like structure within the cluster of VT activity that occurred south of Llaima's summit and was discussed in Chapter 1 for its suggested association with the 2010 M8.8 Maule megathrust earthquake off the coast of Chile and its co-location with a gravitational high (See: Figure 1.4). In addition, InSAR between 2003-2008 shows this location south of the summit to have undergone subsidence that was followed by uplift and then an eruptive episode at Llaima (Bathke et al., 2011).

I show the locations of VT events by the year between 2010-2019 in Figure 3.6 with a close up of the dike-like structure south of Llaima's summit. Several VT events occur near the edges of this structure, and some occur within its walls. Of the events that cluster around this dike, those before 2016 occur south of the dike.

I show the locations of long period events that were provided by Dr. Luis Franco (OVDAS - SERNAGEOMIN) with a -16\% shear wave velocity anomaly in Figure 3.7a.

I show the locations of long period events as well as the $-16 \%$ shear wave velocity anomaly with a $35 \% d v_{s}$ in Figure $3.7 \mathrm{~b}$. LP activity appears to form within a NW-SE alignment. The depths of long period events have not been obtained, and so the long period events are plotted near the surface. Long period events result from volumetric modes of deformation (Chouet, 1996). A common excitation mechanism of these types 


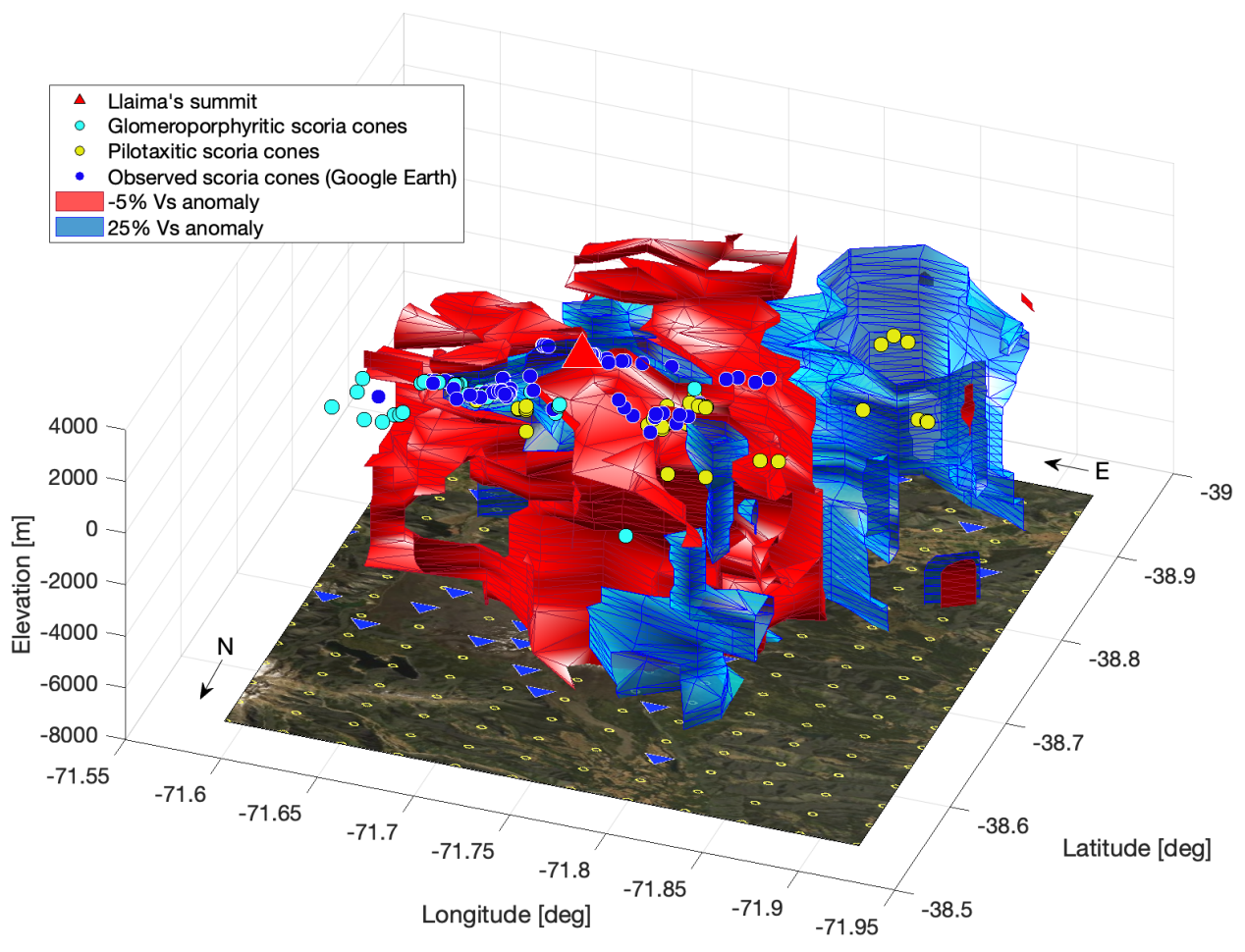

Figure 3.4: $-5 \%$ and $25 \% d v_{s}$ plotted with the locations of glomeroporphyritic scoria cones (cyan circles) and pilotaxitic scoria cones (yellow circles). These locations were obtained from the supplementary information in Schonwalder-Angel et al. (2018). The locations of 'Observed scoria cones (Google Earth)' are shown as dark blue circles. The figures are plotted over an image of the tomographic grid that was shown in Figure 2.10. The hollow yellow circles represent grid points in the map, while the blue triangles show the locations of seismic stations. 


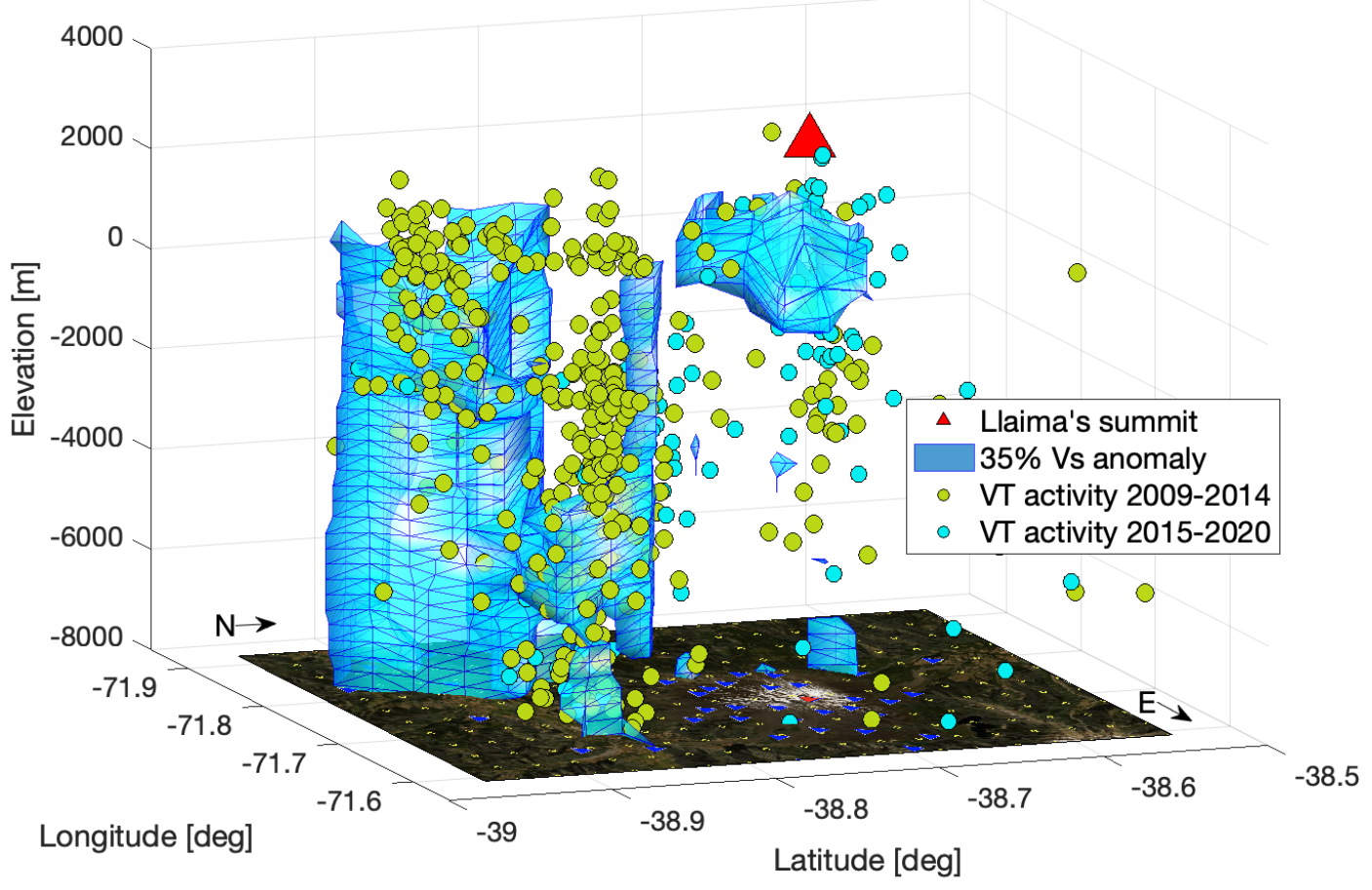

Figure 3.5: A $35 \% d v_{s}$ plotted with the locations of volcano-tectonic (VT) events from 2009-2014 (as lime green circles) and the locations of VT events from 2015-2020 (shown as cyan circles). The locations of these VT events were provided by Dr. Luis Franco (OVDAS - SERNAGEOMIN). The location of Llaima's summit is indicated by a red triangle. The blue triangles on the map represent the locations of seismic stations. The hollow yellow circles represent the locations of grid points. 

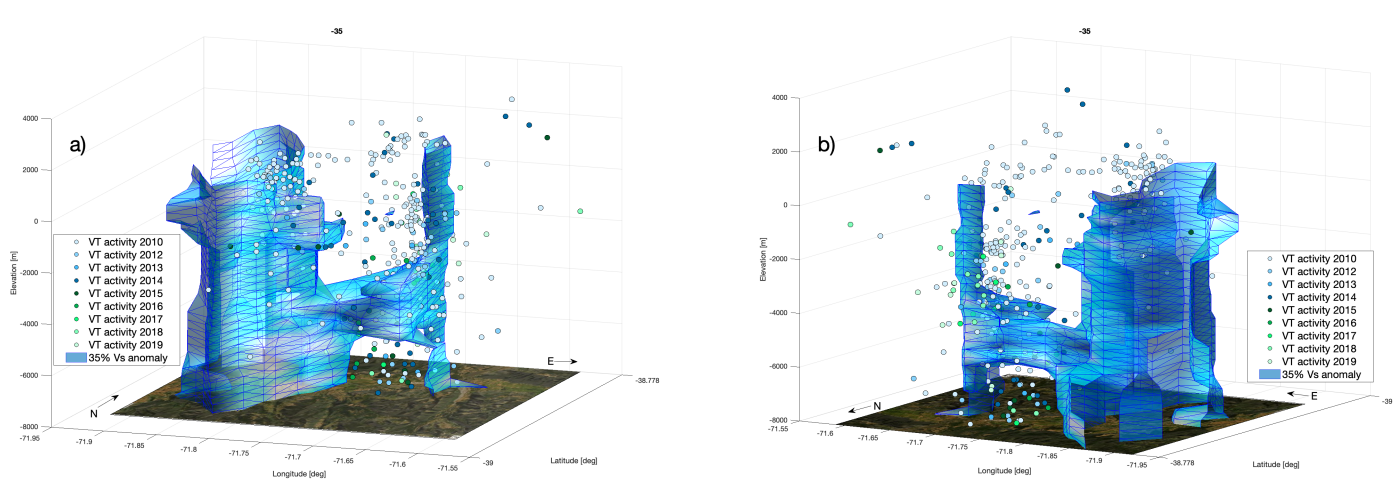

Figure 3.6: A 35\% $d v_{s}$ plotted with the locations of volcano tectonic (VT) events between 2010-2019 from the perspective of a) an observer from the southwest and b) an observer from the northwest. Volcano tectonic events are binned by year and events corresponding to each year are plotted in varying shades of blue and green. The images show a dike-like structure that is surrounded by volcano tectonic events and links to a larger structure at depth in the SW quadrant of the study area.

of events is heating by magmatic activity (Chouet \& Matoza, 2013), which increases the pressure in a steam-filled fracture. This causes an opening, or a fracture, which allows gas to escape suddenly. The loss of pressure collapses the fracture, the escape pathways close, and the cycle of building up pressure begins again.

LP events are typically associated with fluid-rock interactions. In this location, this may be due to the interaction of the positive and negative shear wave velocity anomalies that surround LP activity in Figure 3.7b. The LP events form within an alignment that is parallel to the regional minimum compression. This is different from the deformation that we see for the structure that is interpreted as a lower magma reservoir beneath Llaima's summit (at depths that are greater than $2500 \mathrm{~m}$ ) or the alignment of scoria cones along Llaima's flanks. But it is comparable to the kinematics of the positive shear wave anomaly in the SW quadrant of the study area.

I show a map view of the low velocity anomalies and LP events from Figure 3.7 in 

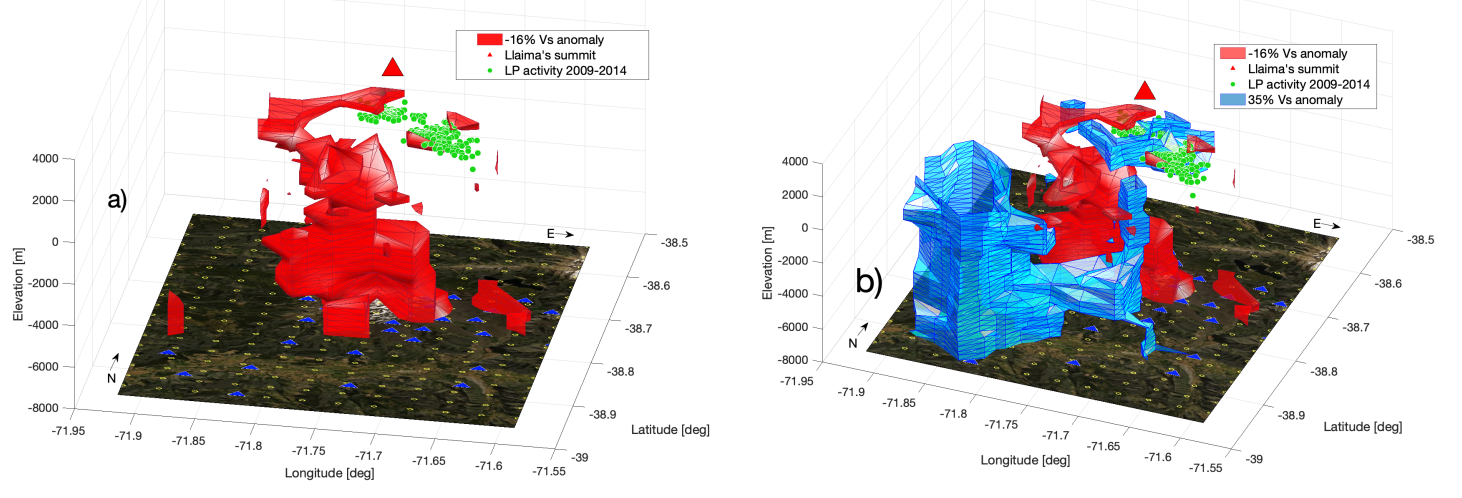

Figure 3.7: a) The $-16 \% d v_{s}$ plotted with the locations of long period (LP) events from 2009-2014 (lime green circles). b) The $-16 \%$ and $35 \%$ $d v_{s}$ plotted with the locations of long period (LP) events from 2009-2014. Clusters of LP activity near the summit and along the SE flank appear to form a NW-SE alignment. The locations of these LP events were provided by Dr. Luis Franco (OVDAS - SERNAGEOMIN). The catalog does not include the depths of the LP events, and so these are plotted near the surface. Llaima's summit is indicated by a red triangle. The blue triangles on the map show the locations of seismic stations. The hollow yellow circles represent the locations of tomography grid points. 
Figure 3.8. This perspective provides a top-down snapshot into the local kinematics that affect deformation in this setting, in that we observe multiple elliptical geometries that are affected by varying alignments of compression and extension.

\subsection{Conclusions}

As the model would have needed to resolve shear wave anomalies that correspond to melt fractions of $40-60 \%$ in order to determine eruptible portions of magma (Annen, 2009), the results do not determine a potential for magma mobility. It is possible that eruptible melt was not present during the time that waveforms were recorded. The waveforms that were used for this analysis were recorded during a quiescent phase at Llaima, which means that there was not eruptive activity. The lowest $v_{s}$ in the BayHunter inversion is $1.09 \mathrm{~km} / \mathrm{s}$ at a depth near $5 \mathrm{~km}$. This corresponds to a $v_{s} / v_{s_{0}}$ of $42 \%$ and a melt fraction of $\approx 25 \%$. Nevertheless, the model still allows for estimations of melt fraction that correspond to partially molten rock. This demonstrates that we are able to determine the presence and geometry of mush in the system. The resolution of the model provides insight into the processes that are related to scoria cones that we see at the surface and shows relationships between diking and shallow lenses of melt. The resulting model shows a dike-like structure within a positive $v_{s}$ anomaly in a location where we see a gravitational high and cluster of volcano-tectonic activity. However, the resolution of the model decreases away from the summit with the decrease of station density within the seismic array. This may be a desirable location to place a denser array of seismic stations with larger interstation distances to capture more detailed as well as longer period information about deeper structure.

Regardless of not having captured eruptible portions of melt, the structure and resolution that has been resolved through this experiment is not frequently achieved 


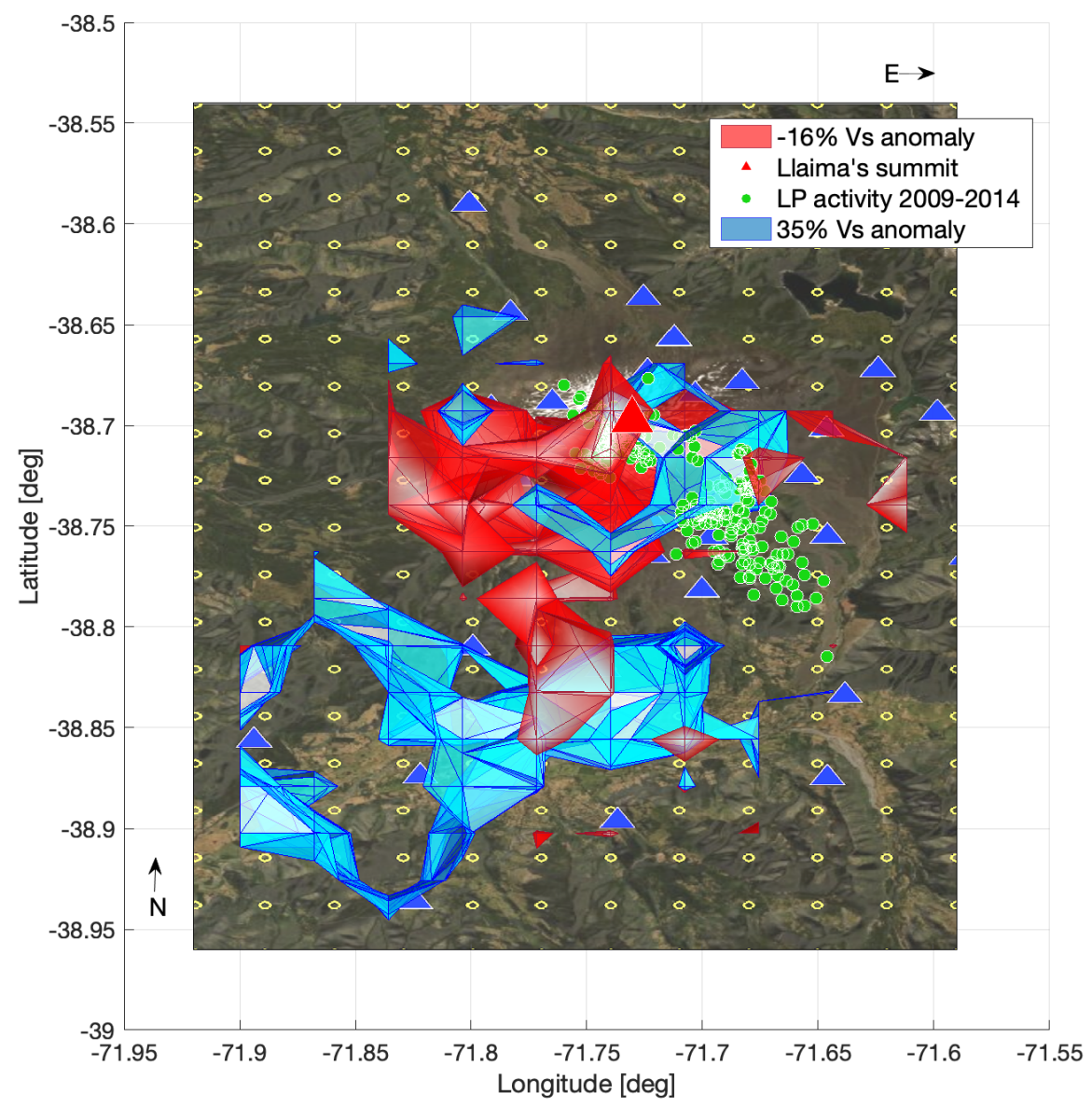

Figure 3.8: A map view of the $-16 \%$ and $35 \%$ shear wave velocity anomalies that are shown in Figure $3.7 \mathrm{~b}$ plotted with the locations of long period (LP) events from 2009-2014. The locations of these long period events were provided by Dr. Luis Franco (OVDAS - SERNAGEOMIN). 
as there are not many volcanoes that have been equipped with a dense network of broadband seismic stations as of yet. The project highlights the benefits of using a broadband seismic network for ANT, as the greatest period that could have been measured by a network of short period seismometers could not have reached $10 \mathrm{~s}$, as I was able to achieve in this experiment. Furthermore, it was extremely beneficial that most of the seismometers were equipped with 3-component seismometers so that it was possible to obtain both Rayleigh and Love wave group velocities. An inversion for shear wave velocity structure using only Rayleigh waves would not have resolved the same structure that we achieve by jointly using both Rayleigh and Love waves. 


\section{REFERENCES}

Aki, Keiiti. 1957. Space and time spectra of stationary stochastic waves, with special reference to microtremors. Bulletin of the Earthquake Research Institute, 35, 415456.

Angel, Dayana A Schonwalder. 2015. The emplacement of satellite scoria cones at Llaima Volcanic System, Chile; The interaction between magmatic overpressure and the local tectonics. Ph.D. thesis, State University of New York at Buffalo.

Annen, Catherine. 2009. From plutons to magma chambers: Thermal constraints on the accumulation of eruptible silicic magma in the upper crust. Earth and Planetary Science Letters, 284(3-4), 409-416.

Araneda, Manuel, Asch, Günter, Bataille, Klaus, Bohm, Mirjam, Bruhn, Carsten, Giese, Peter, Lüth, Stefan, Quezada, Jorge, Rietbrock, Andreas, \& Wigger, Peter. 2003. A crustal model along $39^{\circ} \mathrm{S}$ from a seismic refraction profile-ISSA 2000. Revista geológica de Chile, 30(1), 83-101.

Barmin, MP, Ritzwoller, MH, \& Levshin, AL. 2001. A fast and reliable method for surface wave tomography. Pages 1351-1375 of: Monitoring the comprehensive nuclear-test-ban treaty: Surface waves. Springer.

Bathke, Hannes, Shirzaei, M, \& Walter, Thomas R. 2011. Inflation and deflation at 
the steep-sided Llaima stratovolcano (Chile) detected by using InSAR. Geophysical Research Letters, 38(10).

Bensen, GD, Ritzwoller, MH, Barmin, MP, Levshin, A Lin, Lin, Feifan, Moschetti, MP, Shapiro, NM, \& Yang, Yanyan. 2007. Processing seismic ambient noise data to obtain reliable broad-band surface wave dispersion measurements. Geophysical Journal International, 169(3), 1239-1260.

Berteussen, K-A. 1977. Moho depth determinations based on spectral-ratio analysis of NORSAR long-period $\mathrm{P}$ waves. Physics of the Earth and Planetary Interiors, 15(1), 13-27.

Birch, Francis. 1961. The velocity of compressional waves in rocks to 10 kilobars: 2. Journal of Geophysical Research, 66(7), 2199-2224.

Bishop, JW, Lees, JM, Biryol, CB, Mikesell, TD, \& Franco, L. 2018. Examining the interior of Llaima Volcano with receiver functions. Journal of Volcanology and Geothermal Research, 352, 1-9.

Bohm, Mirjam, Lüth, Stefan, Echtler, Helmut, Asch, Günter, Bataille, Klaus, Bruhn, Carsten, Rietbrock, Andreas, \& Wigger, Peter. 2002. The Southern Andes between 36 and 40 S latitude: seismicity and average seismic velocities. Tectonophysics, 356(4), 275-289.

Bouvet De Maisonneuve, Caroline. 2011. Petrologic and numerical modeling study of Strombolian eruption dynamics at Volcán Llaima (Chile). Ph.D. thesis, University of Geneva. 
Brenguier, Florent, Shapiro, Nikolai M, Campillo, Michel, Nercessian, Alexandre, \& Ferrazzini, Valérie. 2007. 3-D surface wave tomography of the Piton de la Fournaise volcano using seismic noise correlations. Geophysical research letters, 34(2).

Browning, John, Meredith, Philip, \& Gudmundsson, Agust. 2016. Cooling-dominated cracking in thermally stressed volcanic rocks. Geophysical Research Letters, 43(16), $8417-8425$.

Campillo, Michel, \& Paul, Anne. 2003. Long-range correlations in the diffuse seismic coda. Science, 299(5606), 547-549.

Carlson, Richard L. 2014. The effects of alteration and porosity on seismic velocities in oceanic basalts and diabases. Geochemistry, Geophysics, Geosystems, 15(12), $4589-4598$.

Cashman, Katharine V, \& Sparks, R Stephen J. 2013. How volcanoes work: A 25 year perspective. GSA bulletin, 125(5-6), 664-690.

Cashman, Katharine V, Sparks, R Stephen J, \& Blundy, Jonathan D. 2017. Vertically extensive and unstable magmatic systems: a unified view of igneous processes. Science, 355(6331).

Cembrano, José, \& Lara, Luis. 2009. The link between volcanism and tectonics in the southern volcanic zone of the Chilean Andes: a review. Tectonophysics, 471(1-2), 96-113.

Chouet, Bernard A. 1996. Long-period volcano seismicity: its source and use in eruption forecasting. Nature, 380(6572), 309-316. 
Chouet, Bernard A., \& Matoza, Robin S. 2013. A multi-decadal view of seismic methods for detecting precursors of magma movement and eruption. Journal of Volcanology and Geothermal Research, 252, 108-175.

Christensen, Nikolas I. 1970. Compressional-wave velocities in basalts from the Juan de Fuca Ridge. Journal of Geophysical Research (1896-1977), 75(14), 2773-2775.

Christensen, Nikolas I. 1996. Poisson's ratio and crustal seismology. Journal of Geophysical Research: Solid Earth, 101(B2), 3139-3156.

Curtis, Andrew, Gerstoft, Peter, Sato, Haruo, Snieder, Roel, \& Wapenaar, Kees. 2006. Seismic interferometry - Turning noise into signal. The Leading Edge, 25(9), $1082-1092$.

De Luca, G, Scarpa, R, Del Pezzo, E, \& Simini, M. 1997. Shallow structure of Mt. Vesuvius volcano, Italy, from seismic array analysis. Geophysical Research Letters, 24(4), 481-484.

Delph, Jonathan R, Ward, Kevin M, Zandt, George, Ducea, Mihai N, \& Beck, Susan L. 2017. Imaging a magma plumbing system from MASH zone to magma reservoir. Earth and Planetary Science Letters, 457, 313-324.

Díaz Alvarado, Daniel, Zuñiga, Felipe, \& Castruccio Álvarez, Angelo. 2020. The interaction between active crustal faults and volcanism: A case study of the LiquiñeOfqui Fault Zone and Osorno volcano, Southern Andes, using magnetotellurics. Journal of Volcanology and Geothermal Research.

Dreiling, Jennifer. 2020. Crustal structures in southern Madagascar and Sri Lanka in 
the context of Gondwana's assembly and break-up: A study based on surface wave dispersion and receiver functions. Ph.D. thesis, Geowissenschaften.

Dreiling, Jennifer, \& Tilmann, F. 2019. BayHunter-McMC transdimensional Bayesian inversion of receiver functions and surface wave dispersion.

Dueker, Kenneth G, \& Sheehan, Anne F. 1997. Mantle discontinuity structure from midpoint stacks of converted $\mathrm{P}$ to $\mathrm{S}$ waves across the Yellowstone hotspot track. Journal of Geophysical Research: Solid Earth, 102(B4), 8313-8327.

Dziewonski, Adam M. 1979. Elastic and anelastic structure of the Earth. Reviews of Geophysics, $\mathbf{1 7}(2), 303-312$.

Ekström, Göran. 2014. Love and Rayleigh phase-velocity maps, 5-40 s, of the western and central USA from USArray data. Earth and Planetary Science Letters, 402, $42-49$.

Fallahi, Mohammad Javad, Obermann, Anne, Lupi, Matteo, Karyono, Karyono, \& Mazzini, Adriano. 2017. The plumbing system feeding the Lusi eruption revealed by ambient noise tomography. Journal of Geophysical Research: Solid Earth, 122(10), 8200-8213.

Fortin, J, Stanchits, S, Vinciguerra, S, \& Guéguen, Y. 2011. Influence of thermal and mechanical cracks on permeability and elastic wave velocities in a basalt from Mt. Etna volcano subjected to elevated pressure. Tectonophysics, 503(1-2), 60-74.

Franco, Luis Enrique Marín. 2019. Comportamiento eruptivo del Volcán Llaima (2007-2010) e incidencia del terremoto del Maule Mw 8.8 en la actividad volcánica 
y tectónica local. Ph.D. thesis, Universidad de Concepción, Faculty of Chemical Sciences.

Gilbert, Hersh J, Sheehan, Anne F, Dueker, Kenneth G, \& Molnar, Peter. 2003. Receiver functions in the western United States, with implications for upper mantle structure and dynamics. Journal of Geophysical Research: Solid Earth, 108(B5).

González-Vidal, Diego, Obermann, Anne, Tassara, Andrés, Bataille, Klaus, \& Lupi, Matteo. 2018. Crustal model of the Southern Central Andes derived from ambient seismic noise Rayleigh-wave tomography. Tectonophysics, 744, 215-226.

Gualda, Guilherme AR, Ghiorso, Mark S, Lemons, Robin V, \& Carley, Tamara L. 2012. Rhyolite-MELTS: a modified calibration of MELTS optimized for silica-rich, fluid-bearing magmatic systems. Journal of Petrology, 53(5), 875-890.

Heap, Michael J, Baud, Patrick, Meredith, PG, Vinciguerra, Sergio, \& Reuschlé, Thierry. 2014. The permeability and elastic moduli of tuff from Campi Flegrei, Italy: implications for ground deformation modelling. Solid Earth, 5(1), 25-44.

Heeszel, David S, Wiens, Douglas A, Anandakrishnan, Sridhar, Aster, Richard C, Dalziel, Ian WD, Huerta, Audrey D, Nyblade, Andrew A, Wilson, Terry J, \& Winberry, J Paul. 2016. Upper mantle structure of central and West Antarctica from array analysis of Rayleigh wave phase velocities. Journal of Geophysical Research: Solid Earth, 121(3), 1758-1775.

Held, Sebastian, Schill, Eva, Pavez, Maximiliano, Díaz, Daniel, Munoz, Gerard, Morata, Diego, \& Kohl, Thomas. 2016. Resistivity distribution from mid-crustal 
conductor to near-surface across the $1200 \mathrm{~km}$ long Liquiñe-Ofqui Fault System, southern Chile. Geophysical Journal International, 207(3), 1387-1400.

Hennino, R, Trégourès, N, Shapiro, NM, Margerin, L, Campillo, M, Van Tiggelen, BA, \& Weaver, RL. 2001. Observation of equipartition of seismic waves. Physical review letters, 86(15), 3447.

Herrmann, Robert B. 2013. Computer programs in seismology: An evolving tool for instruction and research. Seismological Research Letters, 84(6), 1081-1088.

Hinze, William J. 1985. The utility of regional gravity and magnetic anomaly maps. Society of exploration geophysicists.

Huang, Yu-Chih, Ohkura, Takahiro, Kagiyama, Tsuneomi, Yoshikawa, Shin, \& Inoue, Hiroyuki. 2018. Shallow volcanic reservoirs and pathways beneath Aso caldera revealed using ambient seismic noise tomography. Earth, Planets and Space, 70(1), $1-21$.

Ikeda, Ryuji, Kajiwara, Tatsuya, Omura, Kentaro, \& Hickman, Stephen. 2008. Physical rock properties in and around a conduit zone by well-logging in the Unzen Scientific Drilling Project, Japan. Journal of volcanology and geothermal research, 175(1-2), 13-19.

Janiszewski, Helen A, Gaherty, James B, Abers, Geoffrey A, Gao, Haiying, \& Eilon, Zachary C. 2019. Amphibious surface-wave phase-velocity measurements of the Cascadia subduction zone. Geophysical Journal International, 217(3), 1929-1948.

Kissling, E, Kradolfer, U, \& Maurer, H. 1995. Program VELEST user's guide-Short Introduction. Institute of Geophysics, ETH Zurich. 
Kissling, Edi. 1988. Geotomography with local earthquake data. Reviews of Geophysics, 26(4), 659-698.

Kolzenburg, Stephan, Heap, MJ, Lavallée, Yan, Russell, JK, Meredith, PG, \& Dingwell, Donald B. 2012. Strength and permeability recovery of tuffisite-bearing andesite. Solid Earth, 3(2), 191-198.

La Rocca, Mario, Petrosino, S, Saccorotti, G, Simini, M, Ibanez, J, Almendros, J, \& Del Pezzo, E. 2000. Location of the source and shallow velocity model deduced from the explosion quakes recorded by two seismic antennas at Stromboli volcano. Physics and Chemistry of the Earth, Part A: Solid Earth and Geodesy, 25(9-11), $731-735$.

Lamb, Oliver, Lees, Jonathan, Marin, Luis Franco, Lazo, Jonathan, Rivera, Andrés, Shore, Michael, \& Lee, Stephen. 2020. Investigating potential icequakes at Llaima volcano, Chile. Volcanica, 3(1), 29-42.

Lecocq, Thomas, Caudron, Corentin, \& Brenguier, Florent. 2014. MSNoise, a python package for monitoring seismic velocity changes using ambient seismic noise. Seismological Research Letters, 85(3), 715-726.

Lesage, Philippe, Heap, Michael J, \& Kushnir, Alexandra. 2018. A generic model for the shallow velocity structure of volcanoes. Journal of Volcanology and Geothermal Research, 356, 114-126.

Lin, Fan-Chi, Moschetti, Morgan P, \& Ritzwoller, Michael H. 2008. Surface wave tomography of the western United States from ambient seismic noise: Rayleigh 
and Love wave phase velocity maps. Geophysical Journal International, 173(1), $281-298$.

Lissenberg, C Johan, \& Dick, Henry JB. 2008. Melt-rock reaction in the lower oceanic crust and its implications for the genesis of mid-ocean ridge basalt. Earth and Planetary Science Letters, 271(1-4), 311-325.

Lobkis, Oleg I, \& Weaver, Richard L. 2001. On the emergence of the Green's function in the correlations of a diffuse field. The Journal of the Acoustical Society of America, 110(6), 3011-3017.

Luo, Yinhe, Yang, Yingjie, Xu, Yixian, Xu, Hongrui, Zhao, Kaifeng, \& Wang, Kai. 2015. On the limitations of interstation distances in ambient noise tomography. Geophysical Journal International, 201(2), 652-661.

Masterlark, Timothy, Haney, Matthew, Dickinson, Haylee, Fournier, Tom, \& Searcy, Cheryl. 2010. Rheologic and structural controls on the deformation of Okmok volcano, Alaska: FEMs, InSAR, and ambient noise tomography. Journal of Geophysical Research: Solid Earth, 115(B2).

McNamara, Daniel E, \& Boaz, Richard I. 2010. PQLX: A seismic data quality control system description, applications, and users manual. US Geol. Surv. Open-File Rept, $1292,41$.

Melnick, Daniel, Rosenau, Matthias, Folguera, Andrés, \& Echtler, Helmut. 2006. Neogene tectonic evolution of the Neuquen Andes western flank (37-39^oS). SPECIAL PAPERS-GEOLOGICAL SOCIETY OF AMERICA, 407, 73. 
Métaxian, Jean-Philippe, Lesage, Philippe, \& Dorel, Jacques. 1997. Permanent tremor of Masaya Volcano, Nicaragua: Wave field analysis and source location. Journal of Geophysical Research: Solid Earth, 102(B10), 22529-22545.

Mora, Mauricio M, Lesage, Philippe, Valette, Bernard, Alvarado, Guillermo E, Leandro, Carlos, Métaxian, Jean-Philippe, \& Dorel, Jacques. 2006. Shallow velocity structure and seismic site effects at Arenal volcano, Costa Rica. Journal of volcanology and geothermal research, 152(1-2), 121-139.

Mora-Stock, Cindy, Thorwart, Martin, Wunderlich, Tina, Bredemeyer, Stefan, Hansteen, Thor H, \& Rabbel, Wolfgang. 2014. Comparison of seismic activity for Llaima and Villarrica volcanoes prior to and after the Maule 2010 earthquake. International Journal of Earth Sciences, 103(7), 2015-2028.

Mordret, A, Landès, M, Shapiro, NM, Singh, SC, Roux, P, \& Barkved, OI. 2013. Nearsurface study at the Valhall oil field from ambient noise surface wave tomography. Geophysical Journal International, 193(3), 1627-1643.

Mordret, A, Landès, M, Shapiro, NM, Singh, SC, \& Roux, P. 2014. Ambient noise surface wave tomography to determine the shallow shear velocity structure at Valhall: depth inversion with a Neighbourhood Algorithm. Geophysical Journal International, 198(3), 1514-1525.

Mordret, Aurélien, Rivet, Diane, Landès, Matthieu, \& Shapiro, Nikolaï M. 2015. Three-dimensional shear velocity anisotropic model of Piton de la Fournaise Volcano (La Réunion Island) from ambient seismic noise. Journal of Geophysical Research: Solid Earth, 120(1), 406-427. 
Murase, Tsutomu, \& McBirney, Alexander R. 1973. Properties of some common igneous rocks and their melts at high temperatures. Geological Society of America Bulletin, 84(11), 3563-3592.

Nakata, Nori, Gualtieri, Lucia, \& Fichtner, Andreas (eds). 2019. Seismic Ambient Noise. Cambridge University Press.

Naranjo, Jose A, \& Moreno, Hugo. 1991. Actividad explosiva postglacial en el volcan Llaima, Andes del Sur (38 45'S). Andean Geology, 18(1), 69-80.

Newhall, Christopher G, \& Self, Stephen. 1982. The volcanic explosivity index (VEI) an estimate of explosive magnitude for historical volcanism. Journal of Geophysical Research: Oceans, 87(C2), 1231-1238.

Obermann, Anne, Lupi, Matteo, Mordret, Aurélien, Jakobsdóttir, Steinunn S, \& Miller, Stephen A. 2016. 3D-ambient noise Rayleigh wave tomography of Snæfellsjökull volcano, Iceland. Journal of Volcanology and Geothermal Research, $\mathbf{3 1 7}, 42-52$.

Obermann, Anne, Molinari, Irene, Métaxian, Jean-Philippe, Grigoli, Francesco, Strauch, Wilfried, \& Wiemer, Stefan. 2019. Structure of Masaya and Momotombo volcano, Nicaragua, investigated with a temporary seismic network. Journal of Volcanology and Geothermal Research, 379, 1-11.

Papanicolaou, George C, Ryzhik, Leonid V, \& Keller, Joseph B. 1996. Stability of the P-to-S energy ratio in the diffusive regime. Bulletin of the Seismological Society of America, 86(4), 1107-1115. 
Paulatto, Michele, Moorkamp, Max, Hautmann, Stefanie, Hooft, Emilie, Morgan, Joanna V, \& Sparks, R Stephen J. 2019. Vertically extensive magma reservoir revealed from joint inversion and quantitative interpretation of seismic and gravity data. Journal of Geophysical Research: Solid Earth, 124(11), 11170-11191.

Pavez, Maximiliano, Schill, Eva, Held, Sebastian, Díaz, Daniel, \& Kohl, Thomas. 2020. Visualizing preferential magmatic and geothermal fluid pathways via electric conductivity at Villarrica Volcano, S-Chile. Journal of Volcanology and Geothermal Research, 400, 106913.

Perrier, Laurence, Métaxian, Jean-Philippe, Battaglia, Jean, \& Garaebiti, Esline. 2012. Estimation of the near-surface velocity structure of the Yasur-Yenkahe volcanic complex, Vanuatu. Journal of volcanology and geothermal research, 227, $50-60$.

Peterson, Jon R. 1993. Observations and modeling of seismic background noise.

Petit-Breuilh, Mar ' i to Eugenia. 2004. The eruptive history of the Hispano-American volcanoes (16th to 20th centuries). Publications Service of the Exmo. Island Council of Lanzarote-House of the volcanoes.

Philpotts, Anthony, \& Ague, Jay. 2009. Principles of igneous and metamorphic petrology. Cambridge University Press.

Pourpoint, Maeva, Anandakrishnan, Sridhar, \& Ammon, Charles J. 2018. HighResolution Rayleigh wave group velocity variation beneath Greenland. Journal of Geophysical Research: Solid Earth, 123(2), 1516-1539. 
Reubi, Olivier, Bourdon, Bernard, Dungan, MA, Koornneef, Janne M, Selles, Daniel, Langmuir, Charles H, \& Aciego, S. 2011. Assimilation of the plutonic roots of the Andean arc controls variations in U-series disequilibria at Volcan Llaima, Chile. Earth and Planetary Science Letters, 303(1-2), 37-47.

Richards, Paul G, \& Aki, Keiiti. 1980. Quantitative seismology: theory and methods. Vol. 859. Freeman San Francisco, CA.

Roman, Alberto, \& Jaupart, Claude. 2014. The impact of a volcanic edifice on intrusive and eruptive activity. Earth and Planetary Science Letters, 408, 1-8.

Roman, Diana C., \& Heron, Philip. 2007. Effect of regional tectonic setting on local fault response to episodes of volcanic activity. Geophysical Research Letters, 34(13), $1-5$.

Rosenau, Matthias, Melnick, Daniel, \& Echtler, Helmut. 2006. Kinematic constraints on intra-arc shear and strain partitioning in the southern Andes between $38 \mathrm{~S}$ and 42 S latitude. Tectonics, 25(4).

Ruth, Dawn CS, Cottrell, Elizabeth, Cortes, Joaquin A, Kelley, Katherine A, \& Calder, Eliza S. 2016. From passive degassing to violent strombolian eruption: the case of the 2008 eruption of Llaima volcano, Chile. Journal of Petrology, 57(9), $1833-1864$.

Ruth, Dawn CS, Costa, Fidel, De Maisonneuve, Caroline Bouvet, Franco, Luis, Cortés, Joaquin A, \& Calder, Eliza S. 2018. Crystal and melt inclusion timescales reveal the evolution of magma migration before eruption. Nature communications, $\mathbf{9}(1), 1-9$. 
Saccorotti, Gilberto, Chouet, Bernard, \& Dawson, Phillip. 2003. Shallow-velocity models at the Kilauea Volcano, Hawaii, determined from array analyses of tremor wavefields. Geophysical Journal International, 152(3), 633-648.

Saccorotti, Gilberto, Zuccarello, Luciano, Del Pezzo, Edoardo, Ibanez, Jesus, \& Gresta, Stefano. 2004. Quantitative analysis of the tremor wavefield at Etna Volcano, Italy. Journal of volcanology and geothermal research, 136(3-4), 223-245.

Scheu, B, Kern, H, Spieler, O, \& Dingwell, DB. 2006. Temperature dependence of elastic P-and S-wave velocities in porous Mt. Unzen dacite. Journal of volcanology and geothermal research, 153(1-2), 136-147.

Schimmel, Martin, \& Paulssen, Hanneke. 1997. Noise reduction and detection of weak, coherent signals through phase-weighted stacks. Geophysical Journal International, 130(2), 497-505.

Schindlbeck, JC, Freundt, Armin, \& Kutterolf, Steffen. 2014. Major changes in the post-glacial evolution of magmatic compositions and pre-eruptive conditions of Llaima Volcano, Andean Southern Volcanic Zone, Chile. Bulletin of Volcanology, $\mathbf{7 6}(6), 1-22$.

Schmidt, Sabine, \& Götze, Hans-Jürgen. 2006. Bouguer and isostatic maps of the Central Andes. Pages 559-562 of: The Andes. Springer.

Scholz, CH. 1988. The brittle-plastic transition and the depth of seismic faulting. Geologische Rundschau, 77(1), 319-328.

Schonwalder-Angel, Dayana, Cortés, Joaquín A, \& Calder, Eliza S. 2018. The interplay of magmatism and tectonics: An example based on the satellite scoria cones 
at Llaima volcano, Chile. Journal of Volcanology and Geothermal Research, 367, $31-45$.

Seats, Kevin J, Lawrence, Jesse F, \& Prieto, German A. 2012. Improved ambient noise correlation functions using Welch s method. Geophysical Journal International, 188(2), 513-523.

Shapiro, Nikolai M, \& Campillo, Michel. 2004. Emergence of broadband Rayleigh waves from correlations of the ambient seismic noise. Geophysical Research Letters, $31(7)$.

Shapiro, Nikolai M, Campillo, Michel, Stehly, Laurent, \& Ritzwoller, Michael H. 2005. High-resolution surface-wave tomography from ambient seismic noise. Science, 307(5715), 1615-1618.

Sielfeld, Gerd, Lange, Dietrich, \& Cembrano, José. 2019. Intra-arc crustal seismicity: Seismotectonic implications for the southern Andes volcanic zone, Chile. Tectonics, 38(2), $552-578$.

Smith, Steven W. 1997. The scientist and engineer's guide to digital signal processing. California Technical Pub. San Diego.

Smith, Steven W. 2003. Properties of Convolution. Digital Signal Processing, 123140.

Stanchits, Sergei, Vinciguerra, Sergio, \& Dresen, Georg. 2006. Ultrasonic velocities, acoustic emission characteristics and crack damage of basalt and granite. Pure and Applied Geophysics, 163(5), 975-994. 
Stankiewicz, Jacek, Ryberg, Trond, Haberland, Christian, Natawidjaja, Danny, et al. 2010. Lake Toba volcano magma chamber imaged by ambient seismic noise tomography. Geophysical Research Letters, 37(17).

Stein, Seth, \& Wysession, Michael. 2009. An introduction to seismology, earthquakes, and earth structure. John Wiley \& Sons.

Takei, Yasuko. 2002. Effect of pore geometry on VP/VS: From equilibrium geometry to crack. Journal of Geophysical Research: Solid Earth, 107(B2), ECV-6.

Tassara, Andres, Götze, Hans-Jürgen, Schmidt, Sabine, \& Hackney, Ron. 2006. Three-dimensional density model of the Nazca plate and the Andean continental margin. Journal of Geophysical Research: Solid Earth, 111(B9).

Tikoff, Basil, \& Teyssier, Christian. 1994. Strain modeling of displacement-field partitioning in transpressional orogens. Journal of Structural Geology, 16(11), 15751588.

Tsuji, Takeshi, \& Iturrino, Gerardo J. 2008. Velocity-porosity relationships in oceanic basalt from eastern flank of the Juan de Fuca Ridge: The effect of crack closure on seismic velocity. Exploration Geophysics, 39(1), 41-51.

Turner, Joseph A. 1998. Scattering and diffusion of seismic waves. Bulletin of the Seismological Society of America, 88(1), 276-283.

Venzke, E. 2013. Volcanoes of the World. Global Volcanism Program, 4.9. 1.

Vergniolle, Sylvie, \& Jaupart, Claude. 1986. Separated two-phase flow and basaltic eruptions. Journal of Geophysical Research: Solid Earth, 91(B12), 12842-12860. 
Vinciguerra, S, Trovato, C, Meredith, PG, Benson, PM, Troise, C, \& De Natale, G. 2006. Understanding the seismic velocity structure of Campi Flegrei caldera (Italy): from the laboratory to the field scale. Pure and Applied Geophysics, 163(10), 22052221.

Wang, Xiao-Qiong, Schubnel, Alexandre, Fortin, Jérôme, Guéguen, Yves, \& Ge, Hong-Kui. 2013. Physical properties and brittle strength of thermally cracked granite under confinement. Journal of Geophysical Research: Solid Earth, 118(12), 6099-6112.

Widman, Lawrence E. 2002. Computational inverse problems in electrocardiography. Journal of Biomedical Informatics, 35(1), 51.

Yang, Xiaotao, \& Gao, Haiying. 2020. Segmentation of the Aleutian-Alaska subduction zone revealed by full-wave ambient noise tomography: Implications for the along-strike variation of volcanism. Journal of Geophysical Research: Solid Earth, 125(11), e2020JB019677.

Yang, Yingjie, Ritzwoller, Michael H, Levshin, Anatoli L, \& Shapiro, Nikolai M. 2007. Ambient noise Rayleigh wave tomography across Europe. Geophysical Journal International, 168(1), 259-274.

Yoshino, Takashi, Takei, Yasuko, Wark, David A, \& Watson, E Bruce. 2005. Grain boundary wetness of texturally equilibrated rocks, with implications for seismic properties of the upper mantle. Journal of Geophysical Research: Solid Earth, 110(B8).

Zamora, M, Sartoris, G, \& Chelini, W. 1994. Laboratory measurements of ultrasonic 
wave velocities in rocks from the Campi Flegrei volcanic system and their relation to other field data. Journal of Geophysical Research: Solid Earth, 99(B7), 1355313561.

Zhu, Lupei, \& Kanamori, Hiroo. 2000. Moho depth variation in southern California from teleseismic receiver functions. Journal of Geophysical Research: Solid Earth, 105(B2), 2969-2980. 
APPENDIX A 


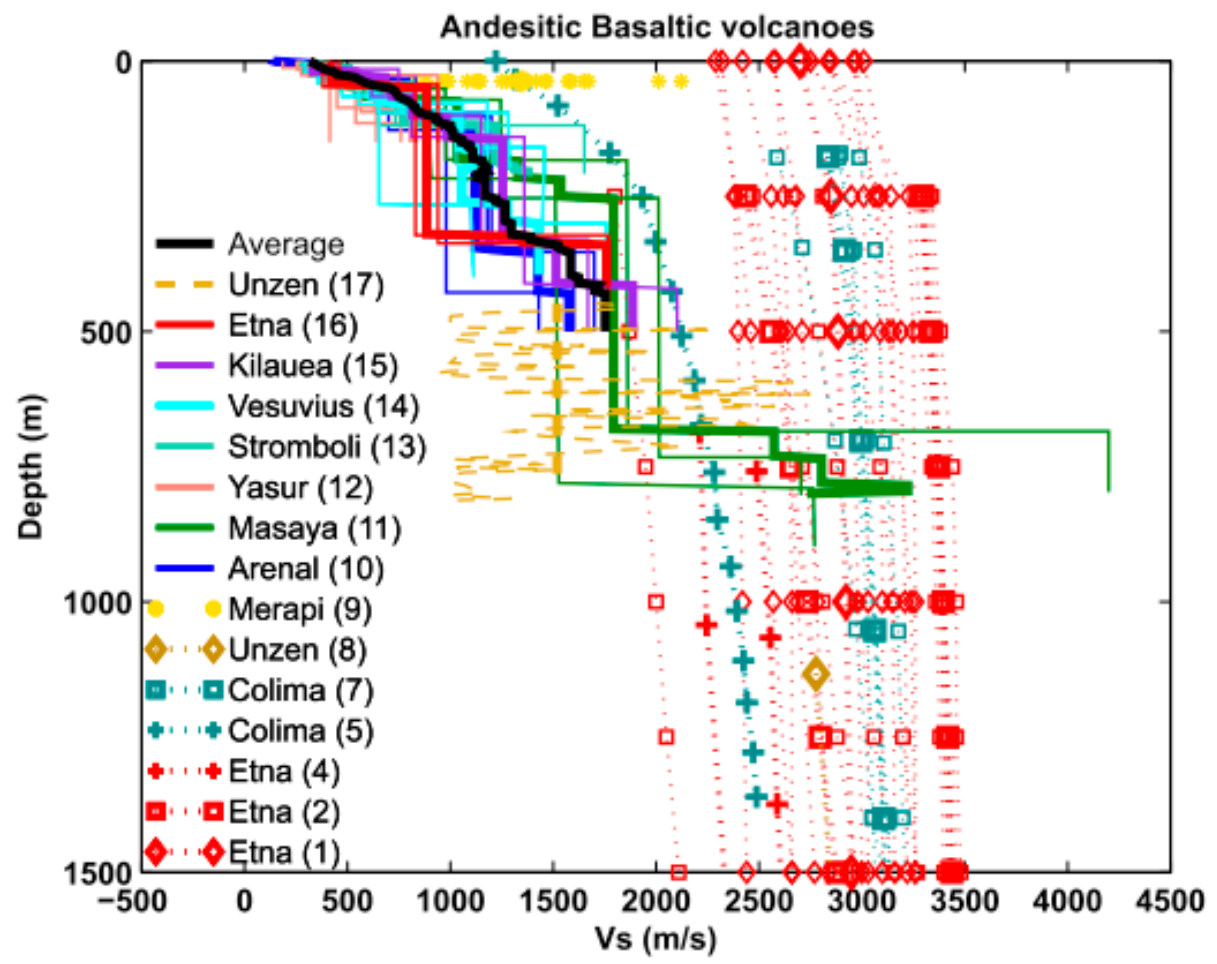

Figure A.1: A plot from Lesage et al. (2018) showing $v_{s}$ models for individual volcanoes (thin lines), laboratory measurements (symbols and dotted lines) and well-logs (dashed lines) for andesitic basaltic volcanoes. The thick lines represent averaged seismic models. The thick black line represents an average of the averaged models. Numbers in labels indicate references (1: Zamora et al. (1994); 2: Vinciguerra et al. (2006); 3: Stanchits et al. (2006); 4: Fortin et al. (2011); 5: Heap et al. (2014); 6,9: Lesage et al. (2018); 7: Kolzenburg et al. (2012); 8: Scheu et al. (2006); 10: Mora et al. (2006); 11: Métaxian et al. (1997); 12: Perrier et al. (2012); 13: La Rocca et al. (2000); 14: De Luca et al. (1997); 15: Saccorotti et al. (2003); 16: Saccorotti et al. (2004); 17: Ikeda et al. (2008)). 

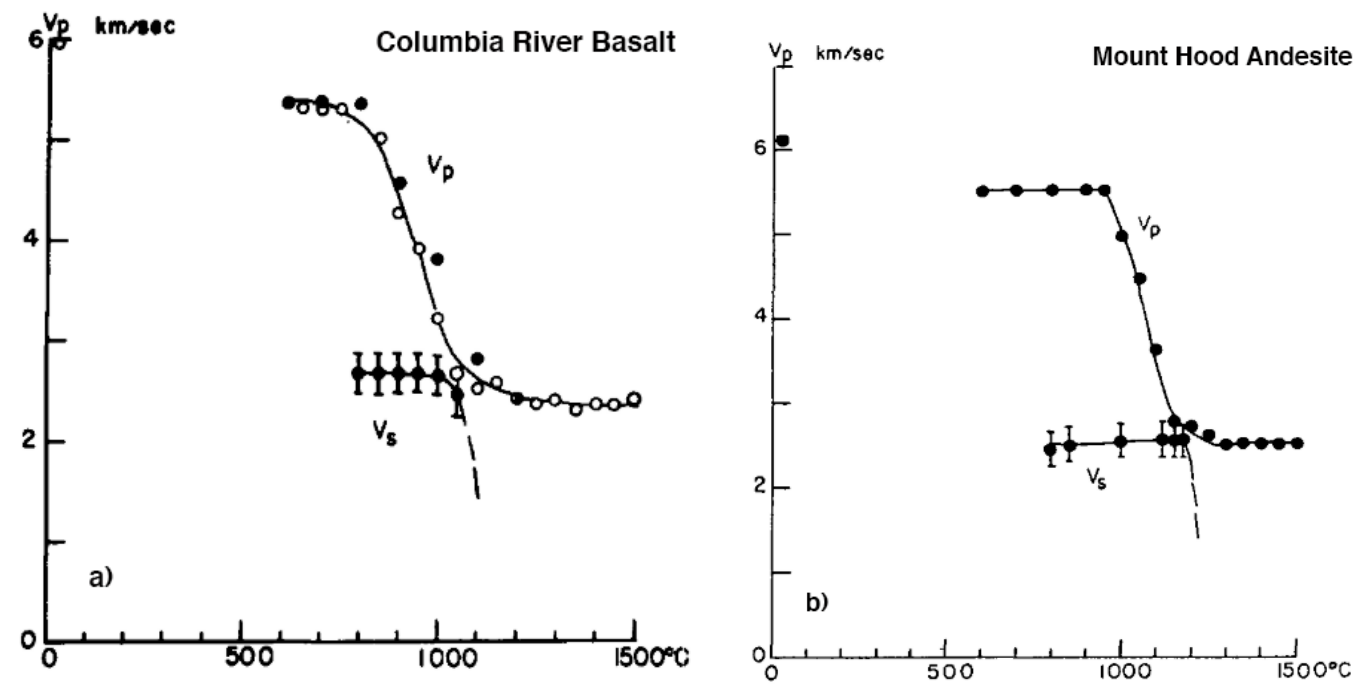

Figure A.2: Compressional wave velocities and shear-wave velocities of a) Columbia River Basalt and b) Mount Hood Andesite (Murase \& McBirney, 1973). Solid points are measured during cooling at a rapid rate $\left(200^{\circ} \mathrm{C}\right.$ per hour $)$, and open circles at a slower rate $\left(35^{\circ} \mathrm{C}\right.$ per hour $)$. 
APPENDIX B 

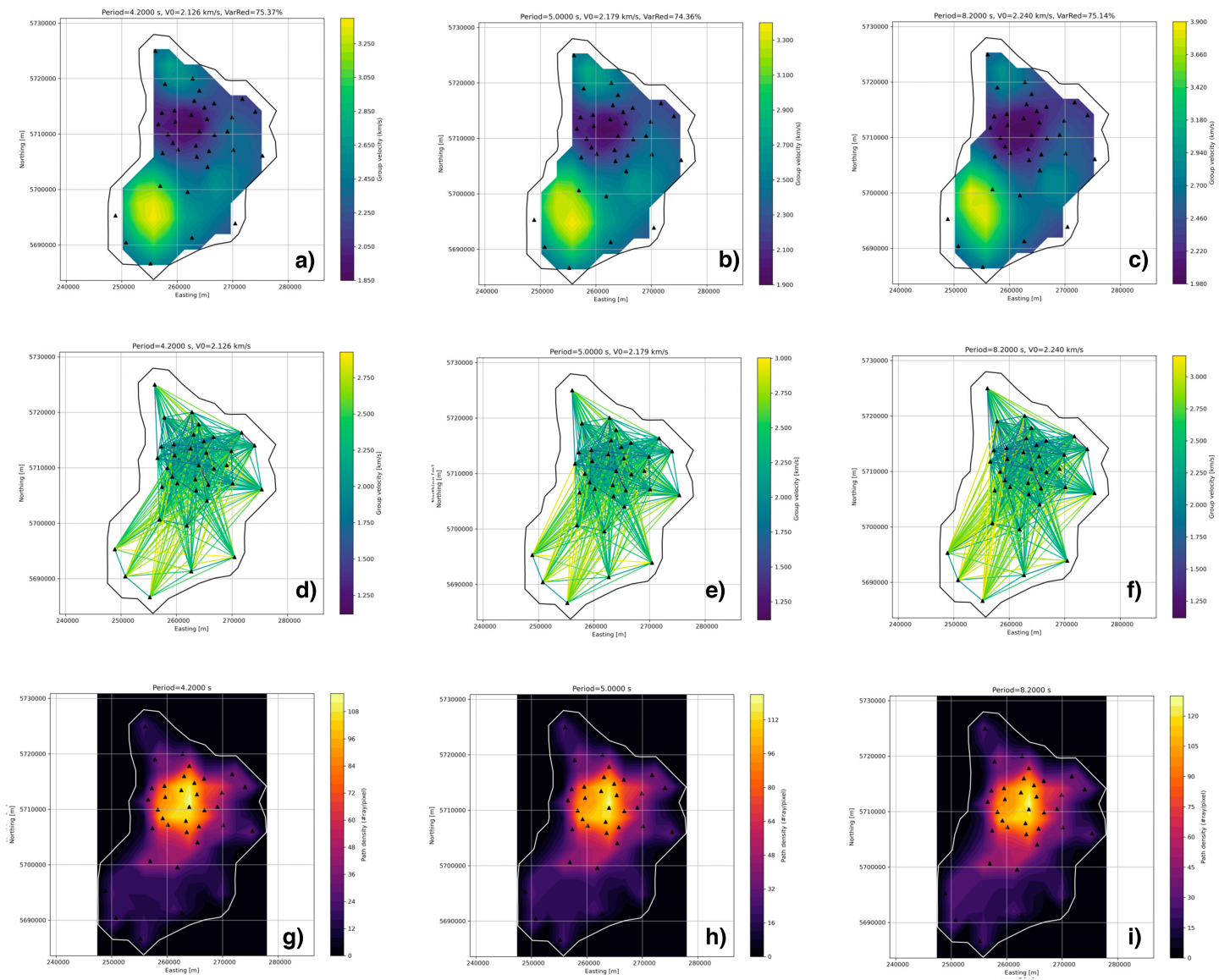

Figure B.1: Rayleigh 2-D group velocity map for a period of a) $4.2 \mathrm{~s}$. b) $5.0 \mathrm{~s}$. c) $8.2 \mathrm{~s}$. Rayleigh wave paths for $2-\mathrm{D}$ group velocity tomography at d) $4.2 \mathrm{~s}$. e) $5.0 \mathrm{~s}$. f) $8.2 \mathrm{~s}$. Rayleigh wave path densities for $2-\mathrm{D}$ group velocity tomography for a period of g) $4.2 \mathrm{~s}$. h) $5.0 \mathrm{~s}$. i) $8.2 \mathrm{~s}$. 

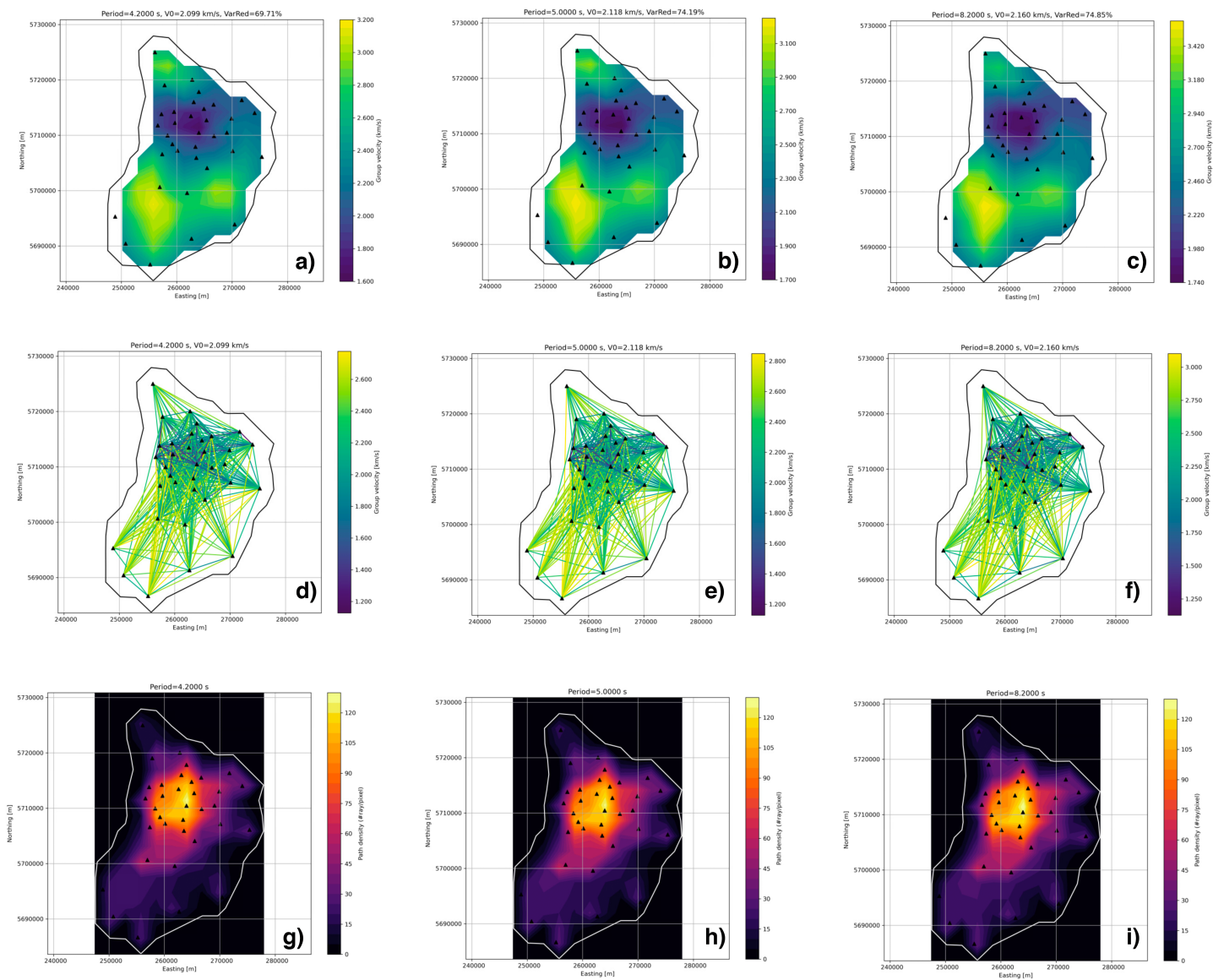

Figure B.2: Love 2-D group velocity map for a period of a) $4.2 \mathrm{~s}$. b) $5.0 \mathrm{~s}$. c) $8.2 \mathrm{~s}$. Love wave paths for 2 -D group velocity tomography for a period of d) $4.2 \mathrm{~s}$. e) $5.0 \mathrm{~s}$. f) $8.2 \mathrm{~s}$. Love wave path densities for 2 -D group velocity tomography at g) $4.2 \mathrm{~s}$. h) $5.0 \mathrm{~s}$. i) $8.2 \mathrm{~s}$. 


\section{APPENDIX C}



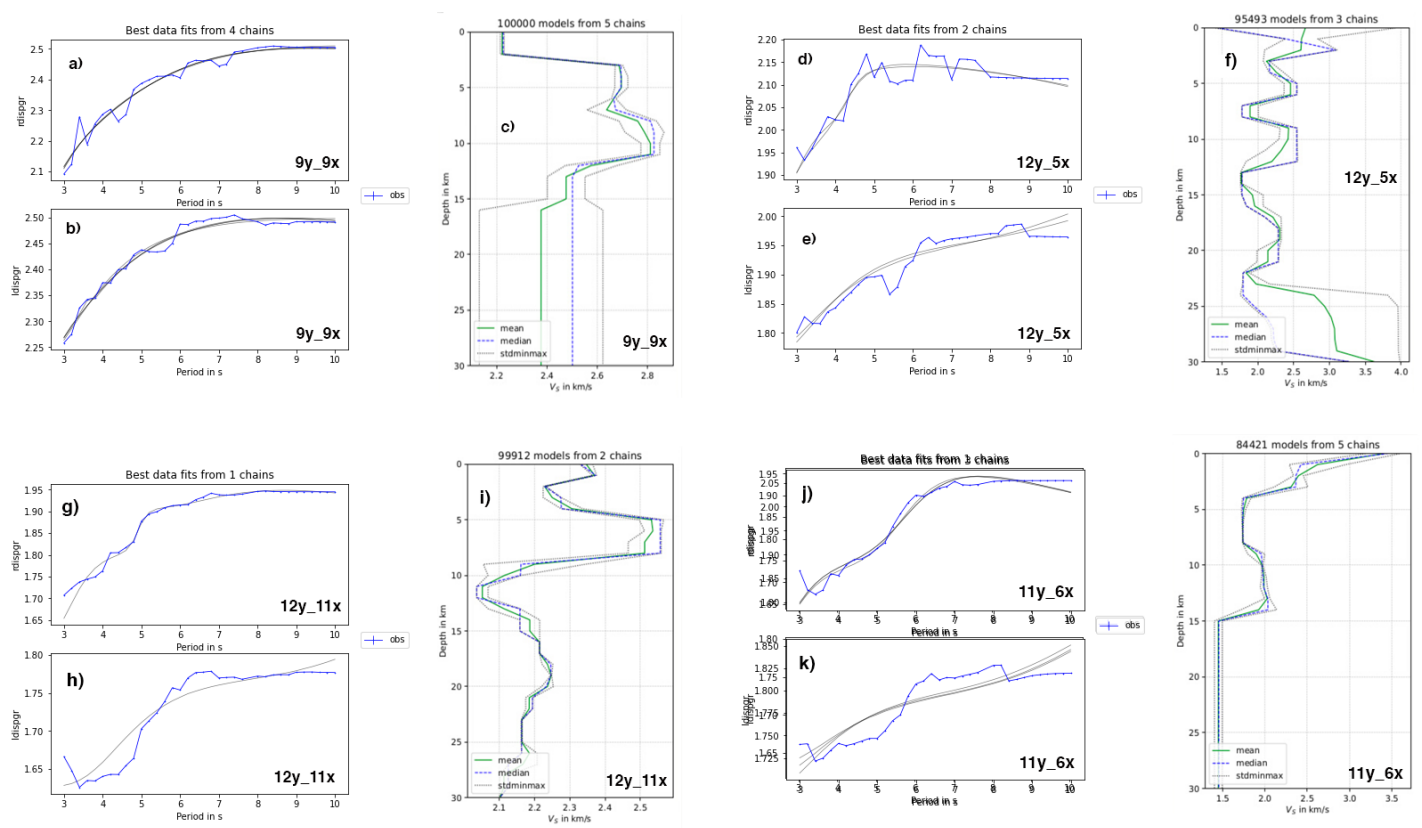

Figure C.1: a) The best data fit for the grid point $(9,9)$ corresponding to observed Rayleigh wave group velocity dispersion. b) The best data fit for the grid point $(9,9)$ corresponding to observed Love wave group velocity dispersion. c) The 1-D shear wave velocity profile at the grid point $(9,9)$ that results from the BayHunter inversion. d) The best data fit for the grid point $(5,12)$ corresponding to observed Rayleigh wave group velocity dispersion. e)The best data fit for the grid point $(5,12)$ corresponding to observed Love wave group velocity dispersion. f) The 1-D shear wave velocity profile at the grid point $(5,12)$ that results from the BayHunter inversion. g) The best data fit for the grid point $(11,12)$ corresponding to observed Rayleigh wave group velocity dispersion. h) The best data fit for the grid point $(11,12)$ corresponding to observed Love wave group velocity dispersion. i) The 1-D shear wave velocity profile at the grid point $(11,12)$ that results from the BayHunter inversion. j) The best data fit for the grid point $(6,11)$ corresponding to observed Rayleigh wave group velocity dispersion. k) The best data fit for the grid point $(6,11)$ corresponding to observed Love wave group velocity dispersion. 1) The 1-D shear wave velocity profile at the grid point $(7,11)$ from the BayHunter inversion. 

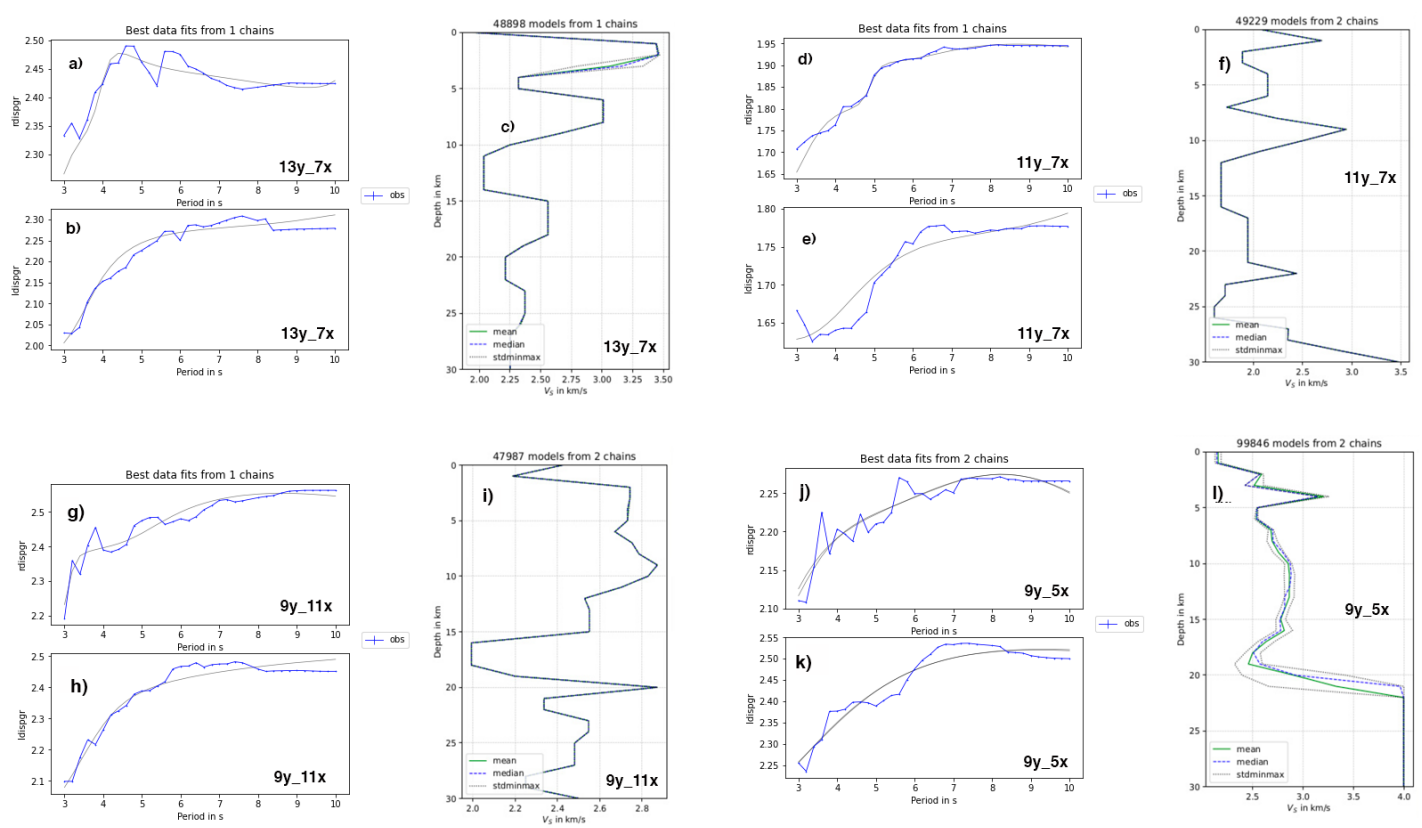

Figure C.2: a) The best data fit for the grid point $(7,13)$ corresponding to observed Rayleigh wave group velocity dispersion. b) The best data fit for the grid point $(7,13)$ corresponding to observed Love wave group velocity dispersion. c) The $1-\mathrm{D}$ shear wave velocity profile at the grid point $(7,13)$ that results from the BayHunter inversion. d) The best data fit for the grid point $(7,11)$ corresponding to observed Rayleigh wave group velocity dispersion. e) The best data fit for the grid point $(7,11)$ corresponding to observed Love wave group velocity dispersion. f) The 1-D shear wave velocity profile at the grid point $(7,11)$ that results from the BayHunter inversion. g) The best data fit for the grid point $(11,9)$ corresponding to observed Rayleigh wave group velocity dispersion. h) The best data fit for the grid point $(11,9)$ corresponding to observed Love wave group velocity dispersion. i) The 1-D shear wave velocity profile at the grid point $(11,9)$ that results from the BayHunter inversion. j) The best data fit for the grid point $(5,9)$ corresponding to observed Rayleigh wave group velocity dispersion. k) The best data fit for the grid point $(5,9)$ corresponding to observed Love wave group velocity dispersion. 1) The 1-D shear wave velocity profile at the grid point $(5,9)$ from the BayHunter inversion. 
APPENDIX D 


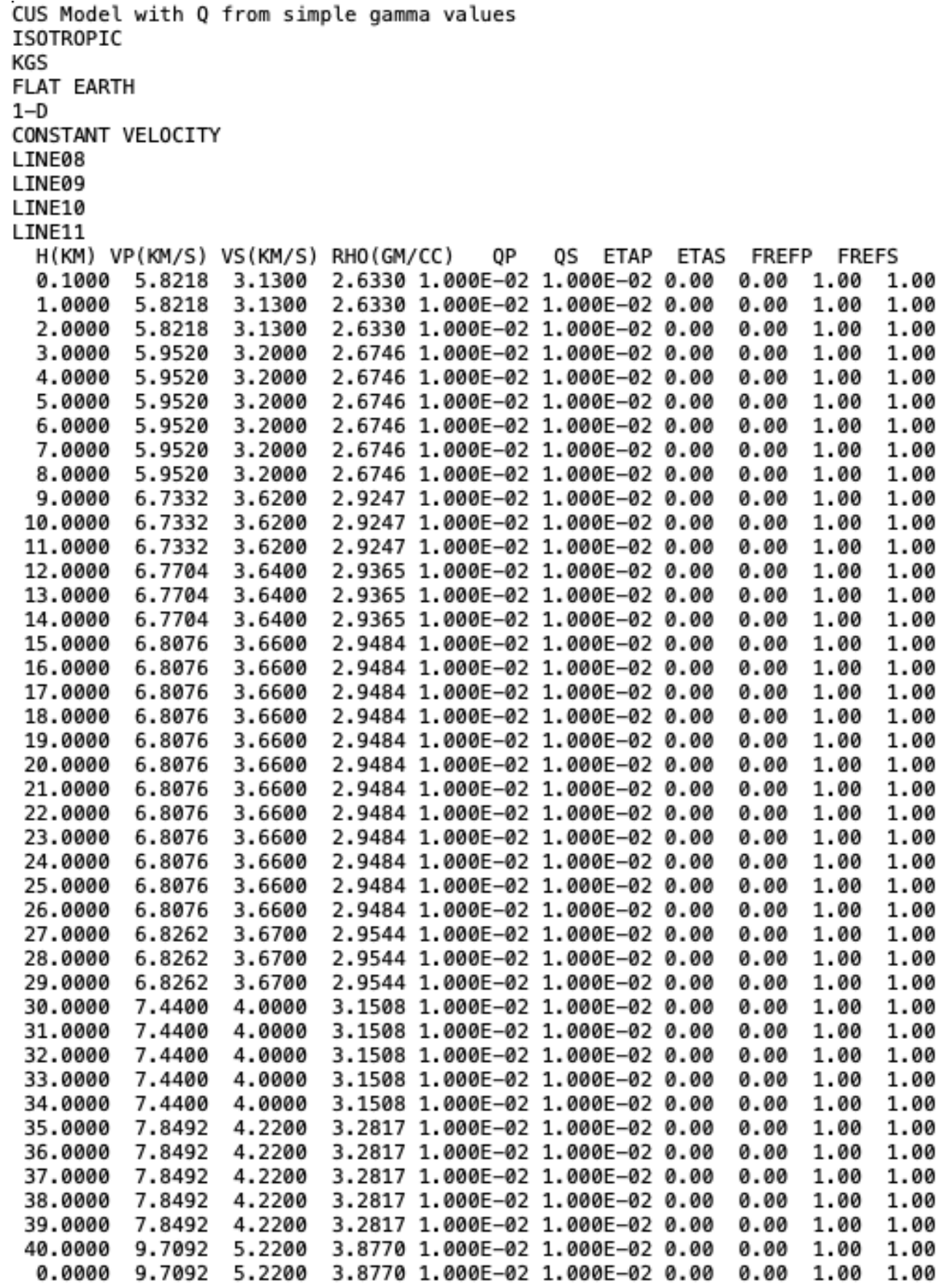

Figure D.1: The velocity model that I constructed as input for the program srfker96 (Herrmann, 2013) to compute kernel sensitivities that are shown in Figure 2.29. The shear wave velocities in the $v_{s}$ model that correspond to materials at elevations above sea level have been omitted in this case. 
APPENDIX E 

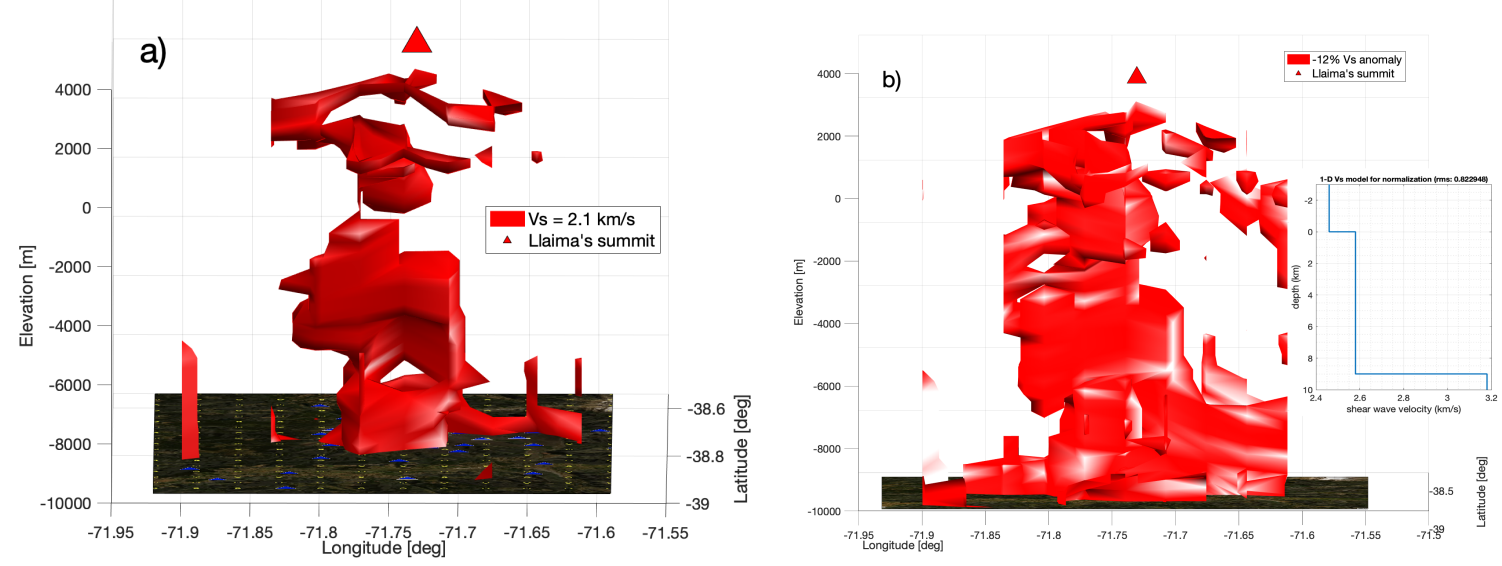

Figure E.1: a) A 3-D isosurface from the BayHunter results (introduced in Section 2.8). The isosurface corresponds to a shear wave velocity of $2.1 \mathrm{~km} / \mathrm{s}$. The model has been corrected for elevations. b) A $-12 \% d v_{s}$ that was constructed through the normalization of the results obtained through BayHunter using the 1-D Vs model that is shown in the figure.
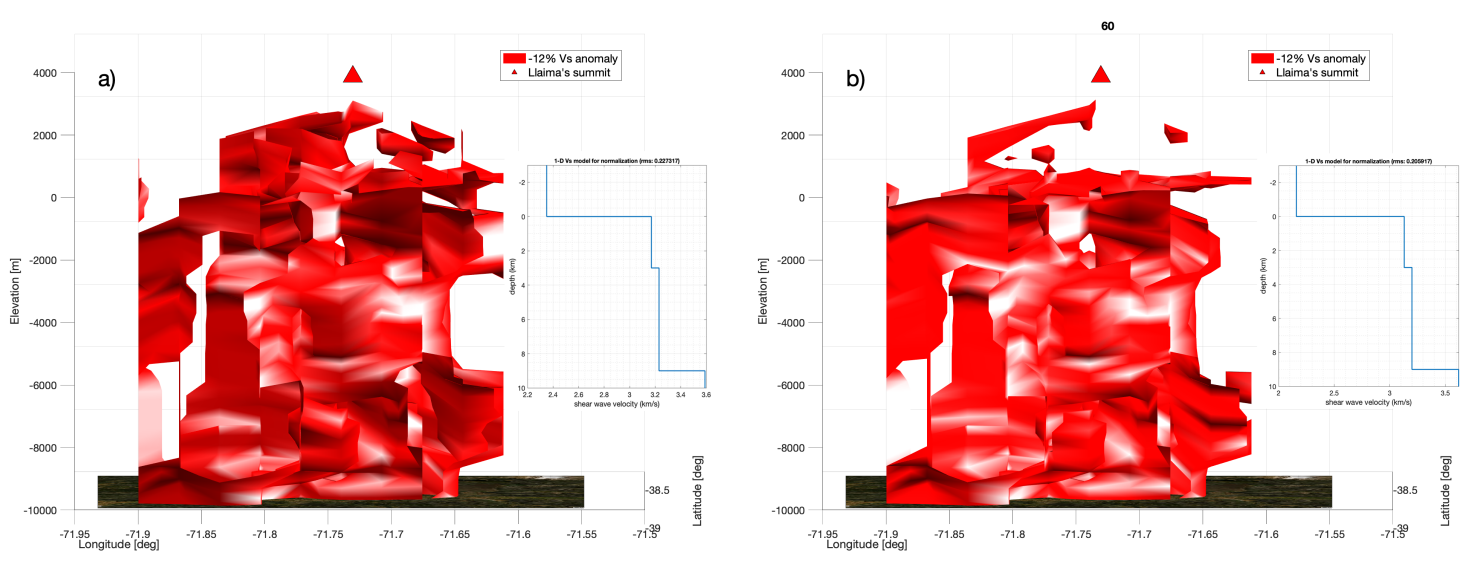

Figure E.2: a) A $-12 \% d v_{s}$ that was constructed through normalization with the 1-D Vs model shown in the figure. b) A $-12 \% d v_{s}$ constructed through normalization with the 1-D Vs model that is shown in the figure. 
APPENDIX F 

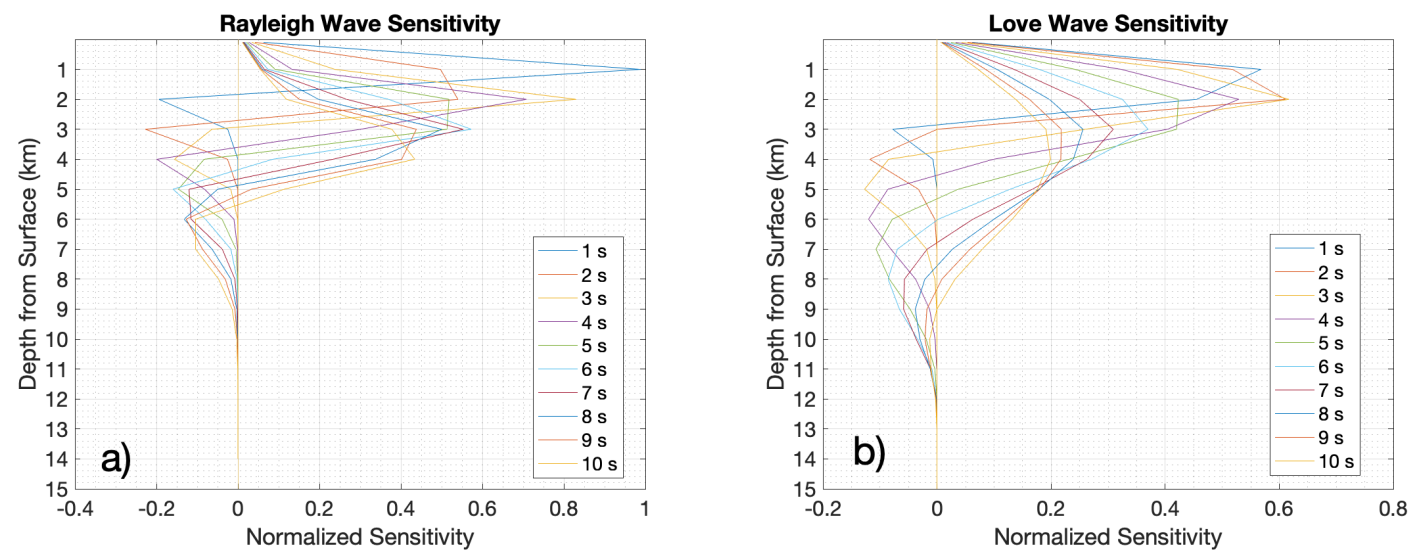

Figure F.1: a) Depth sensitivity kernels for the fundamental mode of Rayleigh group wave velocities for the 1-D $v_{s}$ model from Sielfeld et al. (2019) that was used to obtain final results in this thesis. b) Depth sensitivity kernels for the fundamental mode of Love wave group velocities. 


\begin{tabular}{|c|c|c|c|c|c|c|c|c|c|}
\hline \multicolumn{10}{|c|}{$\begin{array}{l}\text { MODEL. } 01 \\
\text { CUS Model with } 0 \text { from simple gamma values }\end{array}$} \\
\hline \multicolumn{10}{|c|}{$\begin{array}{l}\text { CUS Model with Q from simple gamma values } \\
\text { ISOTROPIC }\end{array}$} \\
\hline \multirow{2}{*}{\multicolumn{10}{|c|}{$\begin{array}{l}\text { KGS } \\
\text { FLAT EARTH }\end{array}$}} \\
\hline \multirow{2}{*}{\multicolumn{10}{|c|}{ FLAI EARIH }} \\
\hline & & & & & & & & & \\
\hline \multicolumn{10}{|c|}{ CONSTANT VELOCITY } \\
\hline \multicolumn{10}{|c|}{ LINE08 } \\
\hline \multicolumn{10}{|l|}{ LINE09 } \\
\hline \multicolumn{10}{|l|}{ LINE10 } \\
\hline \multicolumn{10}{|l|}{ LINE11 } \\
\hline $\mathrm{H}(\mathrm{KM})$ & $\operatorname{VP}(\mathrm{KM} / \mathrm{S})$ & VS (KM/S) & RHO (GM) & (CC) & QS ETAP & ETAS & FREFP & FRE & \\
\hline 0.1000 & 4.5756 & 2.4600 & 2.2341 & $1.000 \mathrm{E}-02$ & $1.000 \mathrm{E}-02$ & 0.00 & 0.00 & 1.00 & 1.00 \\
\hline 1.0000 & 4.5756 & 2.4600 & 2.2341 & $1.000 \mathrm{E}-02$ & $1.000 \mathrm{E}-02$ & 0.00 & 0.00 & 1.00 & 1.00 \\
\hline 2.0000 & 4.5756 & 2.4600 & 2.2341 & $1.000 \mathrm{E}-02$ & $1.000 \mathrm{E}-02$ & 0.00 & 0.00 & 1.00 & 1.00 \\
\hline 3.0000 & 4.7988 & 2.5800 & 2.3056 & $1.000 \mathrm{E}-02$ & $1.000 \mathrm{E}-02$ & 0.00 & 0.00 & 1.00 & 1.00 \\
\hline 4.0000 & 4.7988 & 300 & 56 & $1.000 \mathrm{E}-02$ & $1.000 \mathrm{E}-02$ & 0.00 & 0.00 & 1.00 & 1.00 \\
\hline 5.0000 & 4.7988 & 00 & & $1.000 \mathrm{E}-02$ & $1.000 \mathrm{E}-02$ & 0.00 & 0.00 & 1.00 & 1.00 \\
\hline 6.0000 & 88 & 00 & & $1.000 \mathrm{E}-02$ & $1.000 \mathrm{E}-02$ & 0.00 & 0.00 & 1.00 & 1.00 \\
\hline 7.0000 & 4. 7 & & & $0 \mathrm{E}-02$ & $1.000 \mathrm{E}-02$ & 0.00 & 0. & 1. & 1.00 \\
\hline 8.0000 & 4.7 & 00 & 6 & $1.000 \mathrm{E}-02$ & $1.000 \mathrm{E}-02$ & 0.00 & 0.00 & 1. & 1.00 \\
\hline 9.0000 & 88 & 00 & 6 & $0 \mathrm{E}-02$ & $1.000 \mathrm{E}-02$ & 0.00 & 0.00 & 1. & 1.00 \\
\hline 10.0000 & 4.7988 & 00 & 6 & 1.0 & 1.e & 0.00 & 0.00 & 1.00 & 1.00 \\
\hline 11.0000 & 988 & 00 & 6 & 1.000 & 1.0 & 0.00 & 0.00 & 1.00 & 1.00 \\
\hline 12.0000 & 148 & 00 & 27 & $1.000 \mathrm{E}-02$ & $1.000 \mathrm{E}-02$ & 0.00 & 0.00 & 1.00 & 1.00 \\
\hline 13.0000 & 48 & 300 & 527 & $1.000 \mathrm{E}-02$ & $1.000 \mathrm{E}-02$ & 0.00 & 0.00 & 1.00 & 1.00 \\
\hline 14.0000 & 148 & 300 & 627 & $1.000 \mathrm{E}-02$ & $1.000 \mathrm{E}-02$ & 0.00 & 0.00 & 1.00 & 1.00 \\
\hline 15.0000 & 148 & 3.2100 & 627 & $1.000 \mathrm{E}-02$ & $1.000 \mathrm{E}-02$ & 0.00 & 0.00 & 1.00 & 1.00 \\
\hline 16.0000 & & 100 & 627 & $1.000 \mathrm{E}-02$ & $1.000 \mathrm{E}-02$ & 0.00 & 0.00 & 1.00 & 1.00 \\
\hline 17.0000 & 48 & 2100 & 27 & $1.000 \mathrm{E}-02$ & $1.000 \mathrm{E}-02$ & 0.00 & 0.00 & 1.00 & 1.00 \\
\hline 18.0000 & 49 & 00 & 310 & $1.000 \mathrm{E}-02$ & $1.000 \mathrm{E}-02$ & 0.00 & 0.00 & 1.00 & 1.00 \\
\hline 19.0000 & 149 & 900 & 810 & $1.000 \mathrm{E}-02$ & $1.000 \mathrm{E}-02$ & 0.00 & 0.00 & 1.00 & 1.00 \\
\hline 20.0000 & 6.1149 & 3.2900 & 310 & $1.000 \mathrm{E}-02$ & $1.000 \mathrm{E}-02$ & 0.00 & 0.00 & 1.00 & 1.00 \\
\hline 21.0000 & 6.2868 & & 318 & $1.000 \mathrm{E}-02$ & $1.000 \mathrm{E}-02$ & 0.00 & 0.00 & 1.00 & 1.00 \\
\hline 22.0000 & 6.2868 & 800 & 318 & $1.000 \mathrm{E}-02$ & $1.000 \mathrm{E}-02$ & 0.00 & 0.00 & 1.00 & 1.00 \\
\hline 23.0000 & 6.2868 & 3.3800 & 2.7818 & $1.000 \mathrm{E}-02$ & $1.000 \mathrm{E}-02$ & 0.00 & 0.00 & 1.00 & 1.00 \\
\hline 24.0000 & & 3.3800 & 2.7818 & $1.000 \mathrm{E}-02$ & $1.000 \mathrm{E}-02$ & 0.00 & 0.00 & 1.00 & 1.00 \\
\hline 25.0000 & 6.2868 & & 2.7818 & $1.000 \mathrm{E}-02$ & $1.000 \mathrm{E}-02$ & 0.00 & 0.00 & 1.00 & 1.00 \\
\hline 26.0000 & & & 2.7818 & $1.000 \mathrm{E}-02$ & $1.000 \mathrm{E}-02$ & 0.00 & 0.00 & 1.00 & 1.00 \\
\hline 27 & & & 2.7818 & $1.000 \mathrm{E}-02$ & $1.000 \mathrm{E}-02$ & 0.00 & 0.00 & 1.00 & 1.00 \\
\hline 0.0000 & חכרז & .0500 & .1806 & $1.000 \mathrm{E}-02$ & $1.000 \mathrm{E}-02$ & 0.00 & 0.00 & 1.00 & 1.00 \\
\hline
\end{tabular}

Figure F.2: The model that was used to compute the kernel sensitivities shown in Figure F.1. Values of Vs correspond to the 1-D Vs model that was used to normalize results from BayHunter. I added $3 \mathrm{~km}$ to each depth in the 1-D Vs profile that was used for normalization to set the values of depths above to values below the surface of the volcano. 


\section{APPENDIX G}



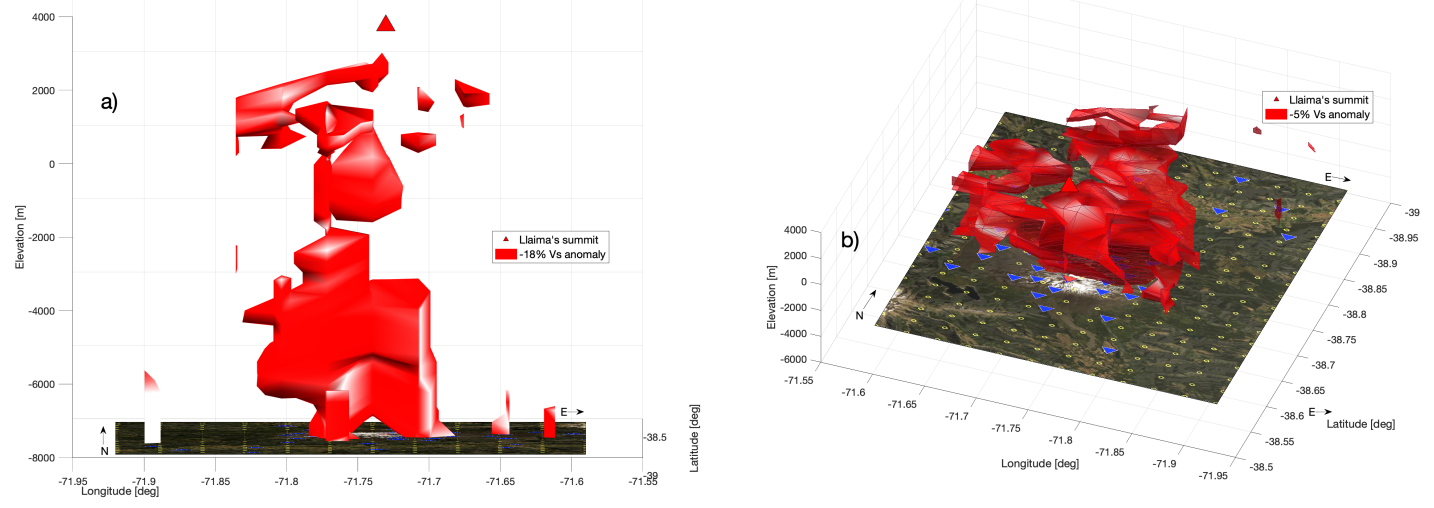

Figure G.1: a) A $-18 \% d v_{s}$. b) A $-5 \% d v_{s}$.
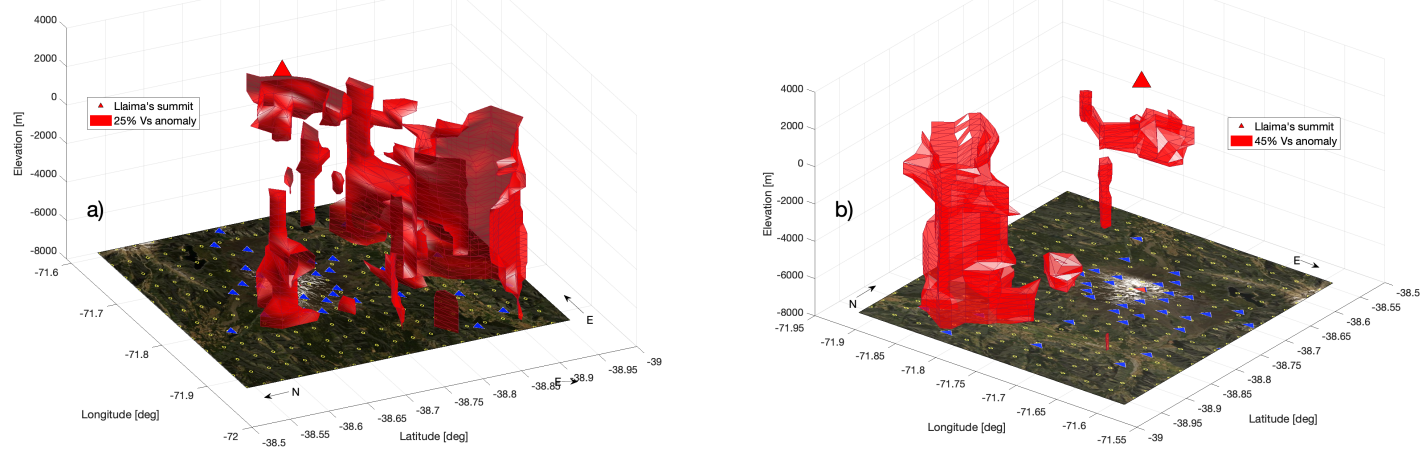

Figure G.2: a) A $25 \% d v_{s}$. b) A $45 \% d v_{s}$. 


\section{APPENDIX $\mathbf{H}$}



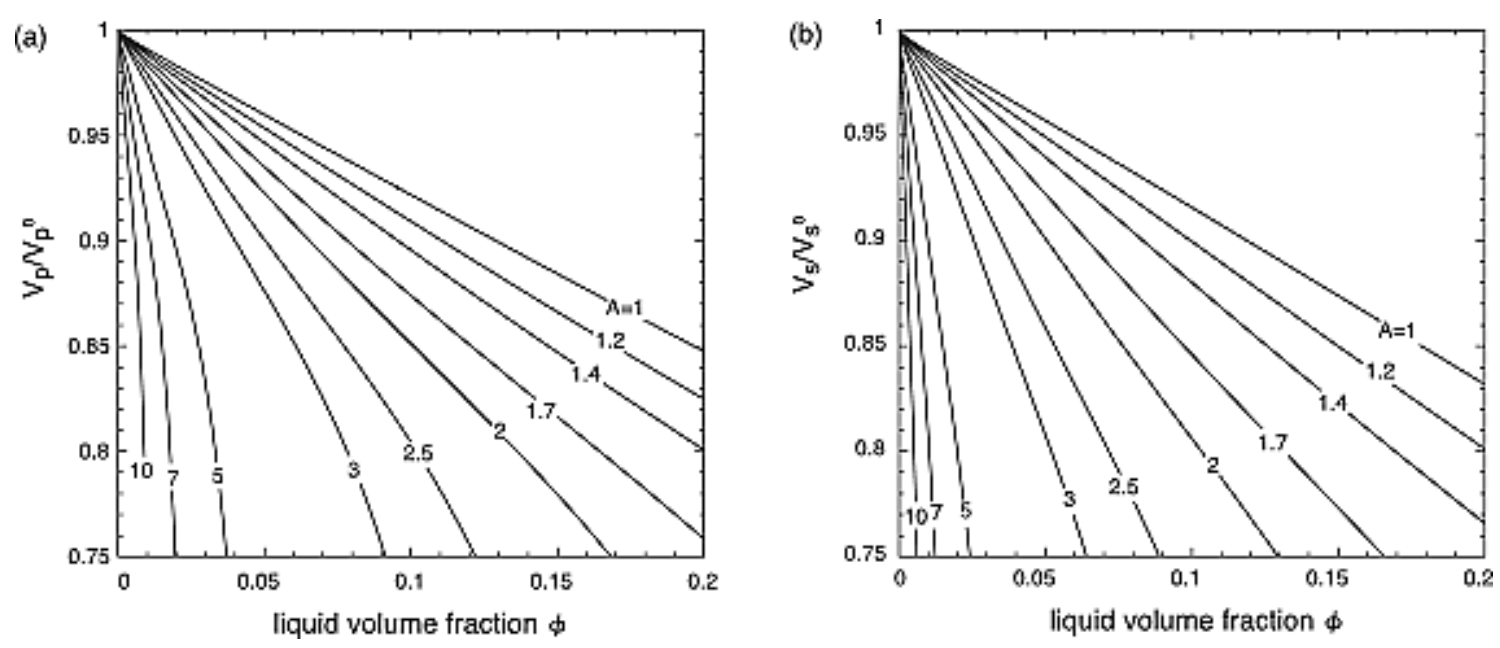

Figure H.1: (a) Longitudinal wave velocity $v_{p}$ and (b) shear wave velocity vs. versus liquid volume fraction $\phi$ from Yoshino et al. (2005). This is used to estimate melt fraction from changes in seismic velocities. 